UNIVERSIDADE DE BRASÍLIA

INSTITUTO DE FÍSICA

PROGRAMA DE PÓS-GRADUAÇÃO EM FÍSICA

Dissertação de mestrado

\title{
CARACTERIZAÇÃO E DETERMINAÇÃO DA OCUPAÇÃO CATIÔNICA DE NANOPARTÍCULAS DE MAGNETITA DOPADAS COM ÍTRIO
}

ARLON FERNANDO DA SILVA

Brasília

2015 
UNIVERSIDADE DE BRASÍLIA

INSTITUTO DE FÍSICA

PROGRAMA DE PÓS-GRADUAÇÃO EM FÍSICA

\section{CARACTERIZAÇÃO E DETERMINAÇÃO DA OCUPAÇÃO CATIÔNICA DE NANOPARTÍCULAS DE MAGNETITA DOPADAS COM ÍTRIO}

ARLON FERNANDO DA SILVA

Dissertação de mestrado apresentada ao Programa de Pós-Graduação em Física, da Universidade de Brasília, como parte dos requisitos para a obtenção do título de Mestre em Física. Área de concentração: Física da Matéria Condensada.

ORIENTADOR: Paulo César de Morais CO-ORIENTADORA: Letícia Nunes Coelho 


\section{CARACTERIZAÇÃO E DETERMINAÇÃO DA OCUPAÇÃO CATIÔNICA DE NANOPARTÍCULAS DE MAGNETITA DOPADAS COM ÍTRIO}

Esta dissertação foi julgada adequada para a obtenção do título de Mestre em Física e aprovada em sua forma final pelo Orientador e pela Banca Examinadora.

Orientador:

Prof. Dr. Paulo César de Morais, IF-UnB.

Doutor pela Universidade Federal de Minas Gerais, UFMG, Brasil.

\section{Banca Examinadora:}

Prof. Dr. Letícia Gonçalves Nunes Coelho, IF-UnB.

Doutora pela Universidade Federal de Minas Gerais, UFMG, Brasil.

Prof. Dr. Sebastião William da Silva, IF-UnB.

Doutor pela Universidade Federal de São Carlos, UFSCAR, Brasil.

Prof. Dr. Marcelo Henrique Sousa, UnB - Ceilândia.

Doutor pela Université Pierre et Marie Curie, LISE/CNRS, França.

Coordenador:

Prof. Dr. Fernando Albuquerque de Oliveira.

Brasília, julho de 2015. 
Wer wartet mit Besonnenheit, Der wird belohnt zur rechten Zeit.

Sinn und Form bekommt Verstand.

Rammstein

Race ov man!

The errors ov a wise man make thy rules,

Ye shall see,

Rather than the perfection ov the fool.

Behemoth

Yeah, fairies wear boots and you gotta believe me,

Yeah, I saw it, I saw it, I tell you no lies.

Black Sabbath 


\section{AGRADECIMENTOS}

A todos que contribuíram para este trabalho:

Minha Co-orientadora Professora Letícia Coelho, por toda contribuição neste trabalho desde seu projeto à escrita desta dissertação, em especial pela parte instrumental.

Marcelo Parise e Prof. Kalil Skeff Neto (in memorian), pela colaboração na síntese das amostras destre trabalho.

Orientador Prof. Paulo César de Morais, por ter me instruído no decorrer desta pesquisa.

Prof. Paulo Souza, pelas discussões e análises de dados no decorrer de toda a pesquisa.

Carlos Leite (Unicamp) e Prof. Carlos Giles (Unicamp), pelo auxílio nas medidas de DRX.

Prof. Geral Boaventura pelas medidas de ICP.

Prof. César Cusatis pelas medidas de XRF.

Banca examinadora: Professores Marcelo Sousa e Sebastião Silva, pela disponibilidade em avaliar este trabalho.

Meu orientador durante a graduação Prof. Kleber Daum Machado (UFPR) por me apresentar os conceitos da técnica EXAFS.

Professores da graduação Cyro Ketzer Saul (UFPR) e Wido Herwig Schreiner (UFPR) pelo incentivo ao estudo da Física Experimental.

Toda equipe do LNLS.

CNPq pela bolsa de mestrado.

Demais amigos. 


\section{RESUMO}

A dopagem de ítrio em nanopartículas de óxido de ferro altera significativamente suas propriedades coloidais, mesmo em concentrações baixas (menores que 1\%). Fluidos magnéticos obtidos com estas partículas se mostram muito estáveis, mantendo-se anos sem decantação ou floculação. Entretanto, pouco se sabe a respeito da origem destas alterações, mesmo o posicionamento relativo do ìtrio nas nanopartículas gera controvérsia. Neste trabalho foi realizada uma investigação das propriedades físicas destas nanopartículas. Para tanto, nanopartículas de ferrita com e sem dopagem de ítrio foram sintetizadas e uma caracterização química e estrutural foi feita em ambas, fluidos magnéticos com as duas espécies de nanopartículas também foram preparados. As técnicas utilizadas neste trabalho para a caracterização das nanopartículas foram Fluorescência de Raios X (XRF) e Espectroscopia de Emissão Ótica com Plasma Acoplado (ICP/AES) para a caracterização estequiométrica, Difração de Raios X (DRX) para a caracterização morfológica, permitindo estimar as dimensões das nanopartículas e o parâmetro de rede. Um experimento de microeletroforese também foi realizado para estimar o potencial eletrostático na superfície das nanopartículas e o valor encontrado para as nanopartículas com ítrio foi de $27 \%$ maior do que para as sem ítrio. Além destas técnicas, a espectroscopia da Fina Estrutura de Absorção de Raios X (XAFS) foi utilizada para a determinação da ocupação os cátions de ítrio na rede cristalina. A caracterização tornou evidente que o ítrio não altera de forma significativa as características estruturais das nanopartículas, como o parâmetro de rede e o diâmetro médio, porém as propriedades coloidais, como o potencial zeta, são drasticamente alteradas.

Palavras-chaves: nanopartículas de ferrita, magnetita, exafs, ítrio. 


\begin{abstract}
The yttrium doping in iron oxide nanoparticles alter significantly their colloidal properties, even at low concentrations (less than 1\%). Magnetic fluids made with these nanoparticles show very stability, keeping years without without decantation or flocculation. However, little is known about the origin of these changes, even the relative positioning of Yttrium in nanoparticles generates controversy. In this work was performed an investigation of the physical properties of these nanoparticles. Therefore, ferrite nanoparticles with and without yttrium doping were synthesized and chemical and structural characterization was performed in both, magnetic fluids with the two kinds of nanoparticles were also prepared. The techniques used in this study to characterize the nanoparticles were X-Ray Fluorescence (XRF) and Optical Emission Spectroscopy Coupled Plasma (ICP/AES) for stoichiometric characterization, X-Ray Diffraction (XRD) for the morphological characterization, allowing estimate the dimensions of the nanoparticles and the lattice parameter. Was also conducted a microelectrophoresis experiment to estimate the electrostatic potential on the surface of the nanoparticles, and the value found for the nanoparticles with yttrium was $27 \%$ higher than for no yttrium. In addition to these techniques, the X-ray Absorption Fine Structure spectroscopy (XAFS) was used to determine the yttrium cations occupation in the crystal lattice. The characterization became apparent that yttrium does not significantly change the structural characteristics of nanoparticles, such as the lattice parameter and the diameter, but the colloidal properties, such as zeta potential, are altered critically.
\end{abstract}

Keywords: ferrite nanoparticles, magnetite, exafs, yttrium. 


\section{SUMÁRIO}

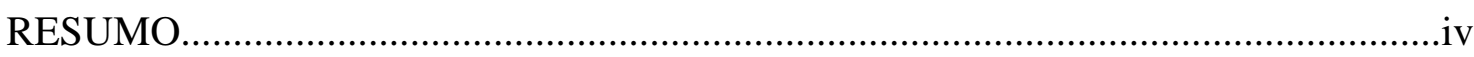

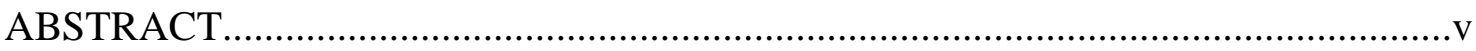

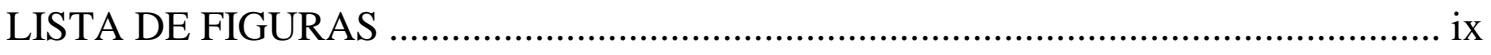

1. INTRODUÇÃ

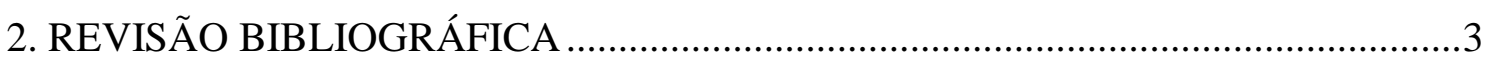

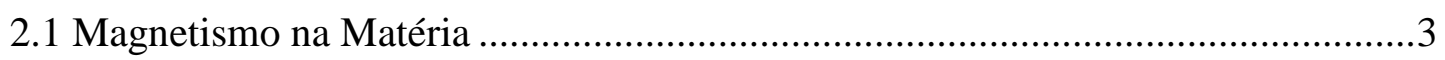

2.2 Propriedades Estruturais da Magnetita .........................................................

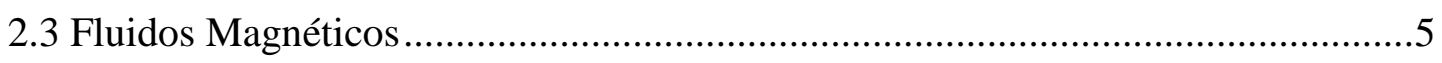

2.4 Estabilidade Coloidal e Potencial Zeta .................................................................

3. ESTRUTURA FINA DE ABSORÇÃO DE RAIOS X ............................................ 16

3.1 Espectroscopia da Estrutura Fina de Absorção de Raios X Estendida .................22

3.2 Espectroscopia Pré Borda e Estrutura de Absorção de Raios X Próxima a

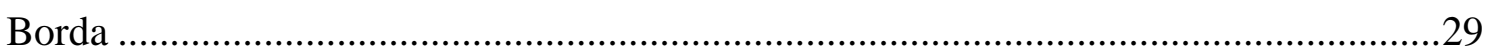

3.3 Instrumentação para Experimentos de XAFS ......................................................33

3.4 Softwares para Tratamento de Dados de XAFS .......................................................36

4. SÍNTESE E TÉCNICAS DE CARACTERIZAÇÃO ....................................................

4.1 Síntese das Nanopartículas e dos Fluidos Magnéticos .........................................37

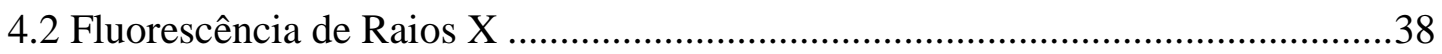

4.3 Espectroscopia de Emissão Ótica com Plasma Acoplado ....................................39

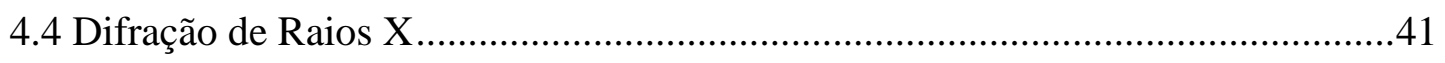

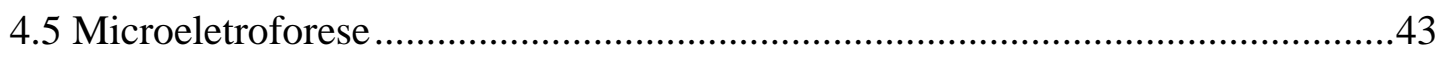

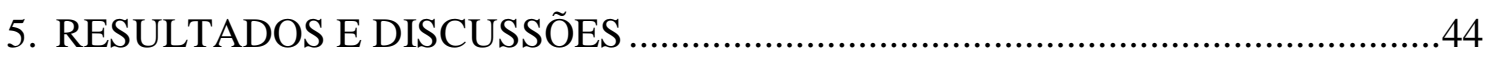

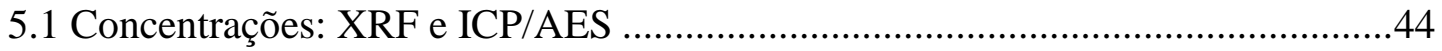

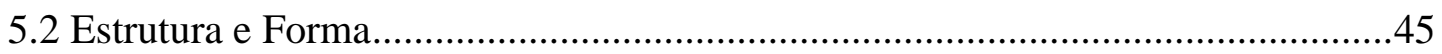

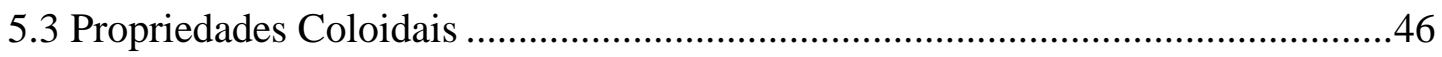

5.4 Espectroscopia da Estrutura Fina de Absorção de Raios X .................................47

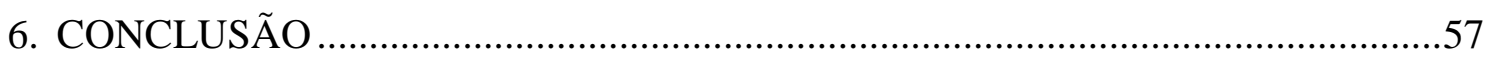

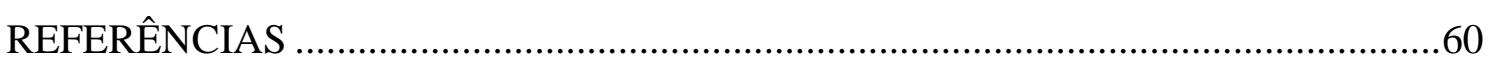




\section{LISTA DE FIGURAS}

Figura 1. Os diferentes tipos de Magnetização. Os pontos representam átomos e as setas a orientação spin: a) material paramagnético ou diamagnético na ausência de campo externo; b) material ferromagnético; c) material antiferromagnético; d) material ferrimagnético. 3

Figura 2. Estrutura e distribuição de cátions da magnetita: a) modelo poliédrico com camadas tetraédricas e octaédricas alternadas. b) modelo de esferas para o cristal. c) ampliação do modelo de esferas evidenciando os sítios tetraédricos e octaédricos. d) direção dos momentos magnéticos dos cátions nos sítios formados por átomos de oxigênio..

Figura 3. Nanopartículas surfactadas. O mecanismo para evitar a aglomeração é a repulsão física entre os agentes tensoativos na superfície das nanopartículas. À esquerda NP com camada única, e à direita NP com camada dupla.....

Figura 4. Nanopartículas iônicas. a) ferrofluido de solução básica de hidróxido de tetrametilamônia (TMA), a superfície da NP acumula carga negativa; b) ferrofluido de solução ácida, a superfície da NP acumula carga positiva. ...... 7

Figura 5. Possíveis formas ligação entre a molécula de ácido cítrico e uma nanopartícula. Na parte a) a molécula inteira se liga à superfície da NP através de dois íons de oxigênio. No esquema representado na parte b) a molécula de citrato é quebrado e carboxilas são liagadas à NP através de íons de carbono. A figura está fora de escala para facilitar a visualização.

Figura 6. Camada dupla eletricamente difusa em uma solução aquosa, resultado da dissociação de íons do sólido no líquido. A camada difusa possui a mesma carga elétrica da superfície da nanopartícula com sinal contrário. 10

Figura 7. Diagrama da dupla camada elétrica em torno de uma nanopartícula de raio $a$, carregada eletricamente em um coloide. O comprimento de Debye $\kappa^{-1}$ é justamente a extensão da camada difusa. 12

Figura 8. O potencial zeta é definido como o potencial elétrico no plano de corte. ..... 14

Figura 9. O potencial zeta em função do $\mathrm{pH}$ da solução coloidal para quatro diferentes óxidos.

Figura 10. Absorção de um fóton de raios $X$ com a emissão de um fotoelétron e comportamento do coeficiente de Absorção, modificada de [46].

Figura 11. Coeficiente de absorção do selênio em sua forma estrutural amorfa, o espectro apresenta notáveis oscilações em energias acima da borda de absorção....... 18

Figura 12. Interferências construtivas e destrutivas do fotoelétron e do elétron retro espalhado, retirada de [57].

Figura 13. Divisões das oscilações de XAFS e região da pré borda. 20 
Figura 14. Espalhamentos simples e múltiplo, o primeiro é o predominante na região de EXAFS, e o segundo na região de XANES

Figura 15. Esquema da lei de Beer-Lambert.

Figura 16. Medida de XAFS de óxido de ferro FeO, mostrando o salto na absorção $\Delta \mu_{0} \mathrm{e}$ o coeficiente de absorção e um átomo de Fe isolado $\mu_{0}$.

Figura 17. À esquerda sinal de EXAFS do Se amorfo em função do vetor de onda k do espectro da Figura 16, e o mesmo sinal multiplicado por $\mathrm{k}^{3}$, à direita, o que torna estas oscilações muito mais evidentes. 25

Figura 18. TF do sinal de EXAFS do Se amorfo da Figura 11. A existência de apenas um pico na função sugere um ordenamento apenas de primeiros vizinhos para este material.

Figura 19. XANES para vários compostos de ferro. A posição da borda de absorção e seu formato dependem do estado de valência, tipo de ligação e coordenação química do material.

Figura 20. Sinal de XANES do $\mathrm{Fe}$ metal e óxidos com $\mathrm{Fe}^{2+}$ e $\mathrm{Fe}^{3+}$. Existe uma visível diferença no formato das oscilações e na posição da borda de absorção dependente da valência dos íons.....

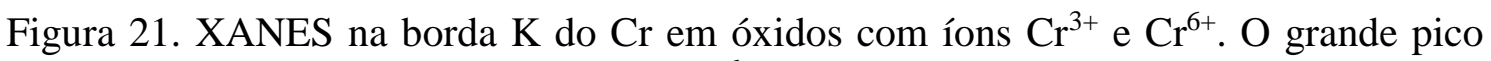
antes da borda no espectro de $\mathrm{Cr}^{6+}$ é uma consequência da simetria tetraédrica causando uma grande hibridização p-d.

Figura 22. Modo Transmissão: o feixe incidente tem sua intensidade $I_{0}$ medida pelo primeiro detector, enquanto o feixe transmitido pela amostra $\left(I_{1}\right)$ é medido por um segundo detector. Um padrão de referência é colocado após o segundo detector, de modo que o espectro de referência simultaneamente medido com a amostra por um terceiro detector.

Figura 23. Modo Fluorescência: a emissão de raios X pela amostra é proporcional ao coeficiente de absorção. Espectrômetros dispersivos são necessários para separar as emissões de espécies químicas diferentes, quando estas possuem bordas de absorção próximas..................................................................... 34

Figura 24. Modo TEY: todos os elétrons produzidos por excitação de raios X são coletados, a corrente elétrica gerada por estes elétrons é proporcional ao coeficiente de absorção de raios X. A medida é feita com multiplicadores de corrente elétrica ou através de câmaras de ionização. 35

Figura 25. Arranjo experimental do experimento de plasma, modificada de [97]. 40

Figura 26. O feixe de entrada faz com que cada um dos dispersores de reemitir uma pequena parte da sua intensidade como uma onda esférica.

Figura 27. Difratograma das NPs com e sem ítrio, o posicionamento de seus picos mostra que que ambas amostras possuem a mesma estrutura cristalina espinélio. Os dois gráficos não apresentam diferenças visíveis. 46 
Figura 28 Espectro de absorção da nanopartículas na borda K-Fe na região de XANES e medida completa no inset. Não é visível nenhuma influência provocada pelo ítrio

Figura 29. Espectro de EXAFS na borda K do Fe para as amostras FNP e YFNP.O sinal foi multiplicado por k3, para evidenciar as oscilações. ............................... 48

Figura 30. TF na borda K-Fe. A TF foi feita a partir do sinal multiplicado por $k^{2}$. 49

Figura 31. Espectro de absorção da NPs na borda K-Y na região de XANES e medida total no insert. Mesmo sendo a média de quatro medidas nota-se muito ruído no espectro.

Figura 32. Sinal de EXAFS da borda K do ítrio 53

Figura 33. TF do sinal de EXAFS da borda K-Y. Os dois primeiros picos bem definidos são uma grande evidência da substituição de íons de Fe por íons de Y nos sítios da rede.

Figura 34. L3 do Y; vermelho: K do Fe para NPs sem Y; verde: K do Fe para NPs com Y. Os três espectros de absorção foram simulados pelo programa Artemis, e são mostrados na Figura 35.

Figura 35. Sinal de $\chi(\mathrm{r})$ para os átomos de ferro presentes na amostra FNP e seu ajuste feito pelo programa Artemis, no insert é mostrado o ajuste para $\mathrm{k}^{2} \chi(\mathrm{k})$...... 50

Figura 36. Sinal de $\chi(\mathrm{r})$ para os átomos de ferro presentes na amostra YFNP e seu ajuste feito pelo programa Artemis, no insert é mostrado o ajuste para $\mathrm{k}^{2} \chi(\mathrm{k})$...... 50

Figura 37. Sinal de $\chi(r)$ para os átomos de ítrio e seu fit feito pelo programa Artemis, no insert é mostrado o ajuste para $k^{2} \chi(k)$. 


\section{INTRODUÇÃO}

Nanopartículas (NPs) de ferrita têm sido intensivamente estudadas nos últimos anos devido as suas notáveis propriedades elétricas e magnéticas [1, 2], sendo estas propriedades a base de suas extensas aplicações em áreas como sistemas de armazenamento de informação e diagnósticos médicos [3, 4]. Essas NPs possuem um grande potencial para aplicações em biomedicina devido à sua biocompatibilidade, podendo ser utilizadas em marcadores tumorais [5], hipertermia magnética [6 - 8], melhoria do contraste em imagens de ressonância magnética $[9,10]$ e sistemas de vetorização de fármacos (drug delivery) [11]. Adicionalmente, as NPs de ferrita possuem um grande impacto nas novas tecnologias industriais como o desenvolvimento de estruturas para a spintrônica [10]. Após a síntese essas partículas podem sofrer tratamentos superficiais adequados para serem dispersas em solventes polares ou apolares produzindo suspensões coloidais altamente estáveis, chamadas ferrofluidos, ou fluidos magnéticos (FMs) [12], tendo estes coloides muito potencial para aplicações industriais, tais como o desenvolvimento de óleos isolantes para transformadores elétricos, tintas magnéticas (para código de barras), acelerômetros e amortecedores magnéticos [13]. Cada aplicação destas nanopartículas requer propriedades específicas, sendo tanto a síntese quanto os tratamentos posteriores etapas desafiadoras. Para os fluidos magnéticos é fundamental possuirem uma alta estabilidade coloidal para que suas aplicações sejam possíveis.

A dopagem das NPs (inserção de diferentes espécies químicas na síntese), tem apresentado resultados notáveis, alterando suas propriedades magnéticas [14], eletrônicas e óticas [15]. Medidas iniciais indicam que a dopagem de NPs de magnetita $\left(\mathrm{Fe}_{3} \mathrm{O}_{4}\right)$ com o elemento ítrio (Y) (mesmo em baixas concentrações, menores que 1\%), altera notavelmente suas propriedades coloidais. Fluidos magnéticos feitos destas NPs dopadas mostram uma estabilidade coloidal muito maior do que FMs feitos com partículas similares, porém sem dopagem, ficando anos sem decantação ou floculação, possuindo grande potencial para aplicações como fluido de transformadores elétricos e sistemas de amortecimento. Entretanto, muito pouco se sabe acerca das origens dos efeitos físicos causados pelos átomos de ítrio na nanopartículas de ferrita. Mesmo o posicionamento do ítrio na nanopartícula ainda é incerto. Supondo-se que os átomos de ítrio permeiem a rede cristalina, eles podem ocupar posições intersticiais, gerando defeitos na rede, ou sítios 
substitucionais, ocupando posições cristalográficas dos átomos de ferro na estrutura espinélio, podendo ainda os átomos de ítrio estarem localizados apenas na superfície das NPs. Para um melhor entendimento dos efeitos do ítrio nas NPs é preciso conhecer a distribuição destes átomos nas nanopartículas e somente então teorizar acerca dos efeitos que eles têm a partir de sua localização.

O objetivo maior deste projeto de pesquisa foi localizar a posição relativa dos átomos de ítrio nas nanopartículas de ferrita. Um segundo objetivo foi caracterizar tais NPs, tanto amostras em pó quanto dispersas em ferrofluido, para descrever as alterações geradas pela dopagem de ítrio em suas propriedades estruturais e coloidais. Para isto foi realizada uma caracterização química e estrutural da amostra, e a determinação da ocupação dos íons de pela técnica de espectroscopia de absorção de raios $\mathrm{X}$, além de um estudo do potencial eletrostático na superfície das NPs por microeletroforese.

Esta dissertação está dividida em seis capítulos sendo que no segundo capítulo serão discutidas as propriedades gerais dos materiais magnéticos e da magnetita, em seguida será falado sobre fluidos magnéticos e estabilidade coloidal. No terceiro capítulo a técnica da Espectroscopia da Estrutura Fina de Absorção de Raios X (XAFS) será descrita aos detalhes, serão abordadas suas duas principais técnicas, a Estrutura Fina de Absorção de Raios X Estendida (EXAFS), e Estrutura de Absorção de Raios X Próxima a Borda (XANES), incluindo os aspectos teóricos, a instrumentação e os softwares para tratamento de dados. No quarto capítulo a síntese das nanopartículas será descrita de forma detalhada, além das técnicas de caracterização utilizadas neste trabalho, sendo estas Fluorescência de Raios X (XRF), Espectroscopia de Emissão Ótica com Plasma Acoplado (ICP/AES), Difração de Raios X (DRX) e Microeletroforese. No capítulo seguinte serão apresentados os resultados dos experimentos, discussões e algumas conclusões iniciais. Sempre que possível, os resultados obtidos neste trabalho serão comparados com dados disponíveis na literatura. No capítulo final serão apresentadas as conclusões deste trabalho e perspectivas de trabalhos futuros. 


\section{REVISÃO BIBLIOGRÁFICA}

\subsection{Magnetismo na MATÉRIA}

A origem do magnetismo na matéria está na orientação dos spins e nas órbitas dos elétrons presentes no material, o que podem ser tratados como momentos de dipolo, sendo a soma de todos estes dipolos o momento magnético total do material em questão.

A maioria dos materiais não apresenta momento magnético permanente, alguns são atraídos por campos magnéticos, sendo chamados de paramagnéticos, e outros são repelidos, os chamados diamagnéticos. Estes dois fenômenos são consequências do alinhamento dos momentos de dipolo em resposta a um campo magnético aplicado no material, sendo este alinhamento chamado de magnetização. Se esta orientação for paralela com campo magnético o material será por este atraído sendo então paramagnético, caso seja antiparalela o material será repelido, sendo, portanto, um material diamagnético.

Alguns materiais permanecem com sua magnetização mesmo após cessar o campo externo, tais materiais são classificados em ferromagnéticos, ferrimagnéticos e antiferromagnéticos. Nos materiais ferromagnéticos, idealmente, todos os momentos de dipolo estão alinhados paralelamente na mesma direção, nos ferrimagnéticos há formação de domínios magnéticos com valores distintos, alinhados antiparalelamente entre si, resultando em um momento magnético total menor que nos materiais ferromagnéticos. Já os antiferromagnéticos também possuem domínios orientados antiparalelamente, porém, com valores iguais, gerando uma magnetização nula. Na Figura 1 estão representados os diferentes tipos de magnetização.

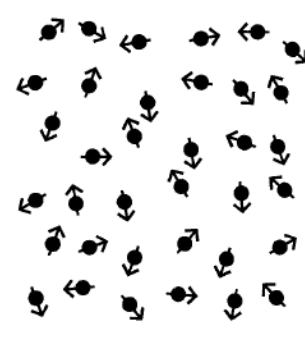

$a$

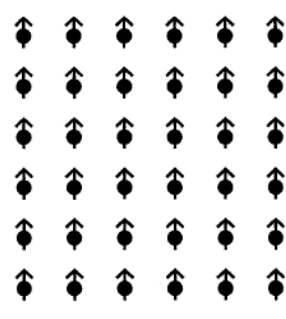

b

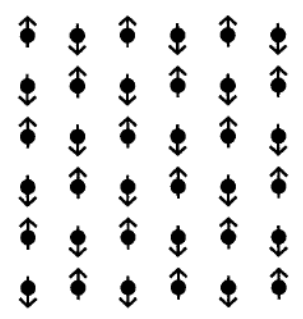

C

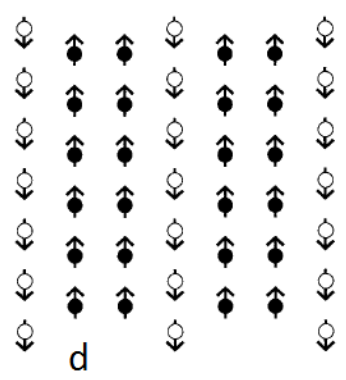

Figura 1. Os diferentes tipos de Magnetização [16]. Os pontos representam átomos e as setas a orientação spin: a) material paramagnético ou diamagnético na ausência de campo externo; b) material ferromagnético; c) material antiferromagnético; d) material ferrimagnético. 


\subsection{Propriedades Estruturais da Magnetita}

Toda a história do magnetismo começa com um mineral chamado magnetita $\left(\mathrm{Fe}_{3} \mathrm{O}_{4}\right)$, o primeiro material magnético descoberto pelo homem [16], sendo este o mais magnético de todos os minerais que ocorrem naturalmente na Terra [17]. Cristais de magnetita são encontrados em diversos organismos vivos, tal como na bactéria Aquaspirillum magnetotacticum [18], que utiliza nanopartículas magnéticas em seu corpo para se orientar. Animais com a capacidade de perceber e se orientar pelo campo magnético da Terra possuem cristais de magnetita no cérebro, estes animais incluem abelhas, lagostas, tubarões, arraias, tartarugas e diversas aves como os pombos [19].

Os principais detalhes da estrutura da magnetita foram descritos em 1915 por Bragg [20] e Nishikawa [21], sendo um dos primeiros minerais a ter sua estrutura determinada pela técnica de Difração de Raios X. A magnetita possui uma estrutura espinélio inversa $(\mathrm{fd} \overline{3} \mathrm{~m})$, como a mostrada na Figura 2, os átomos de oxigênio estão dispostos em uma estrutura cúbica de face centrada (FCC: face centered cubic), na qual formam sítios, ou subredes, com coordenações tetraédrica e octaédrica. Sua célula unitária possui 32 íons $\mathrm{O}^{2-}$, os íons de ferro são dispostos como 8 cátions com coordenação tetraédrica ( sítios A) e 16 íons com coordenação octaédrica (sítios B), num total de 56 átomos. A conservação de carga requer por célula unitária oito íons Fe com valência $2+$ e dezesseis com valência 3+. A distribuição destes cátions pelos sítios é bem conhecida [22], os íons bivalentes ocupam sítios octaédricos e os trivalentes estão distribuídos em ambos os sítios. Como pode ser visto na Figura 2d, os momentos magnéticos dos cátions octaédricos estão alinhados antiparalelamente aos momentos dos cátions tetraédricos, como existem duas vezes mais sítios octaédricos do que tetraédricos a célula unitária da magnetita possui um momento magnético resultante diferente de zero, esta é a origem do ferromagnetismo da magnetita. O magnetismo em sólidos com estrutura espinélio depende criticamente da magnitude do momento magnético e das distribuições de seus cátions entre os sítios tetraédricos (A) e octaédricos (B).

Os íons de ferro da magnetita podem ser substituídos, total ou parcialmente, por íons de outros elementos químicos, como é o caso da substituição do cátion $\mathrm{Fe}^{2+}$ por $\mathrm{Mn}^{2+}$ ou $\mathrm{Zn}^{2+}$ e do cátion $\mathrm{Fe}^{3+}$ por $\mathrm{Al}^{3+}$, as quais acontecem tanto de forma natural quanto sintética [16]. Estas substituições são dependentes da valência, do raio atômico e da química de coordenação do íon substituinte. A introdução de diferentes íons na magnetita 
introduz mudanças em suas propriedades físicas, principalmente estruturais e magnéticas, e a magnitude dessas mudanças dependem diretamente da porcentagem de íons de ferro substituídos, da natureza dos substituintes e da ocupação destes novos íons na estrutura cristalina.
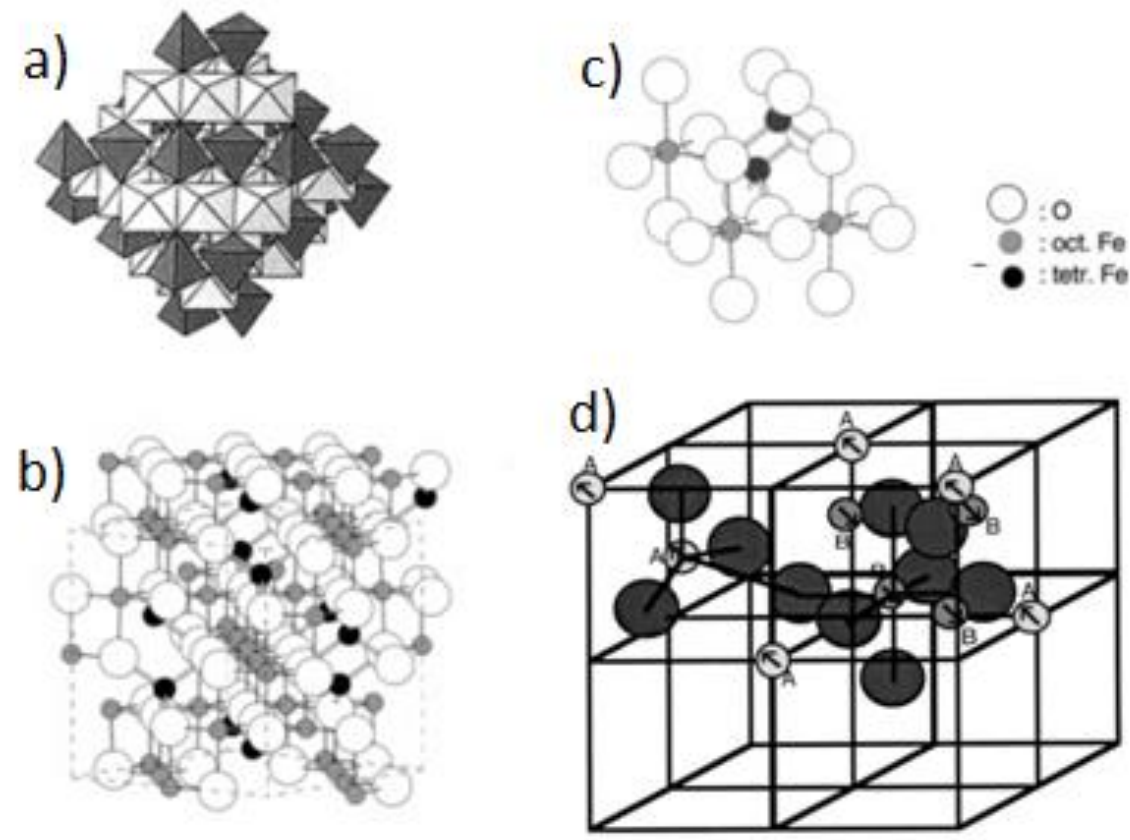

Figura 2. Estrutura e distribuição de cátions da magnetita: a) modelo poliédrico com camadas tetraédricas e octaédricas alternadas. b) modelo de esferas para o cristal. c) ampliação do modelo de esferas evidenciando os sítios tetraédricos e octaédricos [16]. d) direção dos momentos magnéticos dos cátions nos sítios formados por átomos de oxigênio [23].

A diferença de tamanho entre o raio do íon substituinte e do íon de ferro substituído insere distorções na rede cristalina como a variação no parâmetro de rede $a$, já a diferença de momento magnético entre as duas espécies iônicas modificará as propriedades magnéticas do material, tais como sua coercividade e sua saturação magnética. Além destas, propriedades elétricas, ópticas, vibracionais, elétricas e térmicas também podem ser alteradas [17].

\subsection{FLUIDOS MAgNÉTICOS}

Fluidos magnéticos (FMs), também chamados de ferrofluidos, são líquidos que se tornam fortemente magnetizados na presença de um campo magnético [24]. O fluido magnético foi patenteado em 1963 por Steve Papell, pesquisador da NASA, como um combustível líquido para foguetes que poderia ser atraído para a entrada da bomba em um ambiente sem gravidade pela aplicação de um campo magnético [25]. Tais coloides 
são formados de nanopartículas sólidas magnéticas, geralmente de ferritas, suspensas em um líquido de alta constante dielétrica (em geral água) ou apolares (normalmente um solvente orgânico). Fluidos magnéticos possuem propriedades tanto de um sólido quanto de um líquido, sendo possível alterar entre os dois estados físicos com a aplicação de um campo magnético externo [24]. Esta capacidade de mudar as fases permite que sejam utilizados como óleos vedantes, isolantes e lubrificantes, além de possuírem grande potencial para futuras aplicações em sistemas nanoeletromecânicos [26]. Ferrofluidos geralmente não retêm sua magnetização na ausência de um campo aplicado externamente, por isso são muitas vezes classificados como superparamagnéticos em vez de ferromagnéticos ou ferrimagnéticos [27].

Para evitar floculação e decantação, as partículas magnéticas podem ser revestidas com uma camada de um material apropriado [28], e de acordo com o tipo deste revestimento, os FMs são classificados em dois grupos principais: surfactados, se o revestimento é uma molécula de surfactante, e iônicos, se é uma camada elétrica.
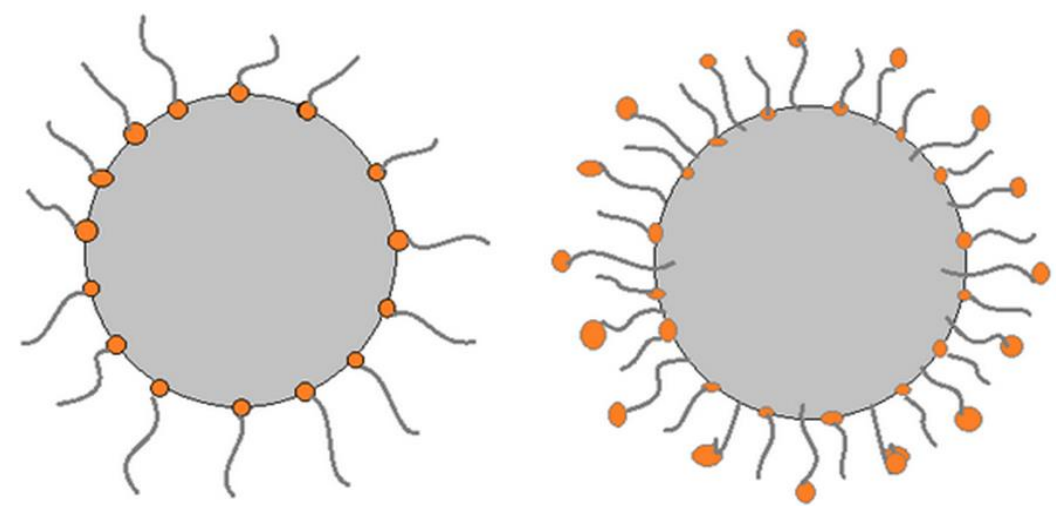

Figura 3. Nanopartículas surfactadas. $O$ mecanismo para evitar a aglomeração é a repulsão física entre os agentes tensoativos na superfície das nanopartículas. À esquerda NP com camada única, e à direita NP com camada dupla.

Ferrofluidos surfactados têm suas nanopartículas revestidas com agentes tensoativos, a fim de impedir a sua agregação. A repulsão física entre as partículas atua como uma barreira física que mantém as NPs em solução e estabiliza o coloide. Se as partículas se encontram dispersas num meio não polar, como óleo, é necessária uma camada de agente tensoativo para formar uma camada externa hidrofóbica. A cabeça polar do surfactante está ligada à superfície das partículas e da cadeia carbônica está em contato com o fluido. Por outro lado, se as partículas são dispersas num meio polar, como água, é necessário um duplo surfactante das partículas para formar uma camada 
hidrofílica em torno deles [29] (Figura 3). Fluidos magnéticos surfactados são amplamente utilizados em dispositivos tecnológicos, estando comercialmente disponíveis [30, 31].
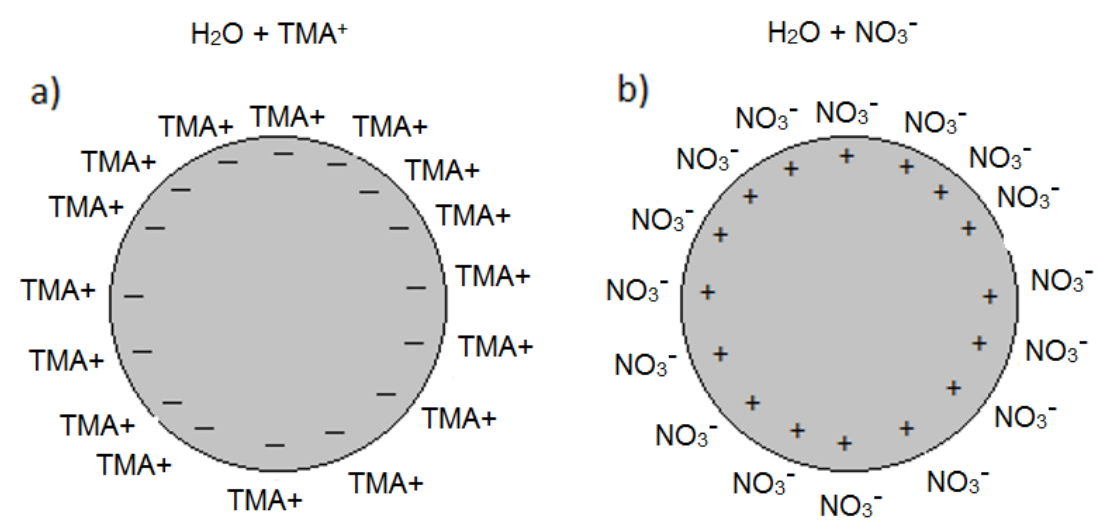

Figura 4. Nanopartículas iônicas. a) ferrofluido de solução básica de hidróxido de tetrametilamônia (TMA), a superfície da NP acumula carga negativa; b) ferrofluido de solução ácida, a superfície da NP acumula carga positiva.

Ferrofluidos iônicos, possuem nanopartículas eletricamente carregadas para manter o sistema coloidal estável. Partículas magnéticas podem ser obtidas através de um método de precipitação química, e um tratamento superficial obtido a partir de uma reação ácido-alcalina mantém a superfície das partículass eletricamente carregada. Normalmente, o líquido utilizado é água, e o pH da solução pode variar de cerca de 2 a 12, o qual determina o sinal da carga da superfície das partículas, ácido $(\mathrm{pH}<7)$ para partículas carregadas positivamente, é alcalino $(\mathrm{pH}>7)$ para partículas carregadas negativamente. Na Figura 4 são apresentados modelos de um ferrofluido ácido e um alcalino. A estabilidade do coloide magnético depende da contribuição térmica e do equilíbrio entre a interação atraente (van der Waals, dipolo-dipolo) e a repulsiva (interações eletrostáticas).

Uma terceira classe de ferrofluidos, os citratados, são considerados um misto de surfactado com iônico. Em tais coloides moléculas de ácido cítrico $\left(\mathrm{C}_{6} \mathrm{H}_{8} \mathrm{O}_{7}\right)$ adsorvidas na superfície das NPs são o mecanismo responsável pela estabilidade coloidal, atuando como agentes tensoativos e também aumentando o acúmulo de carga elétrica na superfície. A forma de ligação da molécula, ou partes desta, com a nanopartícula ainda é objeto de estudo, no entanto, já foram encontradas evidências experimentais para duas formas possíveis para esta ligação: na primeira, a molécula inteira se liga a nanopartícula através de dois íons de oxigênio [32], na segunda, a molécula é quebrada e suas partes se 
ligam à NP através de um íon de carbono [33]. Um esquema simplificado de cada caso esta na Figura 5.

a)
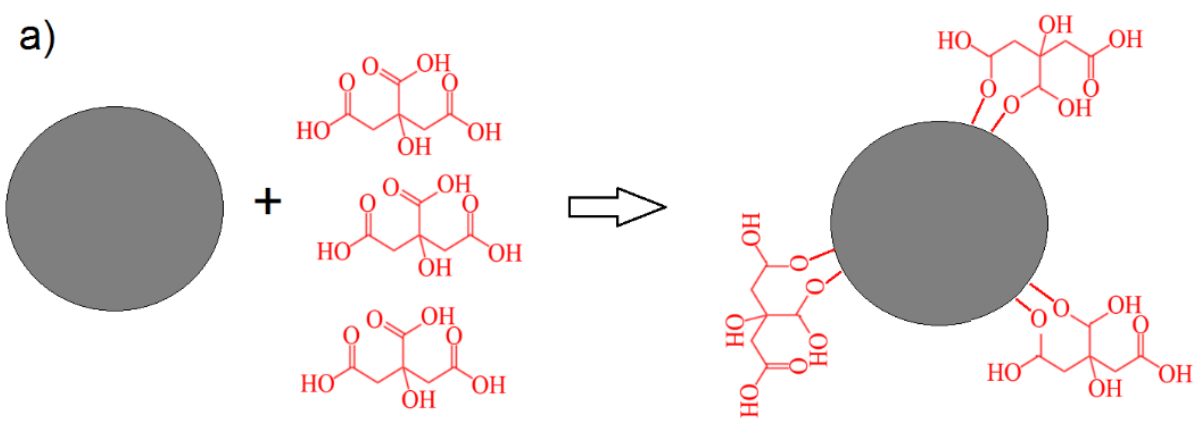

b)
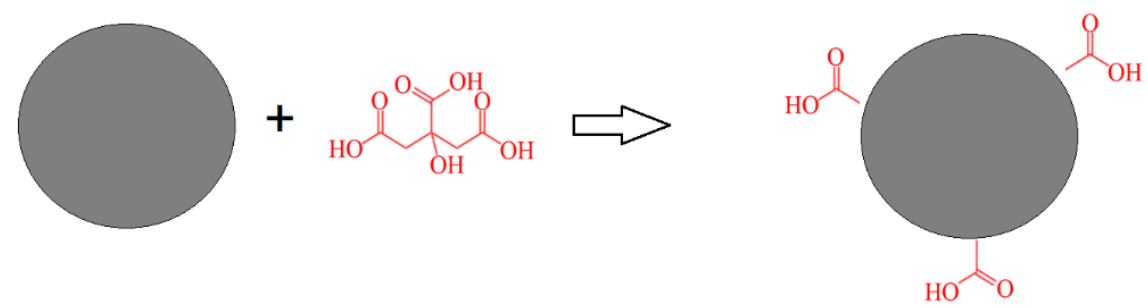

Figura 5. Possíveis formas ligação entre a molécula de ácido cítrico e uma nanopartícula. Na parte a) a molécula inteira se liga à superfície da NP através de dois íons de oxigênio [32]. No esquema representado na parte b) a molécula de citrato é quebrado e carboxilas são liagadas à NP através de íons de carbono [33]. A figura está fora de escala para facilitar a visualização.

Os ferrofluidos utilizados neste trabalho são citratados, porém o foco de estudo não será a forma de ligação entre as moléculas de citrato e a NP. O ponto central desta pesquisa será a investigação do acúmulo de carga elétrica superficial das nanopartículas. Assim o mecanismo de estabilidade coloidal iônico será discutido de forma aprofundada na próxima seção. Nas seguintes referências são encontrados trabalhos sobre fluidos magnéticos citratados: variação do diâmetro médio das NPs em função da concentração de citrato [34], efeitos da presença do citrato na síntese de óxidos de ferro [35], dependência da estabilidade coloidal com o pH [36] e tratamento de tumores cancerígenos por hipertermia [37]. 


\subsection{Estabilidade Coloidal e Potencial Zeta}

A maioria dos sólidos, principalmente nanopartículas, libera ou absorve íons quando imersos em líquidos com alta constante dielétrica, como a água [38]. Isso acontece porque o trabalho para dissociar dois íons é muito menor no líquido em questão do que no ar. A força de atração entre dois íons é dada pela lei de Coulomb:

$$
F_{C}=\frac{q_{1} q_{2}}{4 \pi D \varepsilon_{0} r^{2}}
$$

onde $q_{1}$ e $q_{2}$ são as cargas dos dois íons, $\varepsilon_{0}$ a permissividade elétrica no vácuo, $D$ a constante dielétrica do líquido e $r$ a distância entre os dois íons.

O trabalho para separar dois íons $W_{c}$ é calculado, em uma primeira aproximação, integrando a equação (2.4.1). Para o caso da água, onde $D_{\text {água }}=80$, o trabalho $W_{c}$ tem um valor próximo ao da energia cinética das moléculas em temperatura ambiente, da ordem de $10^{-21} \mathrm{~J}$, tornando possível a liberação de íons devido simplesmente a energia cinética das moléculas. Para o ar, com $D_{a r}=1, W_{c}$ este trabalho é da ordem de $100 \mathrm{KT}$, onde $K$ é a constante de Boltzmann e $T$ a temperatura, o que torna improvável uma dissociação devido apenas à agitação das moléculas. Isto é uma boa aproximação para indicar as condições básicas para a dissociação, porém a situação real é mais complexa.

A dissociação gerará um potencial eletrostático em torno da partícula impedindo que os íons dissociados deixem a partícula completamente. A consequência disto é a formação de uma camada dupla (double layer), como está esquematizado na Figura 6. A primeira camada, é a superfície carregada da nanopartícula (que pode ser positiva ou negativa dependendo da solução). A segunda camada é constituída por íons atraídos para a carga de superfície através da força de Coulomb. Esta camada é fracamente associada com a NP, formada por íons livres que se movem no líquido sob a influência de atrações elétricas e térmicas, sendo chamada de camada difusa (difuse layer). A solução aquosa fora da camada difusa é chamada de bulk.

A estabilidade de muitas soluções coloidais depende criticamente da magnitude do potencial eletrostático $\Psi_{0}$ na superfície das partículas coloidais [38, 39]. Uma das tarefas mais importantes na ciência dos coloides é obter uma estimativa do valor de $\Psi_{0}$. Um dos métodos mais convenientes e mais utilizados para a obtenção deste potencial utiliza o fato de que uma partícula carregada irá mover-se a uma velocidade $v$ constante 
sob a influência de um campo elétrico aplicado. Mesmo partículas muito pequenas (diâmetros menores que $100 \mathrm{~nm}$ ) podem ser observadas usando um microscópio de campo escuro e terem sua velocidade medida diretamente. Esta técnica é chamada de microeletroforese. Neste experimento o que é medido é a eletromobilidade $\mu$ de um coloide, que é a sua velocidade $v$ dividido pelo campo elétrico aplicado $E$. Para este cálculo utiliza-se a equação de Huckel, deduzida a seguir.

\section{Sólido Camada Difusa Bulk}

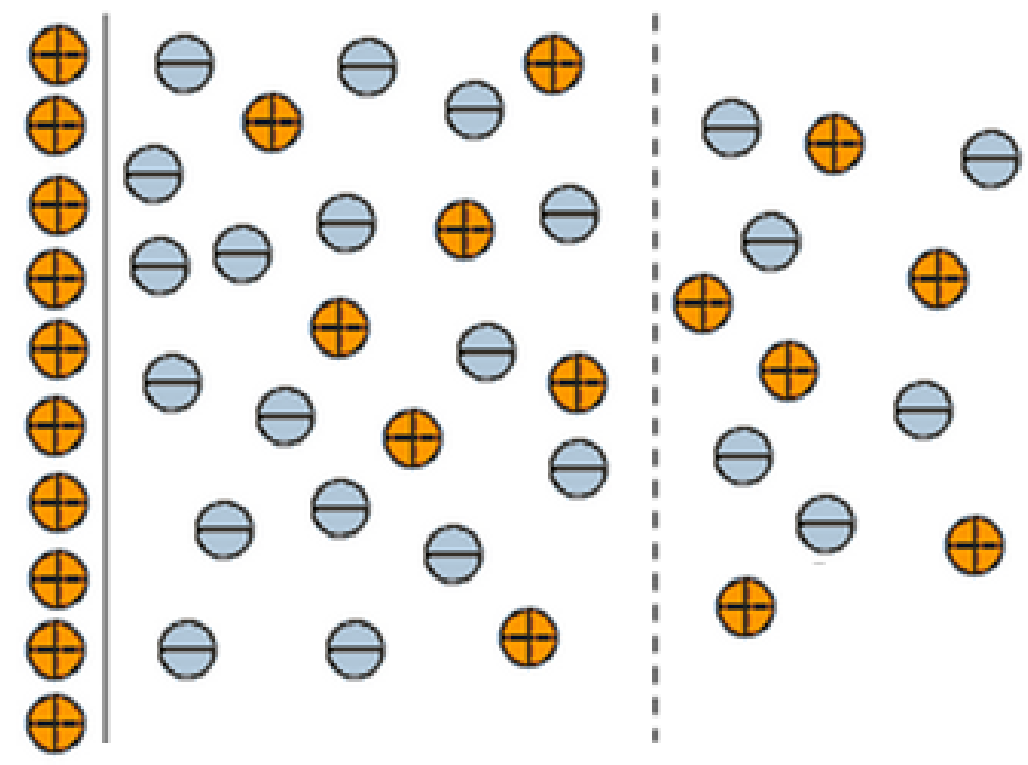

Figura 6. Camada dupla eletricamente difusa em uma solução aquosa, resultado da dissociação de íons do sólido no líquido. A camada difusa possui a mesma carga elétrica da superfície da nanopartícula com sinal contrário.

O potencial esfericamente simétrico em torno de uma esfera carregada é descrito em função da distância radial $r$ pela equação de Poisson-Boltzmann [40]:

$$
\frac{1}{r^{2}} \frac{d}{d r}\left[r^{2} \frac{d \Psi}{d r}\right]=-\frac{\rho(r)}{\varepsilon_{0} D}
$$

onde $\rho(r)$ é a densidade de carga e $\Psi$ o potencial eletrostático.

Esta equação pode ser simplificada utilizando a aproximação de Debye-Hückel válida para potenciais baixos:

$$
\frac{1}{r^{2}} \frac{d}{d r}\left[r^{2} \frac{d \Psi}{d r}\right]=\kappa^{2} \Psi
$$


onde $\kappa$ é o inverso do comprimento de Debye (Debye length) que é definido como:

$$
\kappa^{-1}=\left\{\frac{\varepsilon_{0} D \kappa T}{e^{2} \sum_{i} C_{i}(B) Z_{i}^{2}}\right\}^{1 / 2}
$$

onde $C_{i}(B)$ é a concentração iônica no bulk do elemento $i, Z_{i}$ sua valência e $e$ a carga elementar do próton.

A solução geral da equação (2.4.3) é:

$$
\Psi=\frac{A \exp (\kappa r)}{r}+\frac{B \exp (-\kappa r)}{r}
$$

A constante $A$ deve ser igual a zero para o potencial tender a zero a distância grandes da carga, e a constante $B$ pode ser obtida usando a condição de contorno de que $\Psi=\Psi_{0}$ em $r=a$, onde $a$ é o raio a partícula carregada e $\Psi_{0}$ o potencial eletrostático na superfície da partícula.

Assim, obtém-se o resultado de que:

$$
\Psi_{0}=\frac{B \exp (-\kappa r)}{r}
$$

Dessa maneira:

$$
\Psi=\frac{\Psi_{0} \exp [-\kappa(r-a)]}{r}
$$

A relação entre a carga total $q$ sobre a partícula e o potencial de superfície é obtido utilizando o fato de a carga total na dupla camada elétrica em torno da partícula deve ser igual e de sinal oposto à carga de partículas, que é:

$$
q=-\int_{a}^{\infty} 4 \pi r^{2} \rho(r) d r
$$

O valor de $\rho(r)$ pode ser obtido a partir de combinação de (2.4.2) e (2.4.3), assim tem-se que:

$$
q=4 \pi \varepsilon_{0} D \kappa^{2} \int_{a}^{\infty} r^{2} \Psi d r
$$

Usando $\Psi$ da forma da equação (2.4.7) obtêm-se: 


$$
\begin{gathered}
q=4 \pi \varepsilon_{0} D \kappa^{2} a \Psi_{0} \int_{a}^{\infty} r \exp [-\kappa(r-a)] \\
q=4 \pi \varepsilon_{0} D a \Psi_{0}(1+\kappa a)
\end{gathered}
$$

Reorganizando esta equação:

$$
\Psi_{0}=\frac{q}{4 \pi D \varepsilon_{0} a}-\frac{q}{4 \pi D \varepsilon_{0}\left(a+\kappa^{-1}\right)}
$$

Este resultado corresponde a um modelo da partícula carregada com uma carga de camada difusa (de sinal oposto) a uma separação de $\kappa^{-1}$, tal como ilustrado na Figura 7.

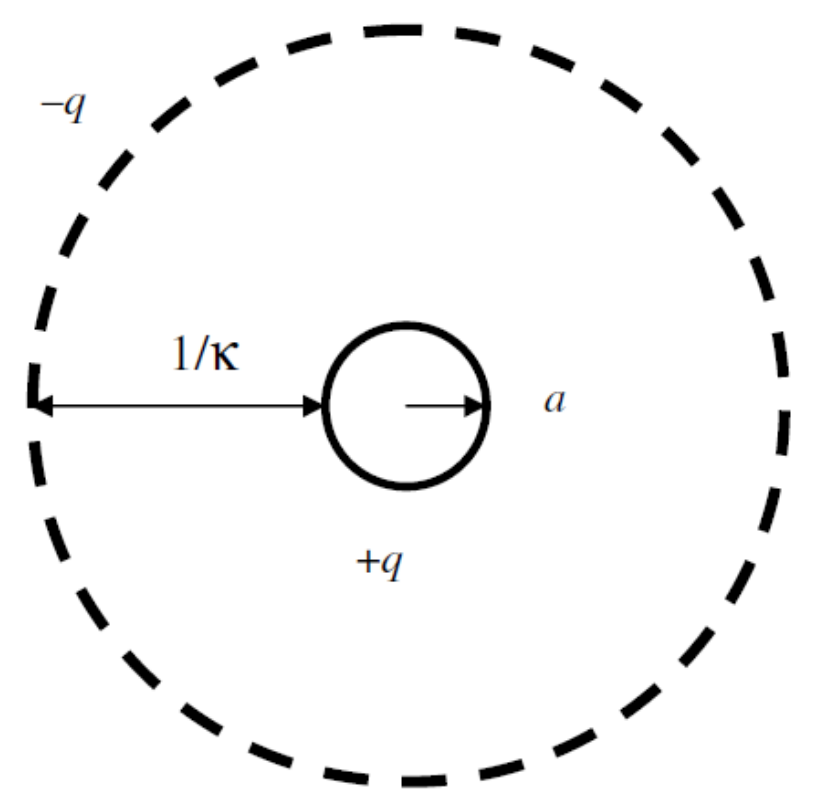

Figura 7. Diagrama da dupla camada elétrica em torno de uma nanopartícula de raio $a$, carregada eletricamente em um coloide. O comprimento de Debye $\kappa^{-1}$ é justamente a extensão da camada difusa.

Após a equação (2.4.11), que relaciona a carga sobre a partícula com o potencial de superfície, ser obtida, as forças que atuam sobre uma partícula em movimento em um campo elétrico aplicado podem ser combinadas. Assim, quando a partícula se move a uma velocidade constante $v$ a força eletrostática sobre a partícula deve ser igual a força de arrasto, $v F=q E$, dada pela lei de Stokes:

$$
F_{\text {arrasto }}=6 \pi a v \eta
$$

onde $\eta$ é a viscosidade do líquido. 
Usando as equações (2.4.11) e (2.4.12), e definindo a eletromobilidade de uma nanopartícula $\mu$ como $v / E$, obtém-se o seguinte resultado:

$$
\Psi_{0}=\frac{3 \mu \eta}{2 \varepsilon_{0} D(1+\kappa a)}
$$

para os casos onde $\kappa a \ll 1$, tem-se que:

$$
\Psi_{0}=\frac{3 \mu \eta}{2 \varepsilon_{0} D}=\zeta
$$

O potencial obtido por este método é chamado de potencial zeta $\zeta$. Neste resultado clássico, a condição de pequenas partículas significa que o tamanho real das partículas não é necessário.

O conceito de potencial zeta foi estabelecido há mais de um século por Smoluchowski [41], sendo definido como o potencial elétrico no plano de corte (do inglês shear plane), um plano hipotético com cerca de $2 \mathrm{~nm}$ a partir da superfície de uma partícula em suspensão. Internamente a este plano está a camada mais próxima da nanopartícula conhecida como (stern layer), o que está esquematizado na Figura 8. O potencial zeta é um grande indicador da estabilidade coloidal. A sua magnitude indica o grau de repulsão eletrostática entre partículas adjacentes, em uma dispersão. Quando o potencial é pequeno, forças atrativas podem exceder as forças repulsivas levando o coloide a coagular ou flocular. A Tabela 1 mostra a relação entre o comportamento coloidal e a magnitude do potencial zeta.

Tabela 2. Coloides com alto potencial zeta (negativo ou positivo) são eletricamente estabilizados, enquanto coloides com potenciais zeta baixos tendem a coagular ou flocular [42].

\begin{tabular}{|c|c|}
\hline Potencial Zeta [mV] & Comportamento Coloidal \\
\hline Entre 0 e \pm 5, & Rápida Coagulação ou Floculação \\
\hline Entre \pm 10 e \pm 30 & Fraca Estabilidade \\
\hline Entre \pm 30 e \pm 40 & Estabilidade Moderada \\
\hline Entre \pm 40 e \pm 60 & Boa Estabilidade \\
\hline Mais de \pm 61 & Excelente Estabilidade \\
\hline
\end{tabular}


A magnitude do potencial zeta depende criticamente de fatores como $\mathrm{pH}$ [43], temperatura [44] e concentração iônica [45]. Estes fatores podem ser alterados para aumentar a estabilizade coloidal de ferrofluidos iônicos, em geral o fator alterado é o pH da solução por ser, na maioria das aplicações, o mais facilmente controlado.

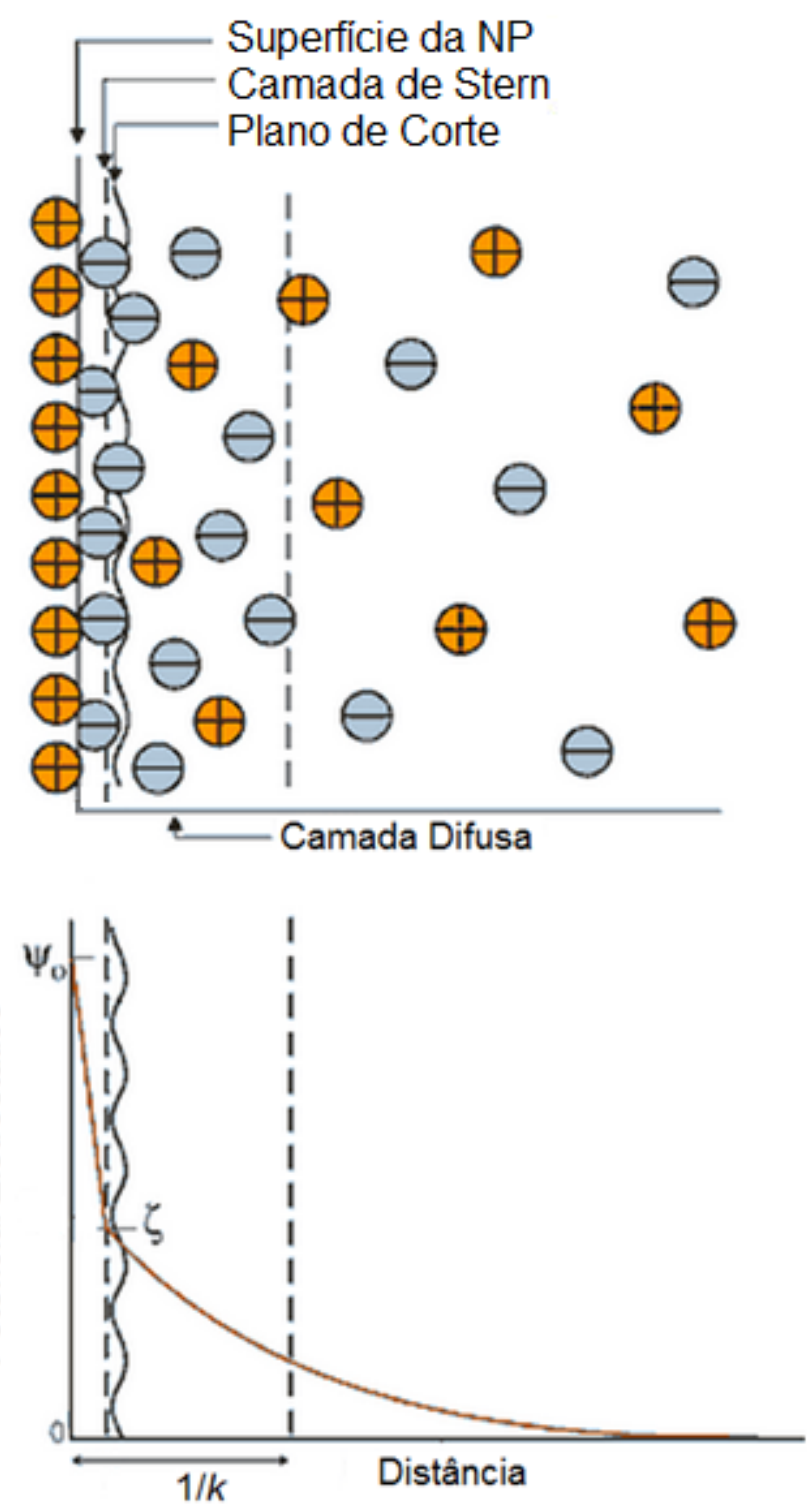

Figura 8. O potencial zeta é definido como o potencial elétrico no plano de corte.

Na Figura 9 é mostrado o potencial zeta como uma função do $\mathrm{pH}$ das dispersões aquosas de quatro óxidos de metais diferentes. Em geral, o pH da amostra é o fator mais importante que afeta o potencial zeta. Se uma nanopartícula em suspensão apresenta um potencial zeta negativo e mais alcalino é adicionado a este coloide, a NP tende a adquirir mais carga negativa, aumentando a magnitude do potencial e consequentemente aumentando a estabilidade coloidal. Se ácido é adicionado a esta suspensão, a NP tende 
a adquirir mais carga positiva até atingir um ponto onde a carga será neutra, ou muito baixa, tornando-se instável. Outra adição de ácido causa uma acumulação de carga positiva que poderá toranar a amostra estável novamente. Dessa forma, o potencial zeta em função de pH será uma curva positiva a pH baixo e negativa para um pH elevado.

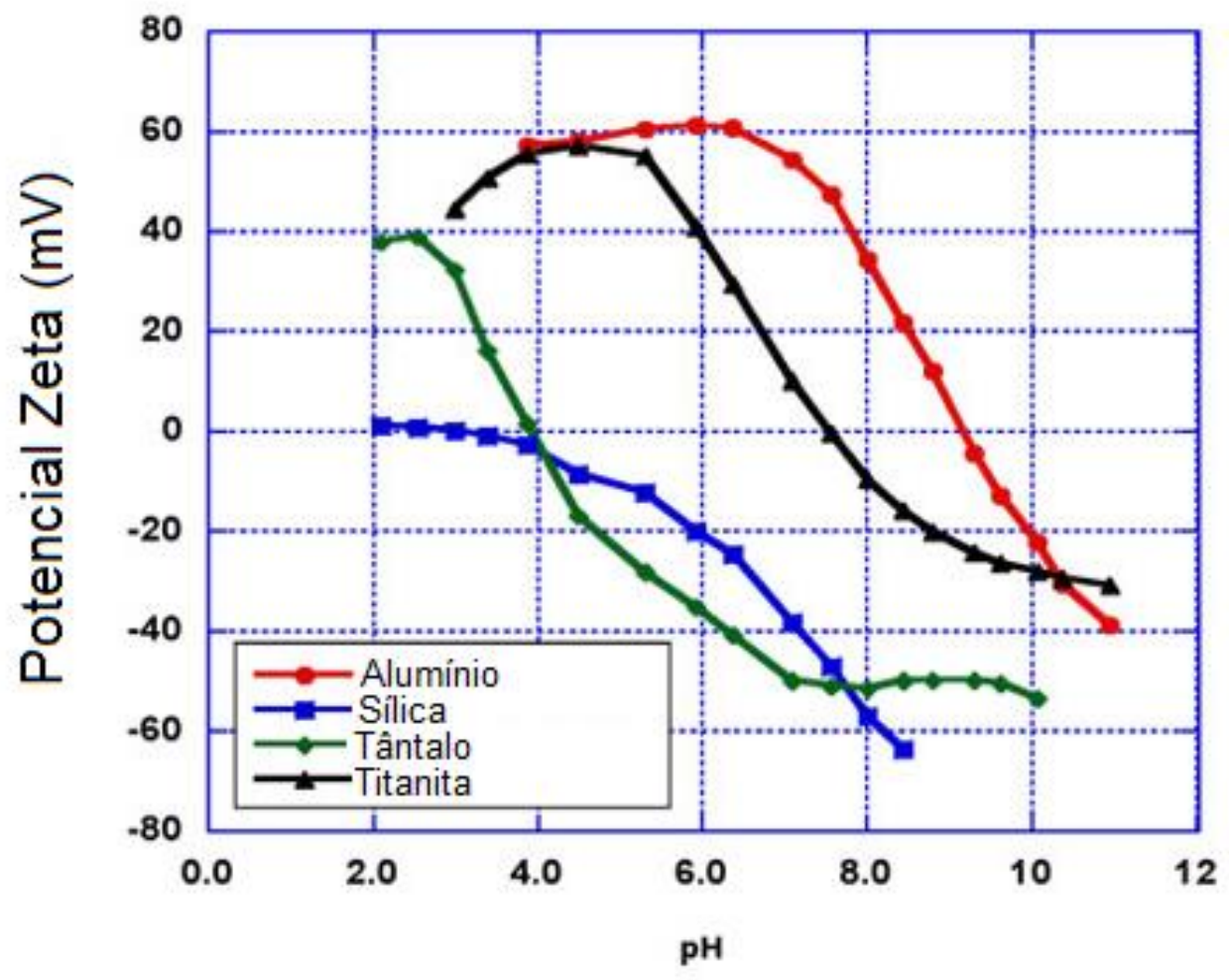

Figura 9. O potencial zeta em função do $\mathrm{pH}$ da solução coloidal para quatro diferentes óxidos. 


\section{ESTRUTURA FINA DE ABSORÇÃO DE RAIOS $X$}

O objetivo principal deste trabalho é determinação da localização do ítrio na estrutura das nanopartículas $\mathrm{Y}-\mathrm{Fe}_{3} \mathrm{O}_{4}$, e a espectroscopia da Estrutura Fina de Absorção de Raios X (XAFS: X-Ray Absorption Fine Structure) foi utilizada para este fim. A técnica de XAFS consiste no estudo da estrutura atômica de um material através de seu coeficiente de absorção de raios $\mathrm{X}$ em energias próximas às energias de ligação dos elétrons de um dos átomos constituintes deste material.

A primeira observação de uma borda de absorção foi feita por de Broglie em 1913 [46], já uma estrutura complexa na borda de absorção foi relatada pela primeira vez simultaneamente em 1920 por Fricke [47], trabalhando com compostos de $\mathrm{Mg}, \mathrm{Fe}$ e Cr, e por Hertz [48], para compostos de Cs e Nd. Porém, a interpretação feita para estes dois experimentos foi feita de forma errônea, a tentativa de explicação para o fenômeno foram transições simultâneas de dois ou mais elétrons como resultado da absorção de um único fóton de raios $\mathrm{X}$ [49].

A primeira teoria para a estrutura fina de absorção de raios $X$ foi feita por Kronig nos anos de 1931 e 1932 [50,51], ela mostrava que um de fóton atravessando uma estrutura cristalina estava sujeito a zonas permitidas e proibidas, dependendo do seu comprimento de onda. E mesmo quando o efeito era a média de todos os sentidos na rede uma estrutura residual era observada. A teoria moderna para XAFS só seria elaborada 40 anos após a teoria de Kronig pelos físicos norte-americanos Sayers, Stern e Lytle, que publicaram no início da década de 70 uma série de artigos [52 - 54] onde XAFS era explicada em termos do comportamento quântico dos elétron ejetados pela absorção de raios X. Além da teoria, estes artigos descrevem toda a técnica de XAFS (experimentos, tratamento de dados e obtenção de parâmetros da amostra). Nas décadas de 80 e 90 XAFS se tornou uma técnica bastante comum para o estudo de estruturas não cristalinas com o avanço dos aceleradores síncrotron. Na década seguinte a popularização da técnica XAFS aumentou devido ao surgimento de programas de computador capazes de simular as estruturas estudadas, tornando assim a análise dos dados e a obtenção de parâmetros estruturais muito mais prática e confiável.

A absorção de raios X (XAS: X-Ray Absorption) pela matéria deve-se pela transferência de energia de um fóton para um elétron em um estado ligado, promovendo 
este elétron para um estado desocupado de maior energia, esquematizado na Figura 10. O coeficiente de absorção do material é proporcional a probabilidade de um fóton de raios $\mathrm{X}$ ser absorvido pela matéria, e esta probabilidade decai suavemente com o aumento da energia do fóton incidente, exceto em determinadas energias, onde essa probabilidade aumenta abruptamente. Esses valores de energia correspondem a energias de ligação dos elétrons nas camadas eletrônicas de um dado elemento. Isso ocorre porque o fóton incidente possui energia suficiente para arrancar elétrons de determinada camada do átomo absorvedor, e a probabilidade de um fóton com esta energia ser absorvido se torna muito alta. O coeficiente de absorção segue este mesmo comportamento.

Os saltos no coeficiente de absorção são chamados de bordas de absorção, e são nomeadas de acordo com a origem do elétron que foi arrancado. Assim, a borda K está relacionada com a ejeção de elétron do nível quântico principal 1, as bordas L estão relacionadas ao nível quântico principal 2, e assim sucessivamente. Para bordas que contém elétrons com diferentes energias de ligação (devido aos momentos angulares diferentes) um índice é posto na nomenclatura de bordas, assim é chamada de $\mathrm{L}_{1}$ aborda relacionada com a excitação de um elétron no estado $2 \mathrm{~s}, \mathrm{~L}_{2}$ com o elétron no estado $2 \mathrm{p}_{1 / 2}$ e $\mathrm{L}_{3}$ para o elétron $2 \mathrm{p}_{3 / 2}$. A Tabela 3 apresenta um resumo da nomenclatura para as bordas de absorção.
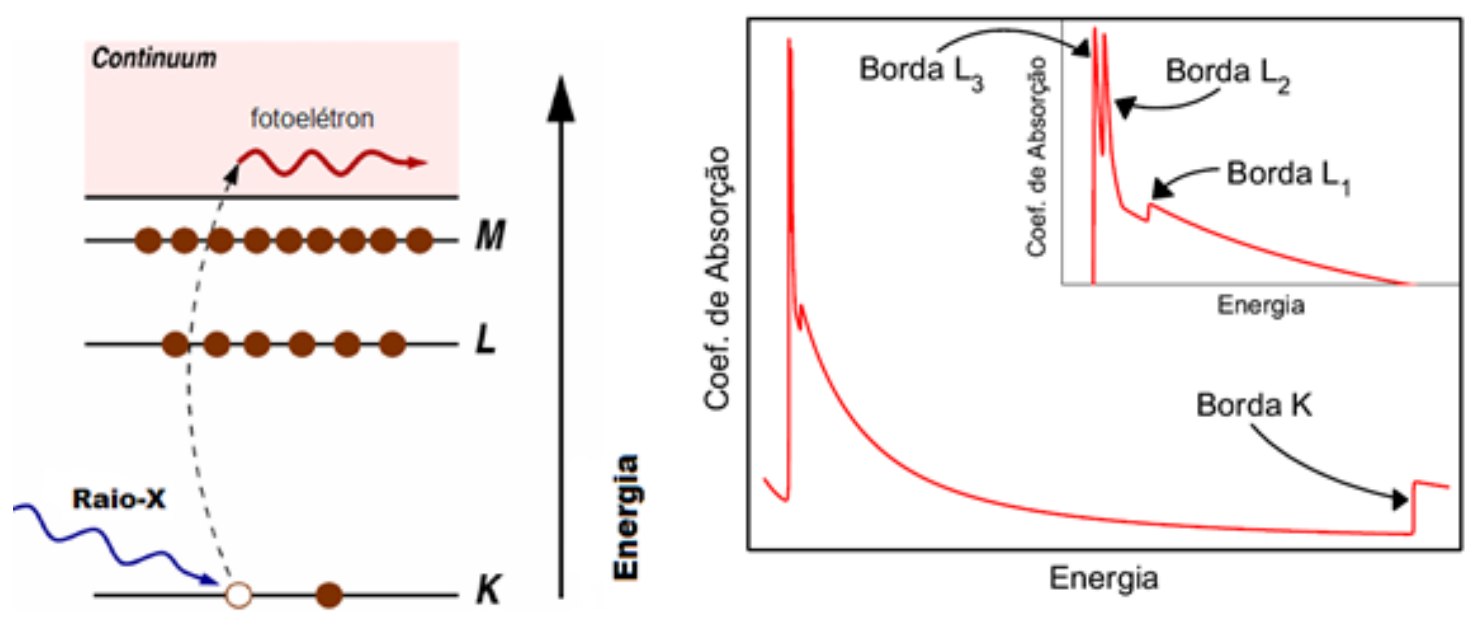

Figura 10. Absorção de um fóton de raios $X$ com a emissão de um fotoelétron e comportamento do coeficiente de Absorção, modificada de [46]. 
Usualmente, um índice com uma letra grega é utilizado para denotar uma transição específica entre estados eletrônicos [56]. Por exemplo a transição $2 p$ para 1s é denotada por $\mathrm{K}_{\alpha}$, a transição 3 p para a 1 s é chamda de $\mathrm{K}_{\beta}$, a 2 p para a 2 s é a $\mathrm{L}_{\alpha}$, como resumido na Tabela 3.1.

Tabela 3.1. Transições de raios $\mathrm{X}$ de acordo com os números quânticos correspondentes.

\begin{tabular}{|c|c|c|c|c|}
\hline $\boldsymbol{N}$ & $\boldsymbol{l}$ & $\boldsymbol{j}$ & Orbital & Transição \\
\hline $\mathbf{1}$ & 0 & $1 / 2$ & $1 \mathrm{~s}$ & $\mathrm{~K}$ \\
\hline $\mathbf{2}$ & 0 & $1 / 2$ & $2 \mathrm{~s}$ & $\mathrm{~L}_{1}$ \\
\hline $\mathbf{2}$ & 1 & $1 / 2$ & $2 \mathrm{p}_{1 / 2}$ & $\mathrm{~L}_{2}$ \\
\hline $\mathbf{2}$ & 1 & $3 / 2$ & $2 \mathrm{p}_{3 / 2}$ & $\mathrm{~L}_{3}$ \\
\hline $\mathbf{3}$ & 0 & $1 / 2$ & $3 \mathrm{~s}$ & $\mathrm{M}_{1}$ \\
\hline $\mathbf{3}$ & 1 & $1 / 2$ & $3 \mathrm{p}_{1 / 2}$ & $\mathrm{M}_{2}$ \\
\hline $\mathbf{3}$ & 1 & $3 / 2$ & $3 \mathrm{p}_{3 / 2}$ & $\mathrm{M}_{3}$ \\
\hline $\mathbf{3}$ & 2 & $3 / 2$ & $3 \mathrm{~d}_{3 / 2}$ & $\mathrm{M}_{4}$ \\
\hline $\mathbf{3}$ & 2 & $5 / 2$ & $3 \mathrm{p}_{5 / 2}$ & $\mathrm{M}_{5}$ \\
\hline
\end{tabular}

Em energias logo acima de uma borda o coeficiente de absorção apresenta oscilações notáveis, assim como pode ser verificado na Figura 11, que contém o espectro de absorção do selênio em seu estado amorfo.

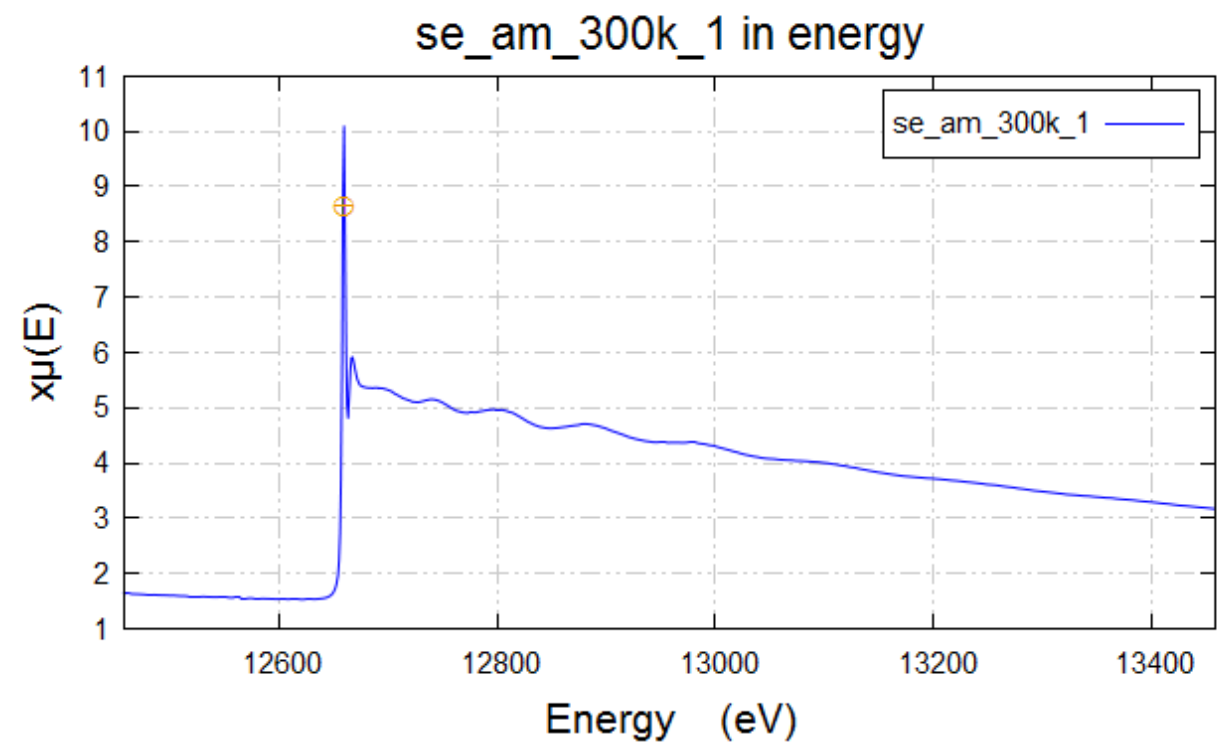

Figura 11. Coeficiente de absorção do selênio em sua forma estrutural amorfa, o espectro apresenta notáveis oscilações em energias acima da borda de absorção. 
Estas oscilações têm origem no comportamento quântico dos elétrons excitados. Ao absorver um fóton de raios X o átomo absorvedor emite um elétron em forma de onda, esta onda interage com os núcleos dos átomos ao redor do átomo absorvedor, sendo difratada por estes átomos, gerando interferências construtivas ou destrutivas entre a onda incidente e a retro espalhada (Figura 12), fazendo assim com que o estado final do elétron seja oscilante. A probabilidade de um fóton ser absorvido por um átomo com a emissão de um elétron, num estado inicial, depende do estado final deste elétron. Por este motivo o fóton só é absorvido se o estado final do elétron for um estado de interferência construtiva. Isto faz a probabilidade de absorção oscilar e o resultado macroscópico são oscilações no coeficiente de absorção do material.
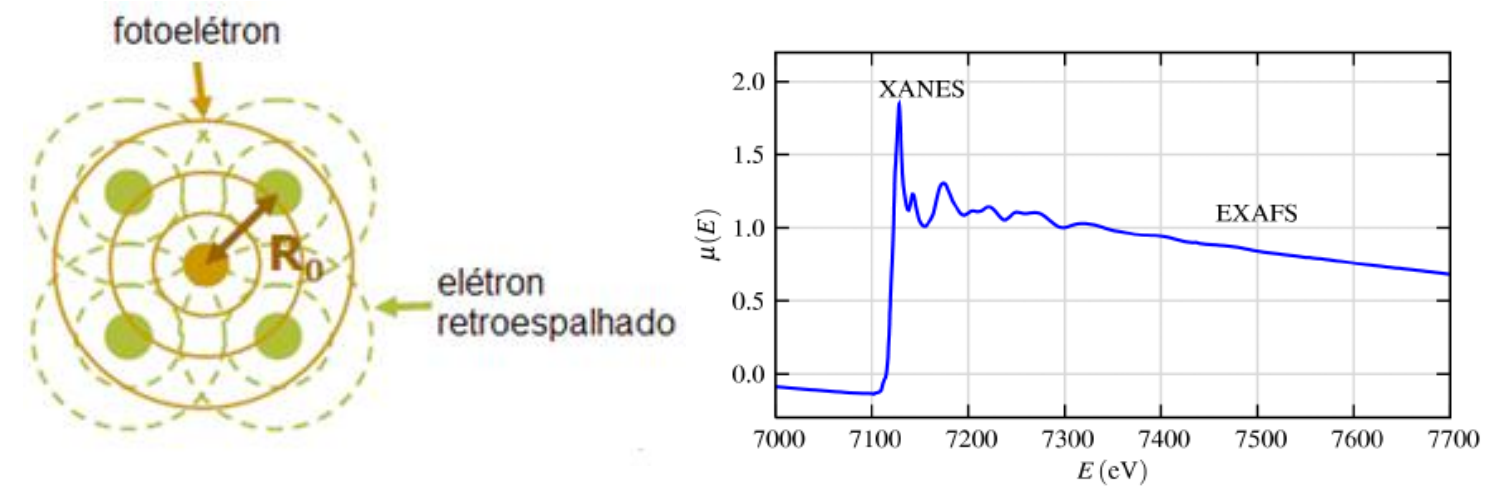

Figura 12. Interferências construtivas e destrutivas do fotoelétron e do elétron retro espalhado, retirada de [57].

Quando o átomo absorvedor se encontra na matéria condensada o espectro apresenta oscilações que podem estender-se até mais de $1 \mathrm{keV}$ acima da borda de absorção com amplitudes de até $10 \%$ em torno do seu valor médio [55]. Desta maneira a estrutura ao redor do átomo absorvedor influencia no comportamento do coeficiente de absorção, assim as medidas de absorção de raios $\mathrm{X}$ trazem informações sobre a estrutura do material, em particular da vizinhança do átomo absorvedor. Entre as principais informações que podem ser obtidas, temos parâmetros estruturais como distâncias interatômicas médias e o número médio de vizinhos de determinada espécie.

Os detalhes destas oscilações são estudados pela teoria da Estrutura Fina de Absorção de Raios X. Os espectros de XAFS são especialmente sensíveis ao estado de oxidação, à química de coordenação, às distâncias interatômicas, aos números de coordenação e às espécies de átomos que cercam ao átomo absorvedor. Devido a isso, XAFS fornece uma forma prática de determinar o estado químico e estrutura atômica local para uma espécie atômica selecionada. Sendo assim utilizada em uma variedade de 
sistemas, em uma ampla gama de campos científicos, incluindo biologia, ciência ambiental, catalisadores e pesquisa e ciência dos materiais.

As oscilações de XAFS são divididas em duas regiões com características distintas:

Estrutura de Absorção de Raios X Próxima a Borda, XANES (X-ray Absorption Near Edge Structure): oscilações estreitas e intensas até $50 \mathrm{eV}$ após a borda de absorção, fortemente sensível ao estado de oxidação e química de coordenação do átomo absorvedor.

Estrutura Fina de Absorção de Raios X Estendida, EXAFS (Extended X-ray Absorption Fine Structure): oscilações suaves entre 50 e $1000 \mathrm{eV}$ após a borda de absorção, usada para determinar as distâncias, os números de coordenação, e as espécies dos vizinhos do átomo absorvedor.

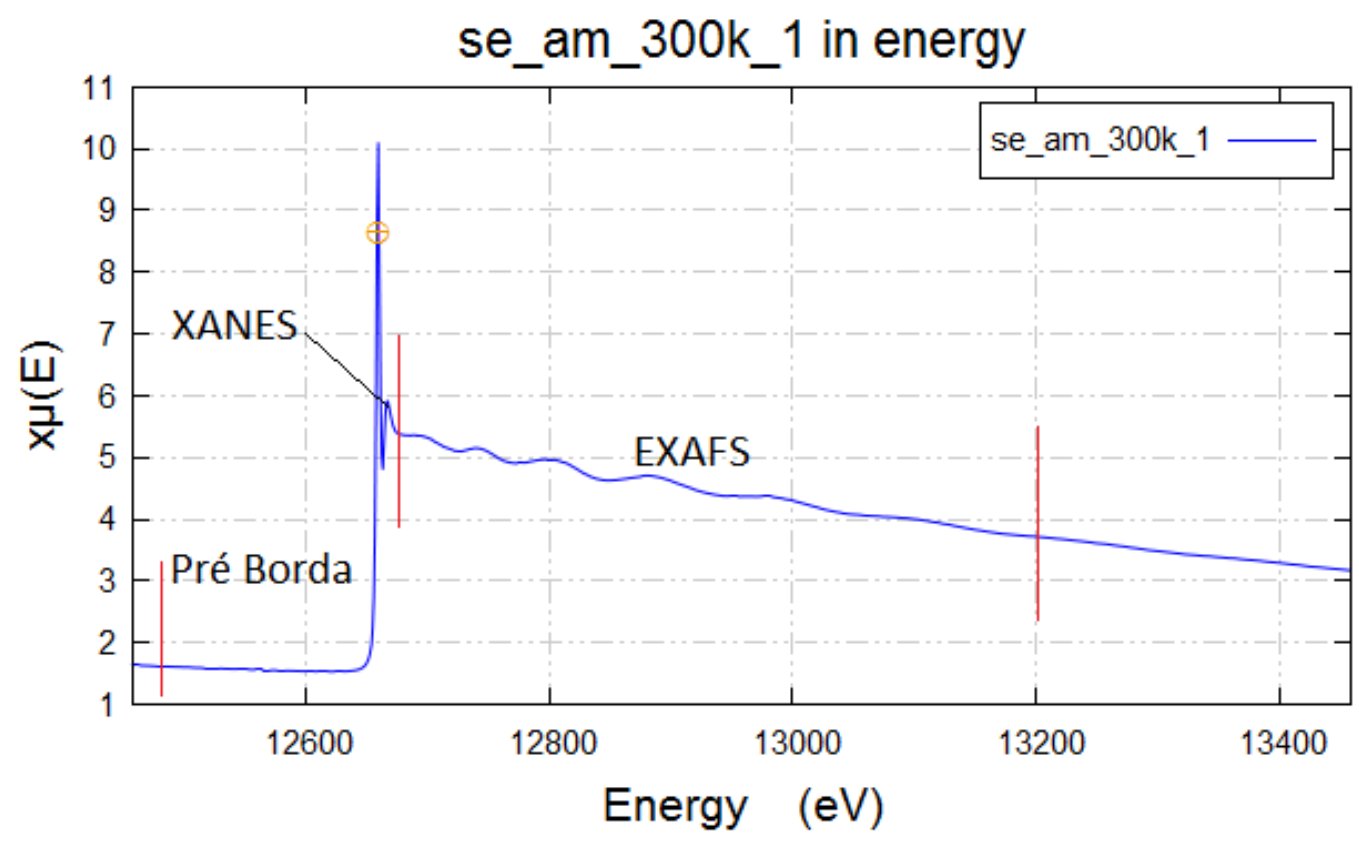

Figura 13. Divisões das oscilações de XAFS e região da pré borda.

As oscilações nas regiões de XANES e EXAFS, mostradas na Figura 13, possuem a mesma origem física, a diferença entre as formas das oscilações está relacionada com as escalas de energia cinética dos fotoelétrons, o que faz com que seus espalhamentos sejam mais ou menos dependentes de determinados fatores físicos e químicos (tais como a estrutura eletrônica para XANES e as distâncias interatômicas para EXAFS) nestas duas faixas de XAFS. 
Na faixa de XANES, o elétron é ejetado com pouca energia cinética, tendo seu comportamento fortemente afetado pelo potencial coulombiano resultante da vizinhança do átomo absorvedor, fazendo com que esta região contenha informações sobre a estrutura eletrônica do composto ao redor do átomo absorvedor. A baixa energia cinética contribui ainda para espalhamentos múltiplos nesta região como esquematizado na Figura 14. A técnica XANES tem sido aplicada no estudo de biomoléculas [58], estrutura da banda eletrônica [59], concentração de dopantes e estado de ionização [60] e fenômenos de superfícies [61].

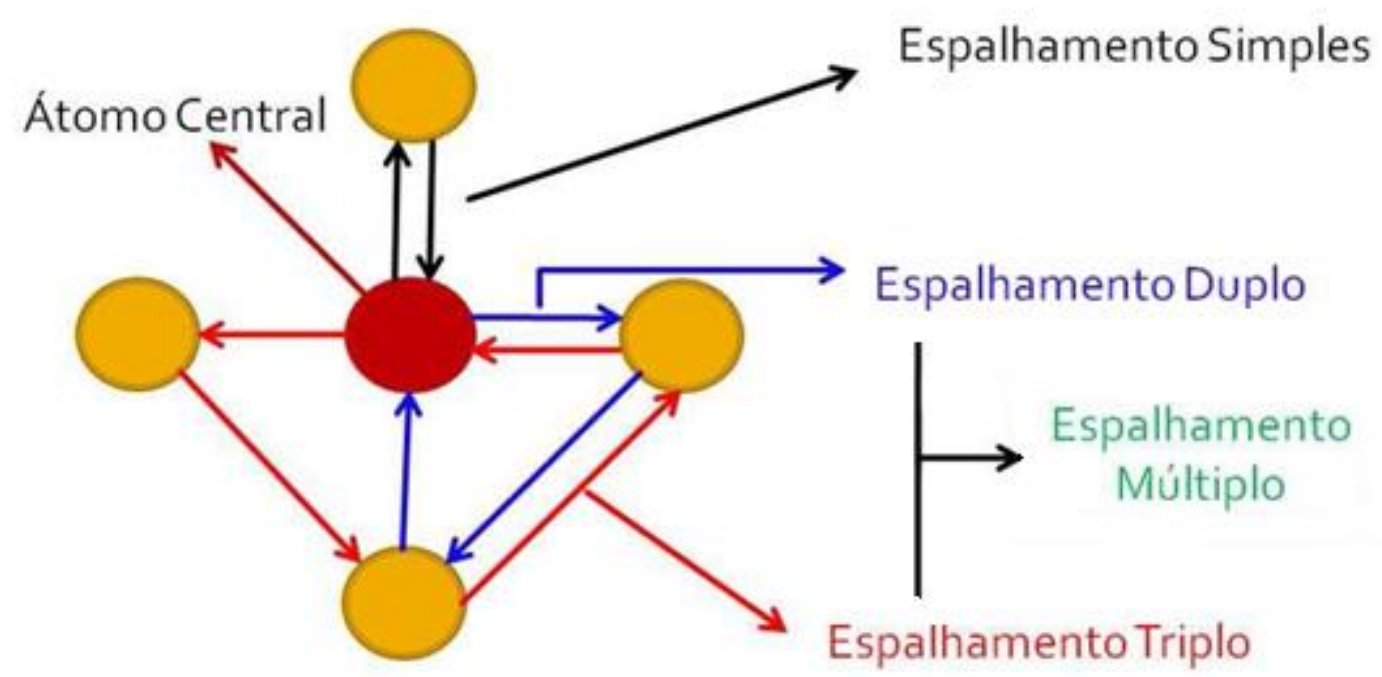

Figura 14. Espalhamentos simples e múltiplo, o primeiro é o predominante na região de EXAFS, e o segundo na região de XANES.

Na faixa de EXAFS, o fotoelétron possui uma energia cinética alta, tendo por esse motivo seu comportamento muito pouco afetado pelo potencial coulombiano ao seu redor, além de ter baixa probabilidade de sofrer espalhamentos múltiplos, fornecendo informações sobre o posicionamento dos átomos ao redor do átomo absorvedor. Estas informações são de curto, e em certos casos, médio alcance (primeiros, segundos e terceiros vizinhos), sendo independentes da estrutura de longo alcance ou simetria da rede cristalina, não havendo nem mesmo a necessidade da existência destes dois fatores no material em questão, o que torna a espectroscopia de EXAFS uma técnica de caracterização estrutural muito eficiente para o estudo de materiais amorfos ou desordenados.

A técnica EXAFS tem sido utilizada para estudar a estrutura local em vidros [62], sistemas líquidos [63], dopagem e implantação iônica em materiais para a eletrônica [64], 
distorções locais na estrutura de um cristal [65], compostos organometálicos [66], metaloproteínas [67], clusters metálicos [68], dinâmica vibracional [69], íons em soluções [70], compostos multiferróicos [71], materiais com estruturas tipo perovskita [72] e nanopartículas de óxido de ferro [73 - 75].

A divisão nas oscilações de XAFS é responsável pela existência de duas técnicas distintas em termos de tratamento de dados e parâmetros físicos e químicos obtidos. Além destas duas, XAFS ainda contém outras técnicas como NEXAFS (Near Edge EXAFS) [76], SEXAFS (Surface EXAFS) [77] e Espectroscopia Pré Borda [78], todas utilizando o mesmo espectro de absorção e formas diferentes de tratamento de dados. Existem ainda técnicas com variações durante o experimento para medição do coeficiente de absorção, como Dicroísmo Circular Magnético (XMCD: X-ray Magnetic Circular Dichroism) [79, 80] que usa luz circularmente polarizada para realizar as medidas de absorção, desta maneira informações sobre os momentos magnéticos atômicos na amostra são obtidas. Além de outras como SPXAS (Spin Polarized XAS) [80] e SPEXAFS (Spin Polarized EXAFS) [82], onde a dependência da polarização dos spins eletrônicos na absorção de raios $\mathrm{X}$ é estudada.

\subsection{ESPECTROSCOPIA DA ESTRUTURA Fina de AbSORÇÃo de RAIOS X EsTENDIDA}

O processo físico que envolve as oscilações de EXAFS é a interferência entre a função de onda do elétron emitido pelo átomo absorvedor e a onda retro espalhada pelo átomo vizinho. Nesta seção as oscilações de EXAFS serão descritas primeiramente de uma forma mais qualitativa até obter-se a equação de EXAFS e depois esta mesma equação será deduzida com um formalismo matemático maior.

A absorção fotoelétrica não é o único fenômeno resultante da interação de fótons com a matéria. O espalhamento elástico (Rayleigh) e inelástico (Compton), além da absorção fotonuclear (absorção de fótons pelo núcleo atômico), são fenômenos que podem afetar de alguma forma o cálculo do coeficiente de absorção. Porém, na faixa de energia correspondente aos raios $\mathrm{X}$ a absorção fotoelétrica é o mecanismo dominante [83], e isto permite fazer uma aproximação e considerar que numa medida de absorção de raios $X$ está sendo quantificando essencialmente o processo de absorção fotoelétrica. Devido a este fato, este trabalho se limitará ao estudo da absorção fotoelétrica de raios $\mathrm{X}$, desprezando outros fenômenos da interação da radiação com a matéria. $\mathrm{O}$ 
comportamento do coeficiente de absorção de uma amostra será estudado como uma função da energia do fóton incidente.

O coeficiente de absorção é quantificado pela lei de Beer-Lambert (esquematizado na Figura 15). De acordo com esta lei a intensidade $I$ de um feixe transmitido por uma amostra de largura $x$ é dado por:

$$
I=I_{0} e^{-\mu(E) x}
$$

onde $I_{0}$ é a intensidade do feixe incidente e $\mu(E)$ o coeficiente de absorção dependente da energia do fóton incidente.

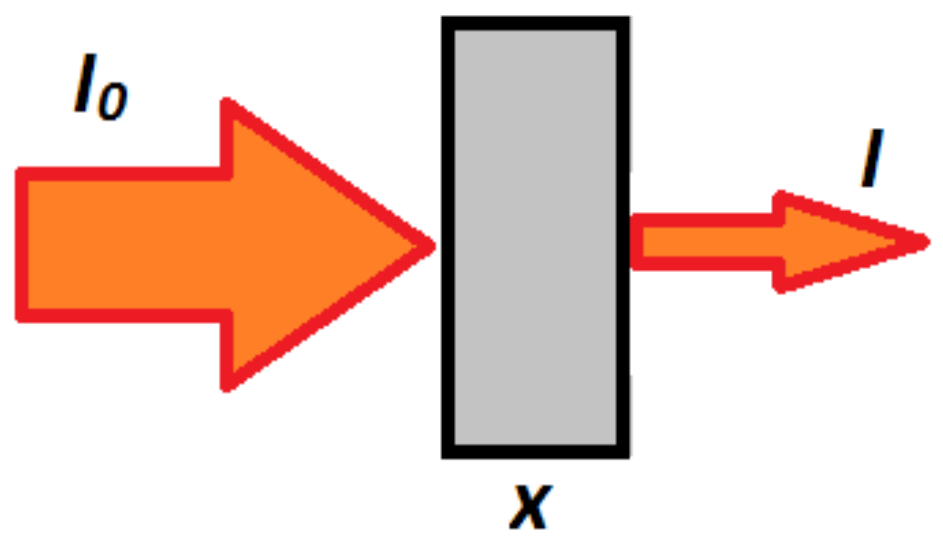

Figura 15. Esquema da lei de Beer-Lambert.

A equação (3.1.1) pode ser escrita como:

$$
\mu(E)=\ln \left(I_{0} / I\right)
$$

Se o átomo absorvedor não possui nenhum vizinho suficientemente próximo, o espectro de absorção terá um rápido aumento na borda de absorção e, acima da borda, uma queda suave sem oscilações, aproximadamente $1 / E^{3}$ [84]. Para este caso definimos o coeficiente de absorção de um átomo isolado $\mu_{0}$. O coeficiente de absorção de um átomo em um sólido pode ser escrito como uma soma do coeficiente de absorção deste átomo isolado e a influência $\chi(E)$ causada pelos átomos ao seu redor:

$$
\mu(E)=\mu_{0}(1+\chi(E))
$$


As oscilações de EXAFS $\chi(E)$ são definidas como:

$$
\chi(E)=\frac{\mu(E)-\mu_{0}}{\Delta \mu_{0}}
$$

onde $\mu(E)$ é o coeficiente de absorção obtido experimentalmente, $\mu_{0}$ é uma função que representa a absorção de um átomo isolado, e $\Delta \mu_{0}$ é o salto na absorção de $\mu(E)$ na energia de ligação $E_{0}$. Detalhes na Figura 16.

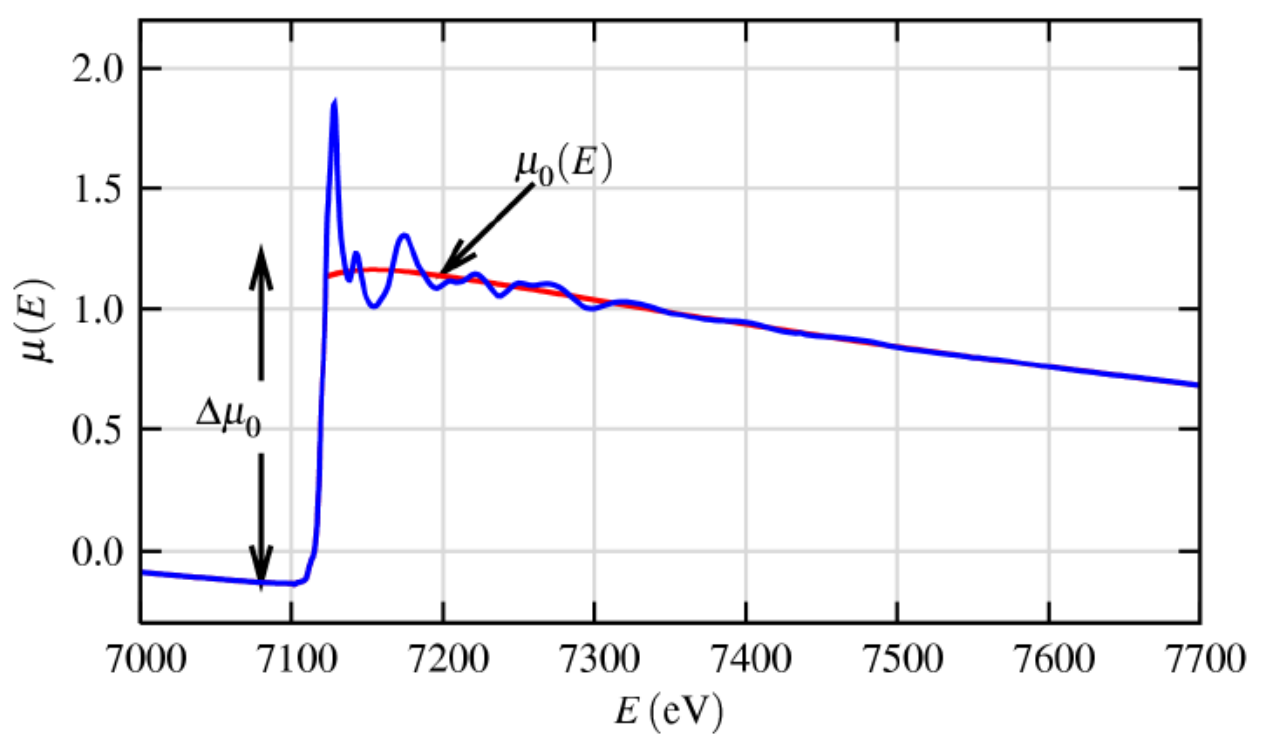

Figura 16. Medida de XAFS de óxido de ferro FeO [55], mostrando o salto na absorção $\Delta \mu_{0}$ e o coeficiente de absorção e um átomo de Fe isolado $\mu$.

O sinal de EXAFS é melhor entendido quando escrito em função do vetor de onda do fotoelétron (Figura 17). O vetor de onda do fotoelétron é definido como:

$$
k=\sqrt{\frac{2 m\left(E-E_{0}\right)}{\hbar^{2}}}
$$

onde $m$ é a massa do elétron, $E$ a energia cinética do fotoelétron, $E_{0}$ a energia de ligação e $\hbar$ a constante de Dirac. 

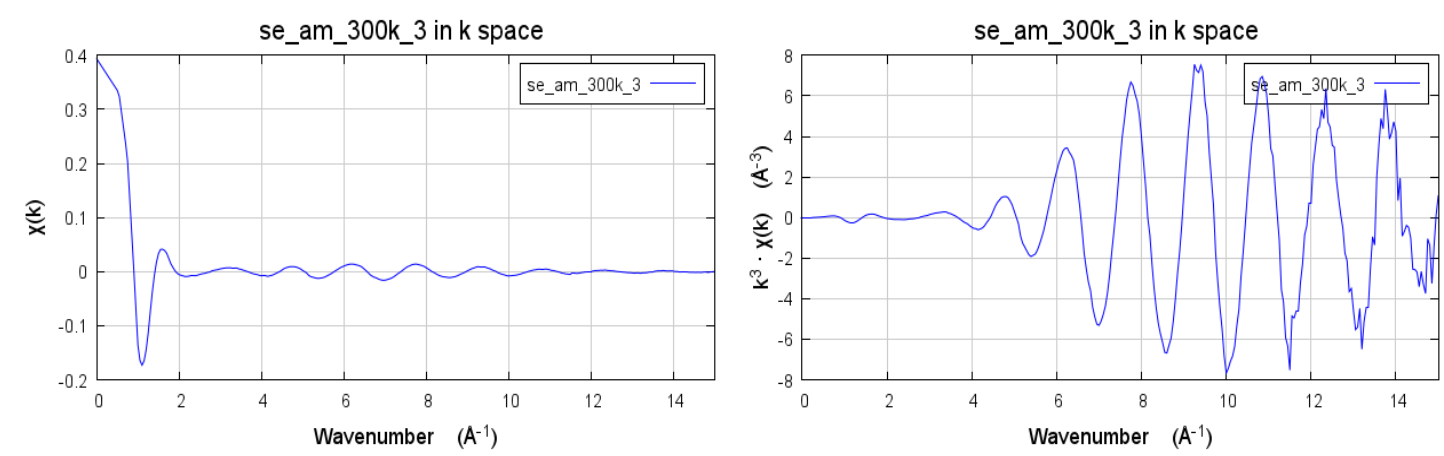

Figura 17. À esquerda sinal de EXAFS do Se amorfo em função do vetor de onda $k$ do espectro da Figura 16, e o mesmo sinal multiplicado por $\mathbf{k}^{3}$, à direita, o que torna estas oscilações muito mais evidentes.

O sinal de $\chi(k)$ decai rapidamente, por este motivo é comum multiplica-lo por uma potência de $k$, em geral $k^{2}$ ou $k^{3}$, para destacar suas oscilações, como mostrado na Figura 17. Essa multiplicação faz com que valores de $k$ mais altos (região de EXAFS) contribuam mais para $\chi(k)$ do que valores mais baixos (região de XANES).

A equação para modelar o sinal de $\chi(k)$ pode ser obtida de forma empírica [55], e possui a seguinte forma:

$$
\chi(k)=\sum_{i} \frac{n_{i} f_{i}(k) e^{-2 k^{2} \sigma_{i}^{2}}}{k r_{i}^{2}} \operatorname{sen}\left[2 k r_{i}+\delta_{i}(k)\right]
$$

onde $f(k)$ é a amplitude de espalhamento, $\delta(k)$ é uma propriedade de espalhamento dos átomos vizinhos do átomo absorvedor, $n_{i}$ é o número de átomos vizinhos do tipo $i, r_{i}$ é a distância ao átomo vizinho, e $\sigma^{2}$ é a desordem na distância vizinho, conhecido como fator de Debye-Waller.

A equação de EXAFS nos permite determinar $n, r$, e $\sigma^{2}$ caso se conheça a amplitude de espalhamento $f(k)$ e $\delta(k)$. Além disso, uma vez que estes fatores de espalhamento dependem do número atômico $\mathrm{Z}$ do átomo vizinho, EXAFS também é sensível às espécies atômicas dos átomos vizinhos.

A principal razão de escrever a equação de EXAFS em função do vetor de onda ao invés da energia é que com a aplicação de transformada de Fourier (TF) em $\chi(k)$ passase do espaço recíproco e para o espaço das coordenadas, obtendo assim o sinal de EXAFS em função da distância radial $\chi(r)$, Figura 18. Esta é, aproximadamente, uma função de distribuição radial, e nos fornece a probabilidade de se encontrar um vizinho à uma distância $r_{0}$. Os picos no sinal de $\chi(r)$ correspondem as maiores probabilidades de se 
encontrar um átomo vizinho, sendo o primeiro pico referente a distância entre os primeiros vizinhos, o segundo a distância entre os segundos vizinhos e assim por diante, em geral, no sinal de $\chi(r)$ é possível identificar no máximo os terceiros vizinhos. Caso só um pico seja observado nas medidas temos que a espécie atômica em estudo só apresenta ordenamento de primeira ordem, e caso não possua nenhum pico no sinal, a espécie atômica em questão não apresenta nenhum ordenamento, possivelmente estando na superfície do material.

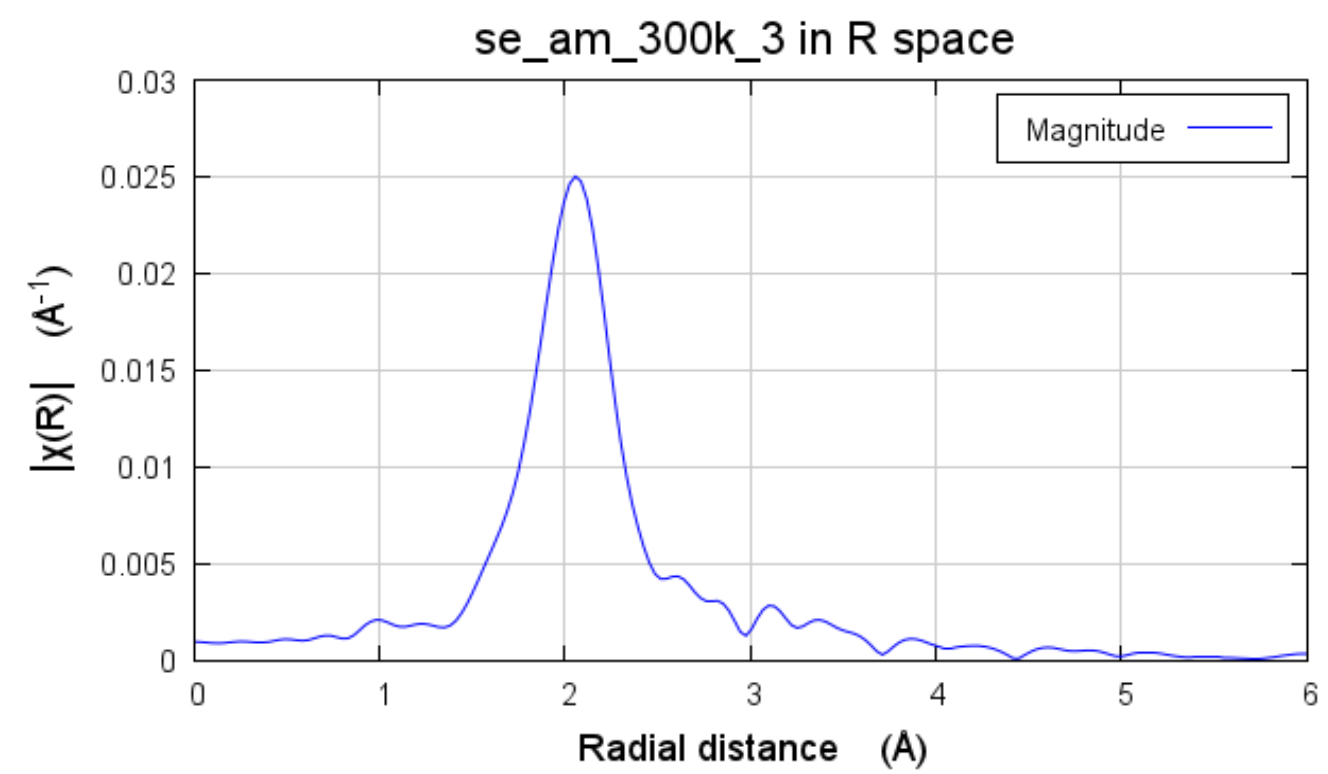

Figura 18. TF do sinal de EXAFS do Se amorfo da Figura 11. A existência de apenas um pico na função sugere um ordenamento apenas de primeiros vizinhos para este material.

Uma dedução mais formal da equação de EXAFS será agora feita. A absorção de um fóton de raios $\mathrm{X}$ por um átomo com a emissão de um fotoelétron é uma transição de estados do elétron, inicialmente num estado ligado para um estado final em forma de onda plana. O coeficiente de absorção é proporcional a probabilidade desta transição ocorrer, o que é calculada pela Regra de Ouro de Fermi [85]:

$$
\mu(E)=|\langle i|H| f\rangle|^{2}
$$

onde $\langle i|$ representa o estado inicial (um fóton de raios $\mathrm{X}$ e um elétron ligado), $|f\rangle$ o estado final (um fotoelétron e uma vacância eletrônica) e $H$ o hamiltoniano de interação.

O elétron inicialmente está em uma das camadas mais internas do átomo absorvedor, por este motivo em seu estado inicial sofre pouco influência dos átomos vizinhos. Já em seu estado final, o fotoelétron é muito mais afetado pela vizinhança. 
Podemos escrever o estado final $|f\rangle$ do elétron como uma soma do efeito do átomo absorvedor $\left|f_{0}\right\rangle$ e a influência da vizinhança $|\Delta f\rangle$ :

$$
|f\rangle=\left|f_{0}\right\rangle+|\Delta f\rangle
$$

Usando a equação (3.1.8) expandimos a equação (3.1.7) da seguinte forma:

$$
\mu(E)=|\langle i|H| f\rangle|^{2}\left[1+\langle i|H| \Delta f\rangle \frac{\left\langle f_{0}|H| i\right\rangle^{*}}{\left|\left\langle i|H| f_{0}\right\rangle\right|^{2}}+C . C .\right]
$$

onde C.C. é o complexo conjugado. Comparando a equação (3.1.9) com a equação (3.1.3) temos:

$$
\mu_{0}(E)=\left|\left\langle i|H| f_{0}\right\rangle\right|^{2}
$$

que depende apenas do átomo absorvedor. Também temos que:

$$
\chi(E)=\langle i|H| \Delta f\rangle
$$

O estado inicial é um estado ligado e o final é uma onda espalhada:

$$
\chi(E)=\int d r \delta(r) e^{i k r} \Psi_{\mathrm{esp}}(\mathrm{r})=\Psi_{\mathrm{esp}}(0)
$$

O sinal de EXAFS é proporcional a amplitude de espalhamento do fotoelétron no átomo absorvedor. Para encontrarmos esta amplitude escrevemos a função de onda do elétron como uma onda esférica:

$$
\Psi(\mathrm{k}, \mathrm{r})=\frac{\mathrm{e}^{\mathrm{ikr}}}{\mathrm{kr}}
$$

Durante o espalhamento o fotoelétron viaja uma distância $R$ até o átomo vizinho e depois viaja novamente a distância $R$ voltando ao átomo absorvedor:

$$
\chi(E)=\Psi_{\mathrm{esp}}(\mathrm{k}, 0)=\frac{\mathrm{e}^{\mathrm{ikR}}}{\mathrm{kR}}\left[2 k f(k) e^{i \delta(k)}\right] \frac{e^{i k R}}{k R}+C . C .
$$

onde $f(k)$ e $\delta(k)$ são propriedades da vizinhança.

Combinando todos os termos e incluindo o complexo conjugado temos:

$$
\chi(E)=\frac{f(k)}{k R^{2}} \operatorname{sen}[2 k R+\delta(k)]
$$


Esta é a equação de EXAFS para um único elétron espalhado por um único átomo. O coeficiente de absorção é uma medida da média dos espalhamentos de muitos elétrons que são espalhados por $n$ vizinhos.

As distâncias entre o átomo absorvedor e o espalhador podem sofrer pequenas variações devido a desordens estruturais e térmicas, a primeira aproximação para esta correção é:

$$
\chi(E)=\frac{n e^{-2 k^{2} \sigma^{2}} f(k)}{k R^{2}} \operatorname{sen}[2 k R+\delta(k)]
$$

onde $n$ é o número de vizinhos (conhecido por número de coordenação) e $\sigma^{2}=\sigma_{\text {estrutural }}^{2}+\sigma_{\text {térmica }}^{2}$ é a desordem total do sistema (conhecida por fator de DebyeWaller), sendo a soma das desordens estrutural e térmica.

$$
\chi(E)=\sum_{\mathrm{j}} \frac{n_{j} e^{-2 k^{2} \sigma_{j}^{2}} f_{j}(k)}{k R_{j}^{2}} \operatorname{sen}\left[2 k R_{j}+\delta_{j}(k)\right]
$$

onde $j$ representa a esfera de coordenação de átomos da mesma espécie com aproximadamente a mesma distância média.

No desenvolvimento da equação (3.1.17) foi considerado que o fotoelétron sofre apenas espalhamentos elásticos. Entretanto, espalhamentos inelásticos por outros obstáculos, que não os núcleos atômicos vizinhos, também são possíveis de ocorrer como elétrons ligados e fônons. Estes espalhamentos são parte significante do sinal de EXAFS, e como forma de corrigir esta aproximação consideramos o fotoelétron como uma onda amortecida.

A função de onda amortecida é escrita como:

$$
\Psi(\mathrm{k}, \mathrm{r})=\frac{\mathrm{e}^{\mathrm{ikr}} \mathrm{e}^{-2 \mathrm{r} / \lambda(\mathrm{k})}}{\mathrm{kr}}
$$

onde $\lambda(k)$ é o livre caminho médio (mean-free-path) do fotoelétron, e representa o quão longe um fotoelétron pode viajar e ainda contribuir para o sinal de XAFS.

Usando a equação (3.1.18) para descrever a função de onda do elétron ao invés da equação (3.1.13) obtemos a seguinte equação para o sinal de EXAFS: 


$$
\chi(E)=\sum_{\mathrm{j}} \frac{n_{j} e^{-2 k^{2} \sigma_{j}^{2}} e^{-2 R_{j} / \lambda(k)} f_{j}(k)}{k R_{j}^{2}} \operatorname{sen}\left[2 k R_{j}+\delta_{j}(k)\right]
$$

Duas conclusões são tiradas da equação (3.1.19). Primeiro, devido a dependência do sinal com $R^{-2}$ e $\lambda(k)$ EXAFS é dependente apenas da estrutura local em torno do átomo absorvedor, não se estendendo muito mais que $5 \AA$. A segunda é que o sinal de EXAFS consiste em diferentes frequências relacionadas a diferentes distâncias para cada esfera de coordenação. Estas distâncias podem ser obtidas por meio de uma transformada de Fourier.

\subsection{Espectroscopia Pré Borda e Estrutura de Absorção de Raios X Próxima}

\section{A BORDA}

Na região de XANES os picos possuem maior amplitude e são mais estreitos do que os picos da região de EXAFS e por esta razão a técnica pode ser usada em compostos com baixas concentrações do elemento em estudo. Porém, a interpretação do sinal de XANES é muito mais complicada que o de EXAFS devido ao fato de não existir uma equação para a modelagem do sinal.

Muita informação química está no sinal de XANES como o estado de oxidação do material, muito difícil de se determinar por um método não destrutivo, e números de coordenação química. A Figura 19 mostra o sinal de XANES para vários compostos de ferro. Podemos perceber claramente que a posição da borda de absorção e seu formato são sensíveis ao estado de valência, tipo de ligação e coordenação química, isto é o que torna possível utilizar a técnica de XANES para identificar as fases do material, como uma impressão digital do composto. 


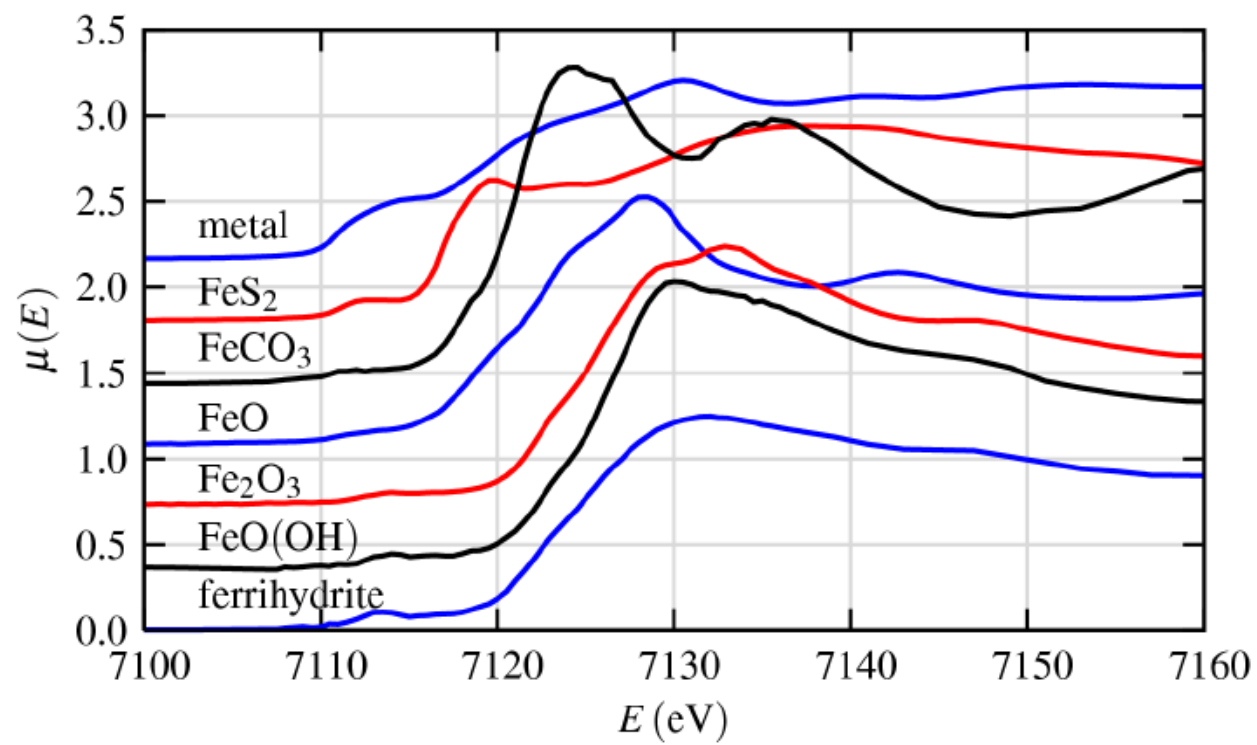

Figura 19. XANES para vários compostos de ferro [55]. A posição da borda de absorção e seu formato dependem do estado de valência, tipo de ligação e coordenação química do material.

O sinal de XANES pode ser descrito de maneira qualitativa (até mesmo semiquantitativa) em termos de:

- Valência: o grau de ionização do material em estudo desloca a borda de absorção para valores maiores quanto maior for a ionização.

- A química de coordenação: regular, octaédrica ou tetraédrica, o que modifica o formato do pico (Figura 19).

- Os orbitais moleculares: hibridização orbital p-d, o qual gera picos antes da borda de absorção, como mostrado na Figura 20.

- Estrutura de banda: a densidade de estados eletrônicos disponíveis.

Uma aplicação comum de XANES é usar a posição da banda de absorção para determinar o estado de valência. A Figura 20 mostra a dependência do sinal de XANES do Fe metal e óxidos com íons $\mathrm{Fe}^{2+} \mathrm{e} \mathrm{Fe}^{3+}$. Com dados precisos de absorção a razão entre os íons de Fe pode ser obtida. Similarmente, razões para íons de outros elementos químicos também podem ser encontradas. 


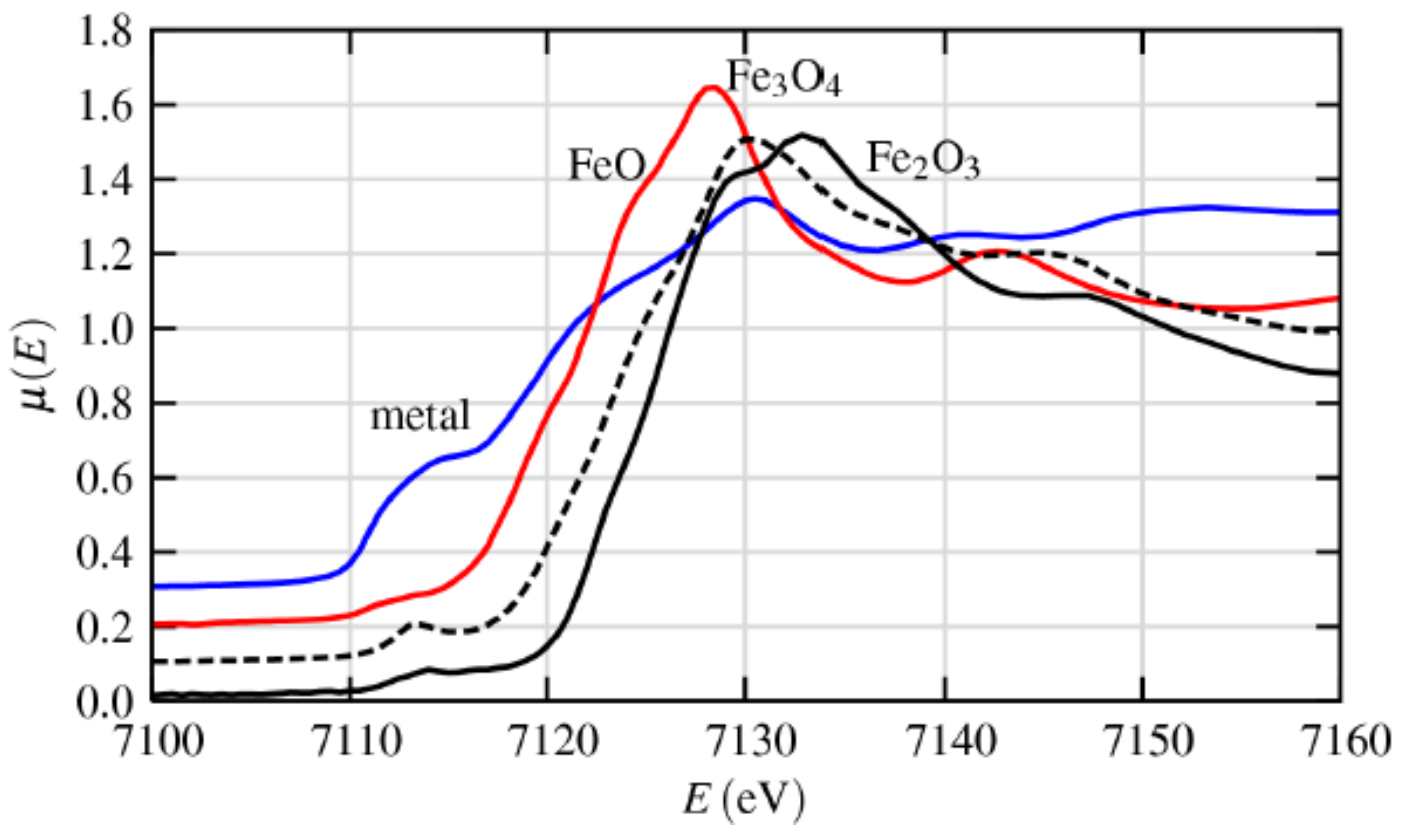

Figura 20. Sinal de XANES do Fe metal e óxidos com $\mathrm{Fe}^{2+} \mathrm{e} \mathrm{Fe}^{3+}$. Existe uma visível diferença no formato das oscilações e na posição da borda de absorção dependente da valência dos íons [55].

Um fato importante que torna a região de pré borda uma impressão digital do material são as excitações eletrônicas sem a criação de fotoelétrons. Usando como exemplo o caso de uma absorção por um elétron 1s que é promovido para um estado p. Em seu estado inicial, o elétron pode absorver um fóton com a mesma energia da diferença dos dois estados somente se houver um estado p livre. Para região de EXAFS isto não é relevante, pois as energias são altas o suficiente para ejetar o elétron do átomo, sendo indiferente aos seus estados vazios. Mas para a pré borda é uma característica muito importante.

Óxidos de metais de transição usualmente possuem muitos níveis $3 \mathrm{~d}$ desocupados e uma banda $3 p$ cheia. Nos átomos de oxigênio temos níveis $2 \mathrm{p}$ vazios, porém estão muito longe de uma sobreposição com a banda 1s do metal. Para que haja uma transferência nestes estados é necessário que o elétron absorva um fóton com a mesma energia da diferença entre eles. Portanto, os elétrons $3 \mathrm{~d}$ do metal não participam do processo de absorção em energias abaixo da borda de absorção a não ser que exista uma grande hibridização de elétrons $3 \mathrm{~d}$ do metal e $2 \mathrm{p}$ do oxigênio. Para íons com bandas desocupadas a hibridização p-d é alterada com a química de coordenação que é muito mais forte para a tetraédrica do que para a octaédrica. Para o caso do íon $\mathrm{Cr}^{6+}$, Figura 21, o resultado é um pico antes da borda de absorção, com uma intensidade comparável com a intensidade da própria borda, indicando uma transição para um estado ligado. 


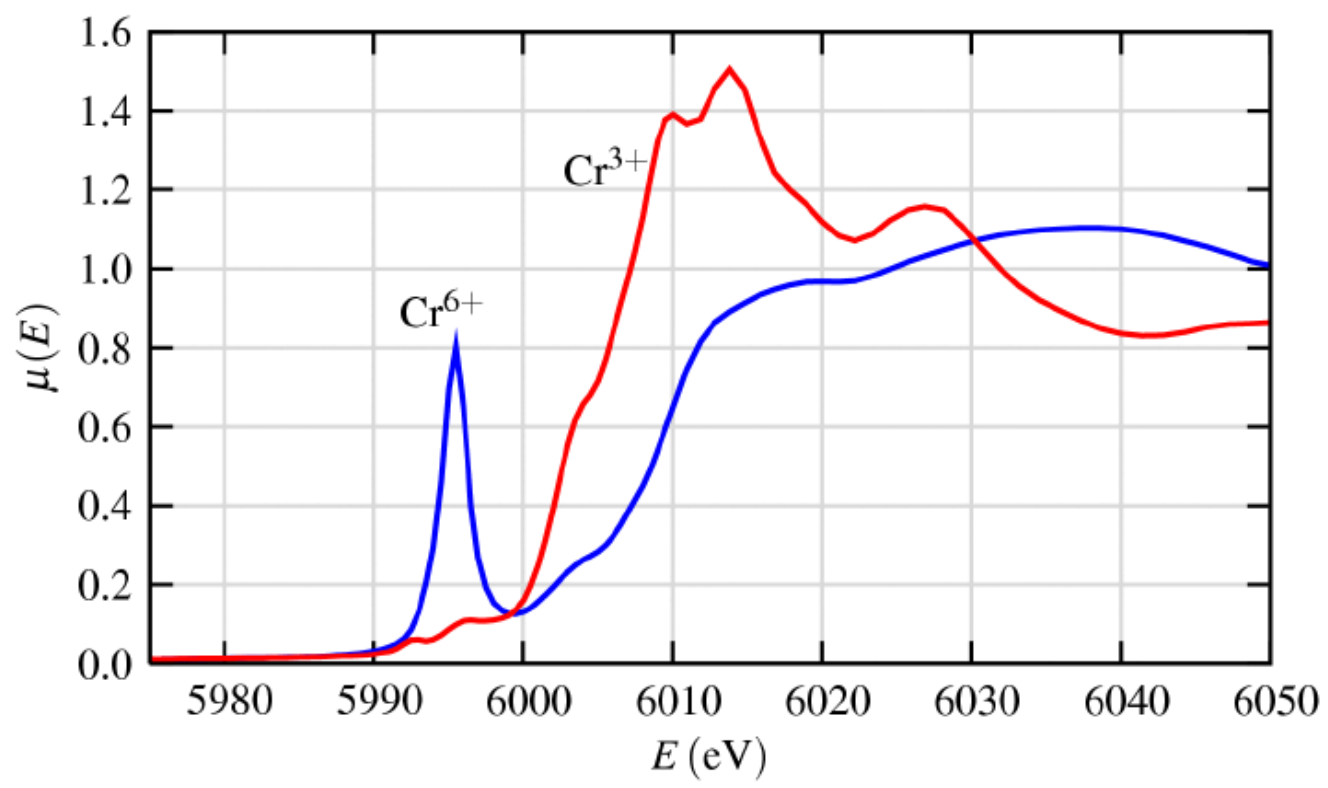

Figura 21. XANES na borda $\mathrm{K}$ do $\mathrm{Cr}$ em óxidos com íons $\mathrm{Cr}^{3+}$ e $\mathrm{Cr}^{6+}$. $\mathrm{O}$ grande pico antes da borda no espectro de $\mathrm{Cr}^{6+}$ é uma consequência da simetria tetraédrica causando uma grande hibridização p-d [55]. 


\subsection{INSTRUMENTAÇ̃̃o PARA EXPERIMENTOS DE XAFS}

Para obter o espectro de absorção é necessário medir o número de fótons que chega à amostra e o número que atravessa a mesma como função da energia incidente, como mostrado na Figura 15, precisa-se então determinar a fonte de radiação a ser utilizada e montar um arranjo experimental para medirmos a radiação incidente $I_{0}$ e a transmitida $I$.

Para definir-se a fonte da radiação a ser utilizada, é necessário primeiro determinar as características que esta fonte precisa possuir para realizar-se um experimento de XAFS. Para uma boa análise da estrutura fina de absorção o erro estatístico em cada ponto do espectro precisa ser menor que $0.1 \%$. O erro na distribuição de fótons absorvidos segue a estatística de Poisson [84], portanto o erro estatístico deve ser:

$$
S=\frac{1}{\sqrt{N}}
$$

onde $N$ é o número de fótons absorvidos. Assim temos que para $S=10^{-3}$ o número de fótons deve ser $N=\sim 10^{6}$ em cada ponto do espectro para realizar um experimento de XAFS.

O espectro de absorção possui oscilações bruscas, que só serão detectadas se a energia do feixe variar em passos da ordem de $1 \mathrm{eV}$ ou menos. Desse modo, a fonte de radiação a ser utilizada num experimento de XAFS deve possui um fluxo de pelo menos $10^{6}$ fótons por ponto em energia e regulável com uma resolução da ordem de $0.5 \mathrm{eV}$, além de a radiação emitida ter energias próxima de uma das bordas de absorção do elemento que se pretende estudar, o que em geral é em torno de $10^{4} \mathrm{eV}$. Essas características são obtidas somente com o uso da radiação produzida por aceleradores síncrotron.

Existem três modos de medição de XAFS. Se o coeficiente de transmissão da amostra for suficientemente alto, o mapeamento da borda de absorção é possível medindo-se a intensidade do feixe que atravessa a amostra em função de sua energia, e comparando-a com a intensidade do feixe incidente, mede-se então EXAFS por transmissão, amostras concentradas e pó são melhor medidas neste modo (Figura 22). A medição da intensidade pode ser feita com câmaras de ionização de gás, fotodiodos ou junções PN. A transmissão é um modo de medição direta do coeficiente de absorção. 


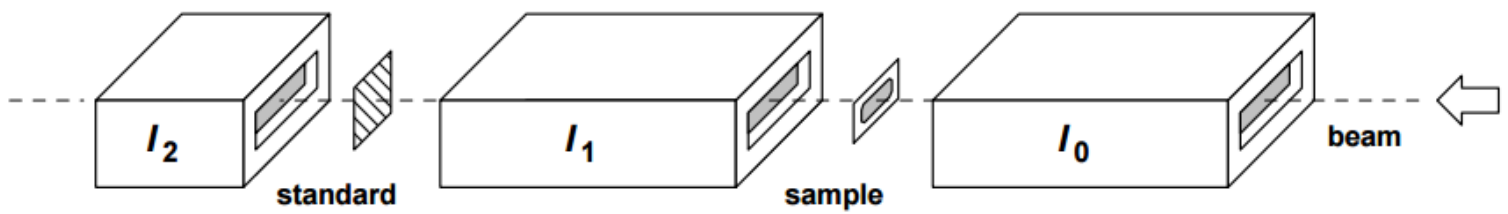

Figura 22. Modo Transmissão: o feixe incidente tem sua intensidade $I_{0}$ medida pelo primeiro detector, enquanto o feixe transmitido pela amostra $\left(I_{1}\right)$ é medido por um segundo detector. Um padrão de referência é colocado após o segundo detector, de modo que o espectro de referência simultaneamente medido com a amostra por um terceiro detector.

No modo fluorescência são medidos os fótons emitidos pelo decaimento do elétron excitado à banda de condução, o número de fótons emitidos é proporcional à quantidade de elétrons excitados. Para amostras finas ou de baixa concentração, o modo de fluorescência de raios X é a medida preferencial.

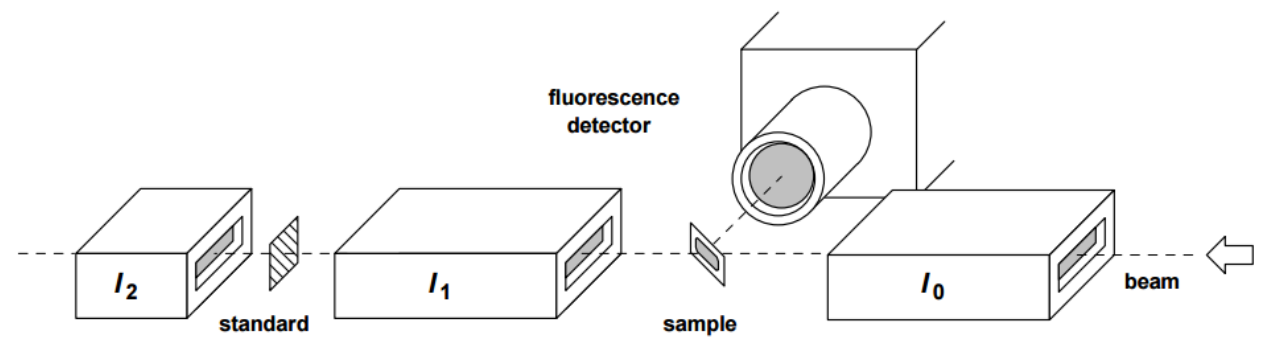

Figura 23. Modo Fluorescência: a emissão de raios $\mathbf{X}$ pela amostra é proporcional ao coeficiente de absorção. Espectrômetros dispersivos são necessários para separar as emissões de espécies químicas diferentes, quando estas possuem bordas de absorção próximas.

As medidas de absorção de raios $\mathrm{X}$ pode ser feita ainda no modo TEY (Total Electron Yield, ou modo de rendimento total de elétrons), em que todos os elétrons ejetados da amostra são detectados, independentemente de suas energias. A profundidade máxima de análise desse modo é em torno $10 \mathrm{~nm}$, dependendo do material estudado. Durante a realização do experimento a amostra é mantida aterrada, e a corrente necessária para torná-la eletricamente neutra é medida. A corrente é geralmente da ordem de nanoampères a picoampères. 

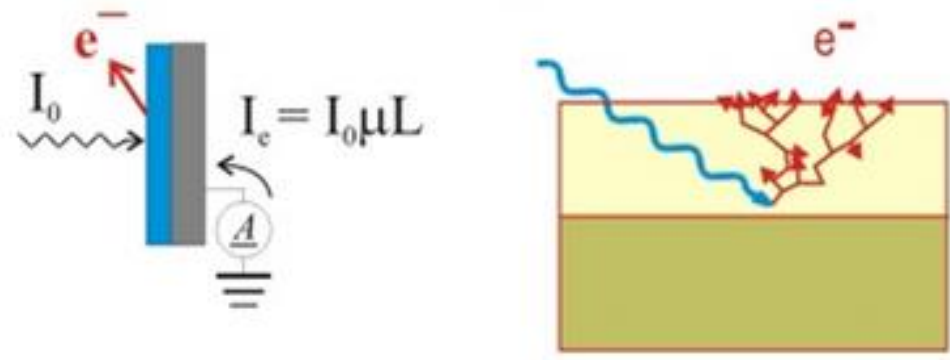

Figura 24. Modo TEY: todos os elétrons produzidos por excitação de raios X são coletados, a corrente elétrica gerada por estes elétrons é proporcional ao coeficiente de absorção de raios $X$. A medida é feita com multiplicadores de corrente elétrica ou através de câmaras de ionização.

ATabela 4 apresenta um resumo das principais considerações para o modo de medição de XAFS de acordo com as caraterísticas da amostra estudada.

Tabela 4. Considerações experimentais para os diferentes modos de medição de XAFS.

\begin{tabular}{|c|c|c|c|}
\hline & Transmissão & TEY & Fluorescência \\
\hline Espessura & Fina & Muito fina & Muito fina \\
\hline Coeficiente de Absorção & Alto & Moderado & Baixo \\
\hline Sensitividade & Bulk & Superfície & Bulk \\
\hline Concentração & Alta & Alta & Baixa \\
\hline
\end{tabular}

Neste trabalho, as medidas de XAFS foram realizadas na linha XAFS2 do Laboratório Nacional de Luz Síncrotron (LNLS), localizado em Campinas, Brasil, para amostras em pó. O anel de armazenamento opera com energia de 1,36 GeV e corrente média de $250 \mathrm{~mA}$. Foram coletados espectros de absorção nas bordas $\mathrm{K}$ do átomo de ferro (K-Fe) e do átomo de ítrio (K-Y), ambas em temperatura ambiente. O monocromador utilizado foi o de dois cristais de silício, no qual o primeiro cristal seleciona a energia desejada, e o segundo redireciona o feixe para a cabana experimental.

As medidas na borda K-Fe $(7124 \mathrm{eV})$ foram obtidas por transmissão. Ao todo foram feitas três varreduras para cada amostra, com energias em torno de $150 \mathrm{eV}$ abaixo e $800 \mathrm{eV}$ acima da borda $\mathrm{K}-\mathrm{Fe}$, posteriormente foi calculada a média destas medidas a fim de minimizar ruídos da medição. O intervalo de energia de 6950 a 7095 eV foi medido com passos de $1 \mathrm{eV}$, entre 7095 e 7170 com passos de $0,5 \mathrm{eV}$, entre 7170 e $7400 \mathrm{com}$ $0,1 \mathrm{eV}$ e até $7800 \mathrm{eV}$ com $3 \mathrm{eV}$. 
O experimento de absorção na foi realizado na linha de luz XAFS2. Devido à baixa concentração do ítrio na amostra, os dados de absorção para este elemento - borda K-Y $(17038 \mathrm{eV})$ - o modo de medição utilizado foi fluorescência com um detector com resolução em energia e janela ajustada para a linha de emissão K deste elemento. Foram feitas quatro varreduras a fim de reduzir o ruído da medida. O intervalo de energia de 16850 a $17030 \mathrm{eV}$ foi medido em passos de $1 \mathrm{eV}$, entre 17030 e $17120 \mathrm{eV}$ com passo de $0,5 \mathrm{eV}$ e de 17120 a $17400 \mathrm{eV}$ com passo de $0,1 \mathrm{eV}$ e passo de $1 \mathrm{eV}$ até $17700 \mathrm{eV}$.

\subsection{Softwares Para Tratamento de DAdOS DE XAFS}

Existem diversos programas disponíveis na internet para fazer a análise do sinal de XAFS, neste trabalho foram utilizados os programas do pacote IFEFFIT $[87,88]$ para obter os parâmetros atômicos e de espalhamento utilizada na equação de EXAFS. O nome IFEFFIT vem do inglês "Interative FEFF Fit", sendo desenvolvido com o intuito de utilizar os cálculos do software FEFF [89] (lançado em 1991 para fazer cálculos ab initio de EXAFS) para extrair parâmetros estruturais da região de EXAFS e estudos comparativos e qualitativos da região de XANES.

O IFEFFIT é um programa que é acionado a partir da linha de comando, para tornar o programa mais fácil de usar foi criada uma interface gráfica para este, chamada HORAE. Esse pacote é composto essencialmente de quatro programas. O Athena que é utilizado na manipulação do espectro de XAFS medido para extrair as oscilações de EXAFS, o Artemis que realiza o ajuste do sinal teórico ao experimental, o Hephaestus que contêm informações úteis sobre absorbância de materiais e suas características e por fim o Atoms, o qual, a partir dos parâmetros cristalográficos, para simulações de espectros com o programa Artemis. 


\section{SÍNTESE E TÉCNICAS DE CARACTERIZAÇÃO}

\subsection{SÍNTESE DAS AMOSTRAS}

As nanopartículas foram sintetizadas no Laboratório de Preparação de Amostras do Instituto de Física da Universidade de Brasília (IF-UnB). Duas sínteses foram realizadas, uma de nanopartículas com dopagem de Y e outra sem dopagem, ambas em meio aquoso pelo método de coprecipitação [90]. As NPs foram sintetizadas através da reação dos cloretos de ferro hidratados $\mathrm{FeCl}_{2}: 4 \mathrm{H}_{2} \mathrm{O}$ (Baker pureza > 99,9\%) e $\mathrm{FeCl}_{3}: 6 \mathrm{H}_{2} \mathrm{O}$ (Vetec pureza $>99,9 \%$ ), para a síntese das nanopartículas com ítrio foi utilizado o sal hidratado $\mathrm{YCl}_{3}: 6 \mathrm{H}_{2} \mathrm{O}$ (Vetec pureza > 99,9\%). A quantidade de reagentes utilizada está na Tabela 4. O percentual de massa de ítrio em relação ao ferro foi aproximadamente $1,4 \%$ na síntese das $\mathrm{NPs} \mathrm{Y}-\mathrm{Fe}_{3} \mathrm{O}_{4}$. Para cada uma das sínteses foram utilizados cerca de 103,7 mols de $\mathrm{Fe}^{3+}$ e 50,2 mols de $\mathrm{Fe}^{2+}$, uma razão $\mathrm{Fe}^{3+} / \mathrm{Fe}^{2+}$ de 2,06. Idealmente, para a magnetita esta razão deve ser exatamente 2,0, sendo a quantidade de íons utilizada satisfatória para se obter amostras de ferrita próximas de uma magnetita ideal $\left(\mathrm{Fe}_{3} \mathrm{O}_{4}\right)$, porém a formação de outros óxidos durante a síntese, especialmente maghemita $\left(\gamma-\mathrm{Fe}_{2} \mathrm{O}_{3}\right)$ não é desprezível.

Tabela 5. Quantidade de reagentes utilizados nas sínteses das amostras.

\begin{tabular}{ccccc}
\hline Sumarização & $\mathbf{F e C l}_{3}$ & $\mathbf{F e C l}_{2}$ & $\mathbf{Y C l}_{3}$ & $\mathbf{Y} / \mathbf{F e}$ \\
\hline FNP & $28,0 \mathrm{~g}$ & $10,0 \mathrm{~g}$ & 0,0 & 0 \\
YFNP & $28,0 \mathrm{~g}$ & $9,62 \mathrm{~g}$ & $0,38 \mathrm{~g}$ & 0,014 \\
\hline
\end{tabular}

No procedimento da síntese, os cloretos de ferro e de ítrio (para as NPs com Y) foram dissolvidos em béqueres com $250 \mathrm{ml}$ de água destilada com o propósito de se obter os íons livres $\mathrm{Fe}^{2+}, \mathrm{Fe}^{3+}$ e $\mathrm{Y}^{3+}$. As duas soluções foram agitadas por agitadores magnéticos, a velocidade de $1200 \mathrm{rpm}$ por $15 \mathrm{~min}$, e em seguida foi aquecida a temperatura de $80^{\circ} \mathrm{C}$, ainda em agitação. Após o aquecimento foram adicionados $80 \mathrm{ml}$ de hidróxido de amônio $\mathrm{NH}_{4} \mathrm{OH}$ para que ocorresse a formação de nanopartículas de magnetita. As soluções resultantes foram mantidas a temperatura de $80{ }^{\circ} \mathrm{C}$ por 20 min para a formação de nanopartículas, depois colocadas em repouso para sedimentação por meia hora, agora sem agitação. Após a sedimentação o magnetismo foi observado com a 
aproximação de um imã. Por fim, as NPs foram lavadas com água destilada por seis vezes, entre cada lavagem foi feita novamente uma sedimentação com campo magnético aplicado.

Parte de cada solução foi retirada nesta etapa e submetida a uma secagem para se obter amostras em pó. Esta secagem foi feita a uma temperatura de $80{ }^{\circ} \mathrm{C}$ por aproximadamente 6 horas.

$\mathrm{Na}$ etapa seguinte, 5,0 $\mathrm{g}$ de ácido cítrico dissolvidas em $10 \mathrm{ml}$ de água foram adicionadas à cada uma das soluções restantes, ainda sob agitação, sendo o citrato o agente responsável pelo acúmulo de carga elétrica na superfície das nanopartículas. A adição deste composto fez o pH de ambas as soluções cair de 7,9 para 4,8. Em seguida as NPs foram decantadas com campo magnético aplicado (imã) e lavadas sucessivamente com água por cinco vezes. Por fim, o pH da solução foi ajustado com solução de $\mathrm{NH}_{4} \mathrm{OH}$ até valores iguais a 6,953 para a solução sem ítrio e 6,943 para a solução com Y, ambas à temperatura de $26,8^{\circ} \mathrm{C}$.

Apenas um lote de cada amostra foi utilizado para este trabalho, por isto elas serão referidas a partir de agora simplesmente como YFNP (Yttrium Ferrite Nanoparticle) para a amostra dopada com ítrio e FNP (Ferrite nanoparticle) para a amostra sem dopagem.

\subsection{FLUORESCÊNCIA DE RAIOS X}

O fenômeno de Fluorescência de Raios X (XRF: X-Ray Fluorescence) é a emissão de raios $\mathrm{X}$ característicos (fluorescentes) de um material excitado pelo bombardeamento com raios X de alta energia ou raios gama [91]. O fenômeno é amplamente utilizado para análise química para determinação de concentrações de espécies químicas, especialmente na investigação de metais [92], vidro [93] e cerâmica [94], sendo por isso utilizada para pesquisas em geoquímica, ciência forense e arqueologia.

Na espectroscopia de XRF utiliza-se uma fonte de radiação para ionizar os níveis internos dos átomos constituintes da amostra, por efeito fotoelétrico. Na relaxação, o elétron libera o excesso de energia através da emissão de um fóton de raios $\mathrm{X}$, de energia igual a diferença de energia de ligação dos níveis entre os quais se deu a transição. Esta radiação é característica do elemento. A detecção e análise deste espectro permite a identificação e, em alguns casos, quantificação dos elementos constituintes da amostra. 
A intensidade de uma determinada radiação característica está relacionada diretamente com a concentração de um elemento na amostra através da relação [91]:

$$
I_{i}=I_{0} K_{i} A_{i} m C_{i}
$$

sendo:

$$
\begin{gathered}
A_{i}=\frac{1-e^{\alpha_{i}}}{\alpha_{i}} \\
\alpha_{i}=\sum_{j} c_{j}\left[\frac{\mu\left(E_{0, j}\right)}{\operatorname{sen} \phi}+\frac{\mu\left(E_{i, j}\right)}{\operatorname{sen} \psi}\right] m
\end{gathered}
$$

onde $I_{0}$ é a intensidade da radiação incidente, $I_{i}$ a intensidade da radiação característica do elemento $i, m$ a massa da amostra, $K_{i}$ um fator de calibração experimental, $E_{0}$ a energia da radiação incidente, $E_{i}$ a energia da radiação característica do elemento $i, \mu\left(E_{0, j}\right)$ o coeficiente de atenuação para o elemento $j$ para a energia do fóton incidente, $\mu\left(E_{i, j}\right)$ o coeficiente de atenuação do elemento $j$ para a energia $E_{i}, \phi$ e $\psi$ os ângulos das radiações incidente e emitida na amostra, respectivamente, e $C_{i}$ a concentração do elemento $i$ na amostra.

Portanto, conhecendo a intensidade da radiação incidente $I_{0}$ e a intensidade da radiação característica $I_{i}$ podemos calcular a concentração do elemento $i$ através da equação (4.2.3).

O experimento de XRF foi realizado no Laboratório Nacional de Luz Síncrotron, na linha de luz XRF, a energia do feixe incidente utilizada foi de $17,5 \mathrm{keV}$.

\subsection{EsPeCtroscopia de EMissão Ótica com Plasma ACOPLAdo}

A técnica de Emissão Ótica com Plasma Acoplado (ICP/AES: Inductively Coupled Plasma Atomic Emission Spectrometry) é uma técnica analítica utilizada para a detecção de metais. É um tipo de espectroscopia de emissão que utiliza o plasma indutivamente acoplado para produzir átomos excitados e íons que emitem raios $\mathrm{X}$ característicos em comprimentos de onda típicos de um elemento em particular [91, 96]. A intensidade da emissão é indicativo da concentração do elemento em estudo no interior da amostra. 
O aparato experimental de ICP/AES é composto de duas partes, mostradas na Figura 25, a tocha de plasma ICP e o espectrômetro óptico, gás de argônio é usualmente utilizado para criar o plasma. Quando a tocha está ligada, um intenso campo eletromagnético é criado no interior da bobina pelo sinal de frequência de rádio de alta potência que flui na bobina. O gás de argônio é ionizado neste campo eletromagnético e flui em um padrão simétrico em particular para o campo magnético da bobina. Uma temperatura elevada de cerca de $7000 \mathrm{~K}$ é então produzida como o resultado de colisões inelásticas entre átomos de argônio neutros e as partículas carregadas. A amostra é introduzida diretamente dentro da chama de plasma. A amostra imediatamente colide com os elétrons e íons carregados no plasma e é dividida em íons carregados. As várias moléculas quebram-se em seus respectivos átomos que, em seguida, perdem elétrons e recombinam-se repetidamente no plasma, emitindo radiações com os comprimentos de onda característicos dos elementos envolvidos.

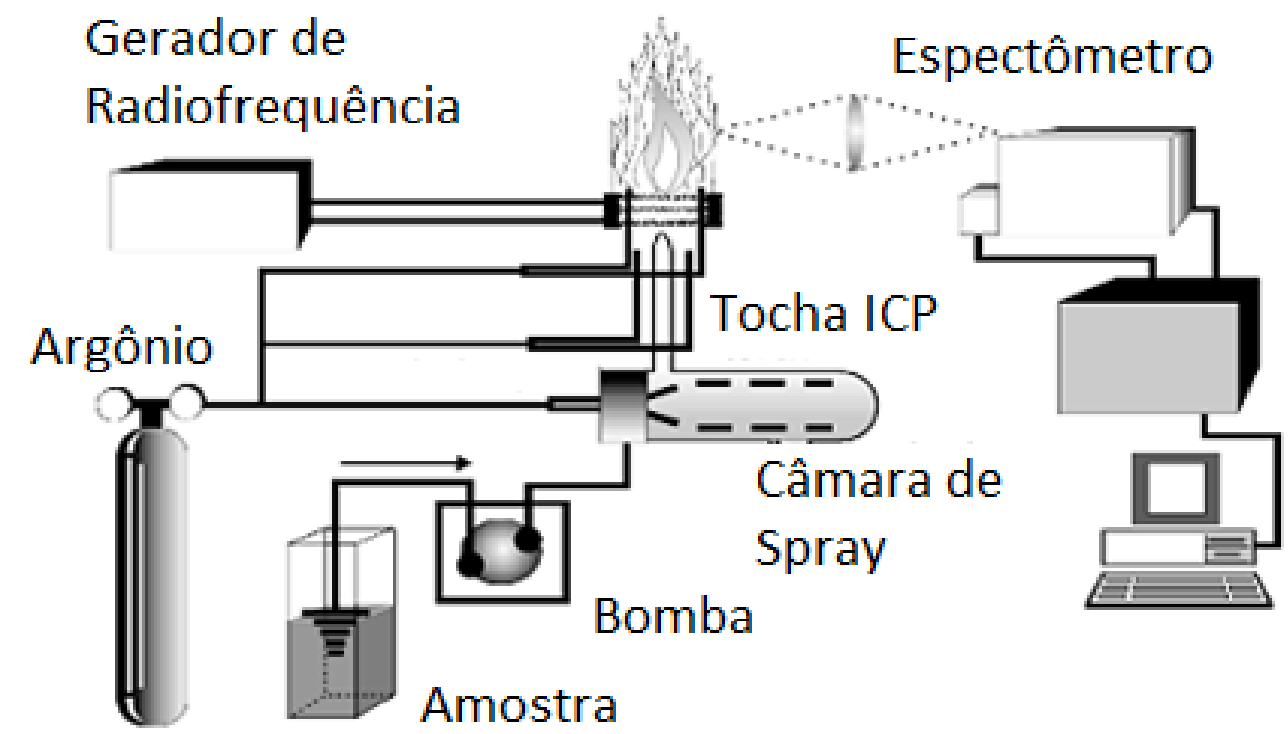

Figura 25. Arranjo experimental do experimento de plasma, modificada de [97].

Dentro da câmara óptica, depois de a luz ser separada nos seus diferentes comprimentos de onda, a intensidade da luz é medida com um tubo fotomultiplicador, ou, em unidades mais modernas, uma matriz de fotodetectores de semicondutores. As intensidades de todos os comprimentos de onda podem ser medidas simultaneamente, permitindo ao instrumento analisar cada elemento a que a unidade é sensível de uma única vez. Assim, as amostras podem ser analisadas muito rapidamente. A intensidade de cada linha é então comparada com intensidades previamente medidas de concentrações 
conhecidas dos elementos, e as suas concentrações são então calculadas por interpolação ao longo das linhas de calibração.

$\mathrm{O}$ experimento de ICP/AES foi realizado no laboratório de Geoquímica do Instituto de Geociências da Universidade de Brasília, as medidas foram realizadas em um espectrômetro de emissão atômica com fonte de plasmada marca SPECTROFLAME modelo FMV 05 SCANNER.

\subsection{DIFRAÇÃo DE RAIOS X}

A difração de raios $X(D R X)$ é uma técnica não destrutiva muito utilizada para a identificação da estrutura atômica e molecular de um sólido, sendo uma das ferramentas mais bem estabelecidas para este fim. Esta técnica se fundamenta no fato de os átomos do material difratarem feixes de raios $\mathrm{X}$ incidentes em direções específicas de acordo com a natureza e posição desses átomos.

Um feixe de raios $\mathrm{X}$ interage elasticamente com os elétrons da nuvem eletrônica produzindo ondas esféricas secundárias que emanam do centro espalhador. A incidência de raios $\mathrm{X}$ em um sólido gera várias dessas interações e consequentemente várias ondas secundárias são produzidas. A maioria dessas ondas se anulam através de interferências destrutivas, algumas delas somam-se quando há interferência construtiva como mostrado na Figura 26. O resultado disto são picos bem definidos nos difratogramas. Em um experimento de difração tem-se controle do comprimento de onda e do ângulo de incidência do feixe de raios $\mathrm{X}$, sendo um dos dois mantido constante e o outro variado, $\mathrm{o}$ único parâmetro da amostra é a distância entre os planos atômicos. Para cada estrutura cristalina o padrão de difração ocorrerá em um conjunto deposições angulares diferente, permitindo assim determinar a distribuição dos átomos na estrutura cristalina. 


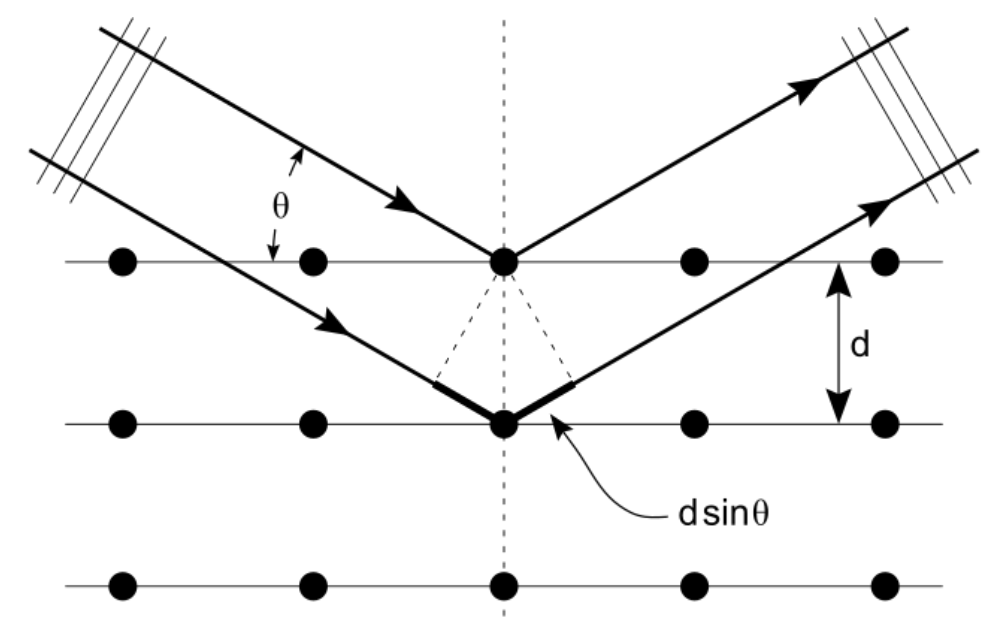

Figura 26. $O$ feixe de entrada faz com que cada um dos dispersores de reemitir uma pequena parte da sua intensidade como uma onda esférica.

A condição para interferências construtivas, que pode ser deduzida pela Figura 26, é dada pela lei de Bragg:

$$
2 d_{h k l} \operatorname{sen} \theta=n \lambda
$$

onde $d_{h k l}$ é distância entre os planos atômicos, $h, k$ e $l$ correspondem aos índices de Miller, $\theta$ é o ângulo de incidência do feixe de raios $X, \lambda$ é o comprimento de onda do fóton incidente, $n$ é o número inteiro que dá a ordem da difração.

A relação entre a distância interplanar $d_{h k l}$ e o parâmetro de rede $a$ para uma rede FCC é dado pela equação [56]:

$$
d_{h k l}=\frac{a}{\sqrt{h^{2}+k^{2}+l^{2}}}
$$

Outro dado importante que pode ser obtido da difração de raios X é o tamanho médio das partículas presentes no material. O diâmetro das NPs pode ser estimado a partir da largura de linha a meia altura do pico difratado no ângulo $\theta$ através da fórmula de Scherrer [56]:

$$
D=\frac{0,9 \lambda}{b \cos \theta}
$$

onde $D$ é o diâmetro da partícula, $b$ é a largura de linha a meia altura e $\theta$ é o ângulo de incidência.

As medidas de difração de raios $\mathrm{X}$ foram realizadas no Laboratório de Cristalografia Aplicada do Instituto de Física da Unicamp com um difratômetro Rigaku Ultima IV. A fonte utilizada foi um tubo de cobre emitindo na linha $K_{\alpha}$ deste elemento 
$\left(\lambda_{\alpha}=1,5418 \AA\right)$. Para a varredura foi utilizada a geometria $2 \theta$, com passo de $0,02^{\circ} \mathrm{e}$ velocidade de varredura de $0,5^{\circ}$ por min, no intervalo de $10^{\circ}$ à $90^{\circ}$, em temperatura ambiente.

\subsection{MiCROELETROFORESE}

O potencial zeta não pode ser medido diretamente, para estimar seu valor usa-se uma medida indireta. A técnica mais usada e mais aceita é a medição da mobilidade eletroforética. Um experimento de microeletroforese consiste, basicamente, na observação microscópica da velocidade de um coloide sob a ação de um campo elétrico aplicado.

No experimento, o coloide é colocado em uma cuba com dois eletrodos e aplicase um potencial elétrico à suspensão, as partículas carregadas eletricamente irão moverse na direção do eletrodo de carga contrária à sua. A velocidade deste movimento depende tanto do campo elétrico aplicado quanto da carga das partículas. O potencial zeta pode então ser estimado utilizando a equação (2.4.14) desenvolvida na seção 2.4:

$$
\zeta=\frac{3 \mu \eta}{2 \varepsilon_{0} D}
$$

O experimento de microeletroforese foi realizado pelo Professor Dr. Kalil Skeff Neto utilizando um Analisador de potencial zetaZM3-D-G, Zeta Meter systems 3.0. O pH das amostras apresentava valores iguais a 6,953 para a solução sem ítrio e 6,943 para a solução com Y, ambas à temperatura ambiente. Ambas as amostras foram diluídas em água obtendo uma concentração final de $0.0001 \%$. 


\section{RESULTADOS E DISCUSSÕES}

\subsection{CONCENTRAÇÕES: XRF E ICP/AES}

A técnica de Fluorescência de Raios X fornece diretamente a fração da massa dos elementos investigados, $m_{i} m$, onde $m_{i}$ é a massa do elemento $i$ e $m$ a massa total da amostra, a partir do tratamento dos dados. Os resultados obtidos pelo experimento de XRF estão dispostos na Tabela 6.

Tabela 6. Dados do experimento de XRF com os valores da fração mássica dos elementos investigados. Não foram encontradas concentrações relevantes de contaminantes.

\begin{tabular}{ccc}
\hline $\mathrm{Fe}$ & $\mathrm{Y}$ & $\mathrm{Y} / \mathrm{Fe}$ \\
\hline 0,8010 & 0,0065 & 0,0081 \\
\hline
\end{tabular}

A técnica de ICP/AES fornece diretamente a densidade dos elementos investigados na amostra. Os resultados obtidos pelo experimento de ICP/AES estão disponíveis na Tabela 7.

Tabela 7. Dados do experimento de ICP/AES com os valores das densidades dos elementos investigados. Assim como o experimento de XRF não foram encontradas contaminações relevantes de outras espécies químicas.

\begin{tabular}{cccc}
\hline Amostra & Fe (g/L) & Y (g/L) & Y/Fe \\
\hline FNP & 21.73 & 0 & 0 \\
YFNP & 34.96 & 0.3066 & 0,00877 \\
\hline
\end{tabular}

Os resultados obtidos pelos experimentos de XRF e ICP/AES apresentaram uma boa concordância entre as duas técnicas, os valores encontrados para a concentração de ítrio em relação ao ferro foram $0,81 \%$ para XRF e 0,88\% para ICP/AES, indicando que em torno de $60 \%$ do ítrio disponível na síntese efetivamente está presente nas NPs.

No estudo de nanopartículas de gadolínio $\left(\mathrm{Gd}_{\mathrm{x}} \mathrm{Fe}_{(3-\mathrm{x})} \mathrm{O}_{4}\right)$ da referência [99] foi constatado, através de um tratamento de Rietveld [100] de medidas de DRX, que menos de $10 \%$ do gadolínio utilizado na síntese de fato está presente na estrutura das nanopartículas. Uma explicação para esta considerável diferença do teor efetivo de incorporação dos dois íons pode estar associada ao tamanho dos raios iônicos dos elementos em questão. O raio do íon $\mathrm{Gd}^{3+}, 132$ pm [101], é 17,4 \% maior que do íon $\mathrm{Fe}^{2+}$, 
109 pm, e 22,7 \% maior que o do íon $\mathrm{Fe}^{3+}$, já o raio iônico do íon $\mathrm{Y}^{3+}, 124$ pm, é 12,1 \% e 17,4 \%, maior que os raios iônicos dos íons $\mathrm{Fe}^{2+}$ e $\mathrm{Fe}^{3+}$, respectivamente. Um íon com um raio consideravelmente maior que o raio de um íon de ferro tem pouca probabilidade de substituí-lo na rede cristalina devido as próprias dimensões do sítio. Se o raio do íon em questão for muito maior que dos íons de ferro a substituição torna-se até mesmo impossível de ocorrer sem uma grande deformação da rede cristalina. Assim, tal íon pode apenas ocupar a superfície das nanopartículas ou se inserir na rede em concentrações muito menores que de íons com dimensões semelhantes aos dos íons ferro.

\subsection{ESTRUTURA E FORMA}

Na Figura 27 são mostrados os difratogramas das nanopartículas com e sem ítrio, os parâmetros estruturais das amostras estão disponíveis na Tabela 8. Os picos de maior amplitude estão em $2 \theta=35,73^{\circ} \pm 0,01$ e $2 \theta=35,62^{\circ} \pm 0,01$ para as amostras FNP e YFNP, respectivamente, correspondendo ao pico (311) da estrutura espinélio, com simetria $F d \overline{3} \mathrm{~m}$. Para o erro na medida dos ângulos foi considerado metade do passo utilizado nas medições. Os diâmetros médios das NPs das amostras FNP e YFNP, encontrados pelo método de Scherrer, foram, respectivamente, $D_{F N P}=13,02 \pm 0,01 \mathrm{~nm}$ e $D_{Y F N P}=12,92 \pm 0,01 \mathrm{~nm}$, uma diferença menor que $1 \%$, indicando que a dopagem de ítrio não interfere de forma significativa no tamanho das nanopartículas.

Tabela 8. Parâmetros obtidos através do tratamento das medidas de DRX das NPs.

\begin{tabular}{cccc}
\hline Amostras & $\mathbf{2} \boldsymbol{\theta}\left({ }^{\circ}\right)$ & $\boldsymbol{D}_{\text {scherrer }}(\mathbf{n m})$ & $\boldsymbol{a}(\stackrel{\AA}{\mathbf{A}})$ \\
\hline FNP & $35,73 \pm 0,01$ & $13,02 \pm 0,01$ & $8,33 \pm 0,07$ \\
YFNP & $35,62 \pm 0,01$ & $12,92 \pm 0,01$ & $8,36 \pm 0,07$ \\
\hline
\end{tabular}

Os parâmetros de rede da estimados para as amostras FNP e YFNP foram, respectivamente, $a_{F N P}=8,33 \pm 0,07 \AA$ e $a_{Y F N P}=8,36 \pm 0,07 \AA$, estando de acordo com resultados da literatura $a=8,395 \AA$ [102]. Um aumento menor que $0,5 \%$ foi observado com a adição de Y nas NPs, isso poderia ser considerado uma evidência de que o ítrio se encontra na rede cristalina e aumenta seu tamanho devido ao seu raio iônico maior que o do ferro, entretanto, esta diferença é menor que o erro experimental. A grande similaridade de resultados para o difractograma de raios $\mathrm{X}$ para as duas amostras indica 
ainda que esta não é a ferramenta ideal para determinar o posicionamento de dopantes em nanopartículas. Se o parâmetro de rede aumentasse de forma considerável se teria uma grande evidência de que o ítrio entra na estrutura cristalina, porém ainda não seria possível determinar em qual sítio o dopante se encontra.

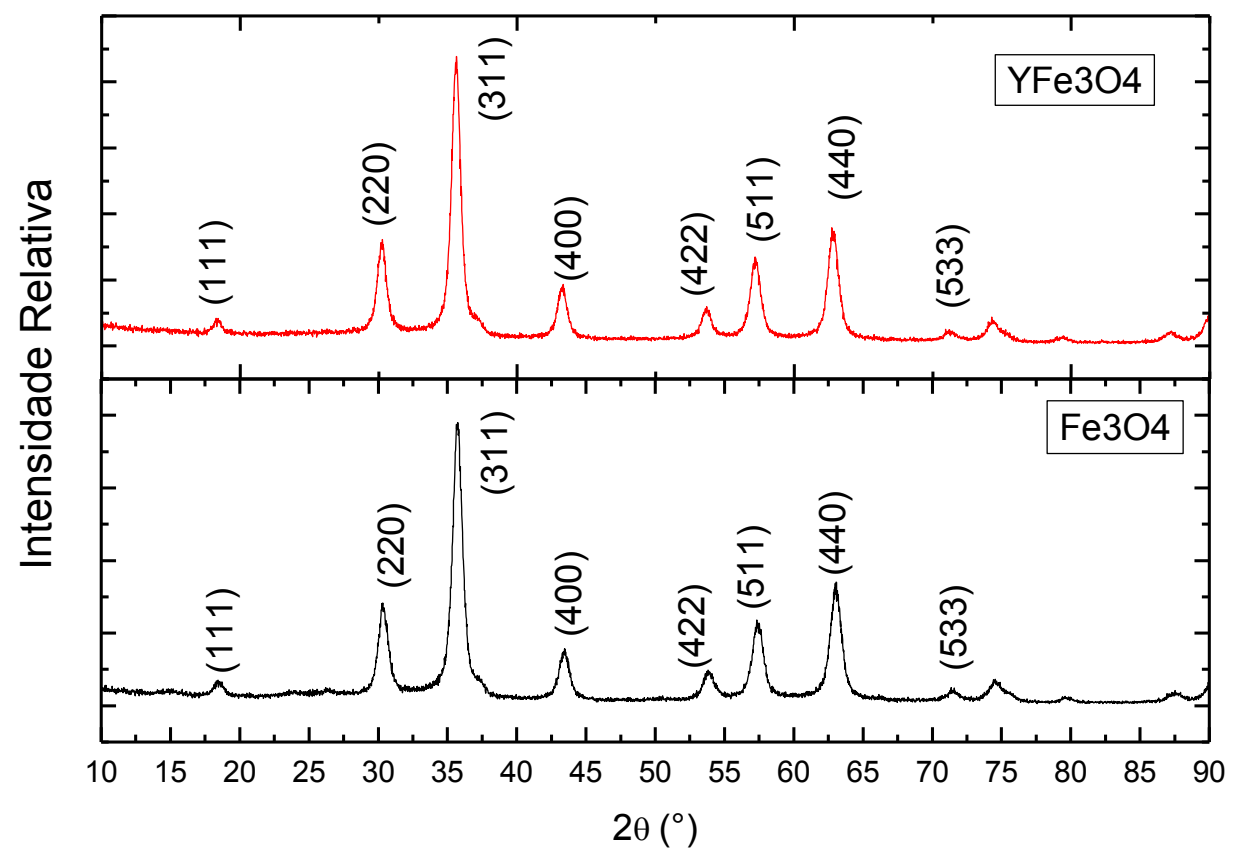

Figura 27. Difratograma das NPs com e sem ítrio, o posicionamento de seus picos mostra que que ambas amostras possuem a mesma estrutura cristalina espinélio. Os dois gráficos não apresentam diferenças visíveis.

\subsection{Propriedades Coloidais}

Com experimento de microeletroforese os valores para o potencial zeta encontrados para as amostras FNP e YFNP foram $\zeta_{F N P}=-26,7 \mathrm{mV}$ e $\zeta_{Y F N P}=-36,7 \mathrm{mV}$, respectivamente. A dopagem de ítrio provocou um aumento de $27 \%$ na magnitude do potencial zeta nas nanopartículas. Este é um dado interessante, o qual sugere que uma grande alteração na carga de superfície das nanopartículas ocorre devido ao ítrio presente em sua estrutura.

Dois fatos tornam o aumento do potencial zeta ainda mais notável. O primeiro é referente à baixa concentração de ítrio nas NPs, menos de $1 \%$ em massa em relação ao ferro (cerca de um átomo de ítrio para cada duzentos átomos de ferro), revelando que poucas quantidades de ítrio provocam grandes alterações nas propriedades coloidais. Em segundo, como visto na seção anterior, a morfologia das NPs praticamente não é alterada 
com a dopagem de ítrio, concluindo que este elemento altera somente as propriedades coloidais das nanopartículas. Resultados similares não foram encontrados na literatura.

\subsection{Espectroscopia da Estrutura Fina de AbsorÇão de RAIOS X}

Os dados de absorção de raios $\mathrm{X}$ foram tratados utilizando o pacote de programas IFFEFIT. Primeiramente os espectros foram tratados normalizados programa Athena e depois simulados pelo programa Artemis.

A Figura 28 mostra o espectro de absorção na borda K-Fe de ambas as amostras. A comparação entre os dois espectros apresenta apenas uma pequena diferença nas intensidades relativas do sinal. O pico da borda de absorção do ferro para as duas amostras se encontra na mesma energia de $7132 \mathrm{eV}$. É observado no espectro um pico pré-borda em 7114 eV típico da magnetita e da maghemita [103 - 105] que sugere a fase das amostras é uma mistura destas duas ferritas.

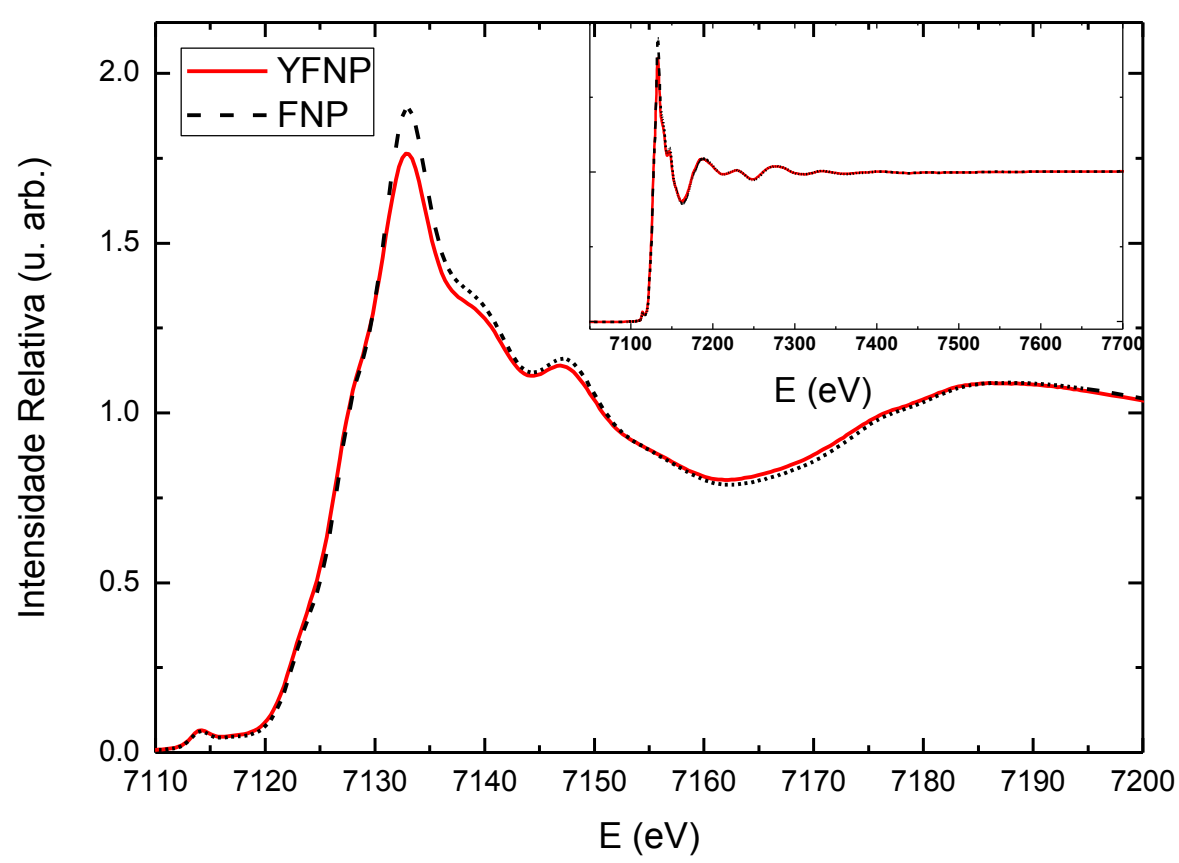

Figura 28. Espectro de absorção da NPs na borda K-Fe na região de XANES e medida completa no inset. Não é visível nenhuma influência provocada pelo ítrio 
Na Figura 29 são mostradas as oscilações de EXAFS, com os valores multiplicados por $k^{2}$, para as duas amostras.

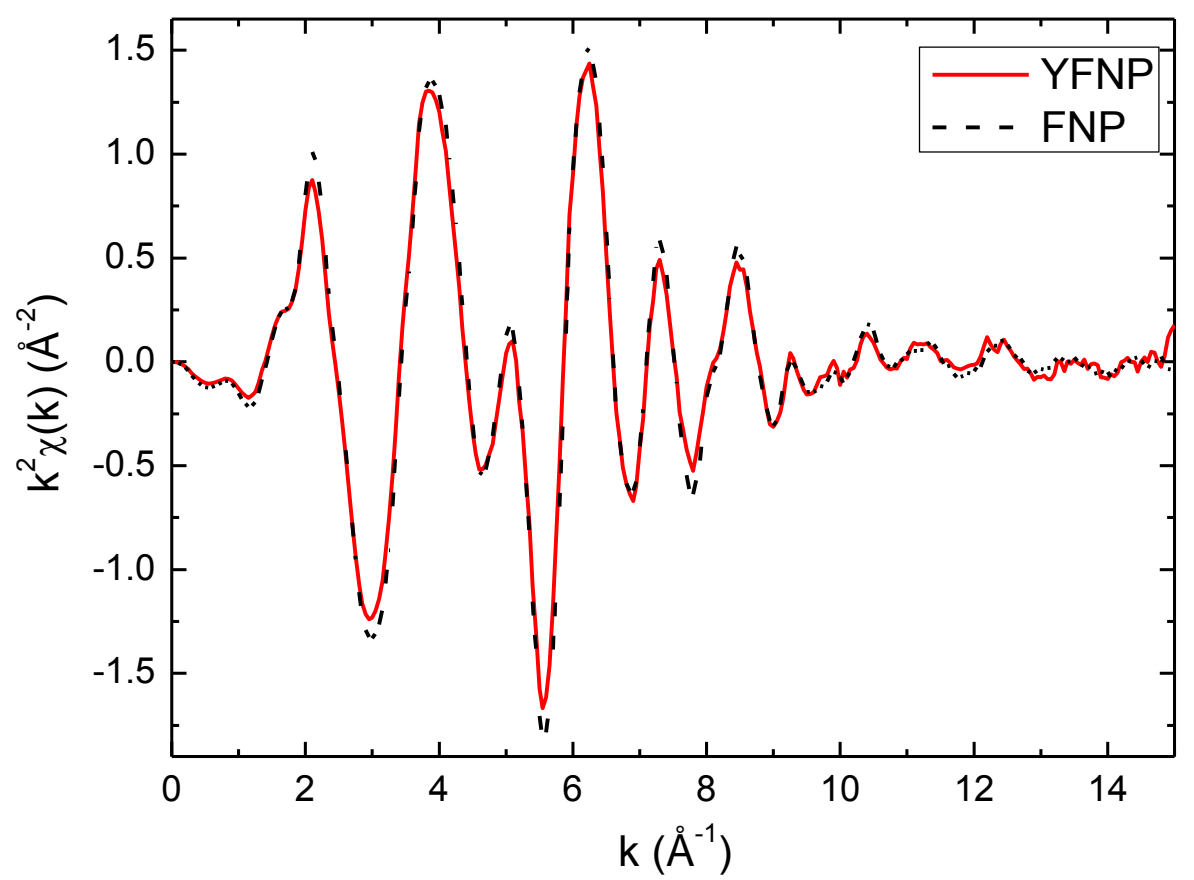

Figura 29. Espectro de EXAFS na borda K do Fe para as amostras FNP e YFNP.O sinal foi multiplicado por $k^{2}$, para evidenciar as oscilações.

A Transformada de Fourier (TF) do sinal de EXAFS na borda K-Fe está na Figura 30. Para o cálculo da TF no programa Athena foram considerados os valores de $k$ entre $3 \AA^{-1}$ e $12 \AA^{-1}$. Novamente, a diferença entre os dois espectros é mínima. O primeiro pico da FT está próximo a 1,5 ̊, correspondente aos primeiros vizinhos (átomos de oxigênio) tanto para os sítios [A] quanto para os sítios [B] que possuem valores de distâncias aos átomos de oxigênio muito próximos. O segundo referente aos segundos vizinhos (átomos de ferro e oxigênio), pico possui uma notável cisão com picos em 2,5 A e 3,0 A. Esta cisão ocorre devido as diferentes distâncias entre os segundos vizinhos para os dois sítios. O pico em 2,5 Å é formado apenas por espalhamentos entre um átomo absorvedor num sítio [B] com outro átomo também em um sítio [B], sendo este caminho denotado por B2 na Tabela 9. O pico em 3,0 Å possui contribuições tanto dos sítios [A] quanto nos sítios [B], caminhos A2, A3, A4, B3, B4 e B5 da Tabela 9. Como o coeficiente de absorção é uma média da absorção de átomos em ambos sítios seu espectro possue um segundo pico com uma bifurcação. 


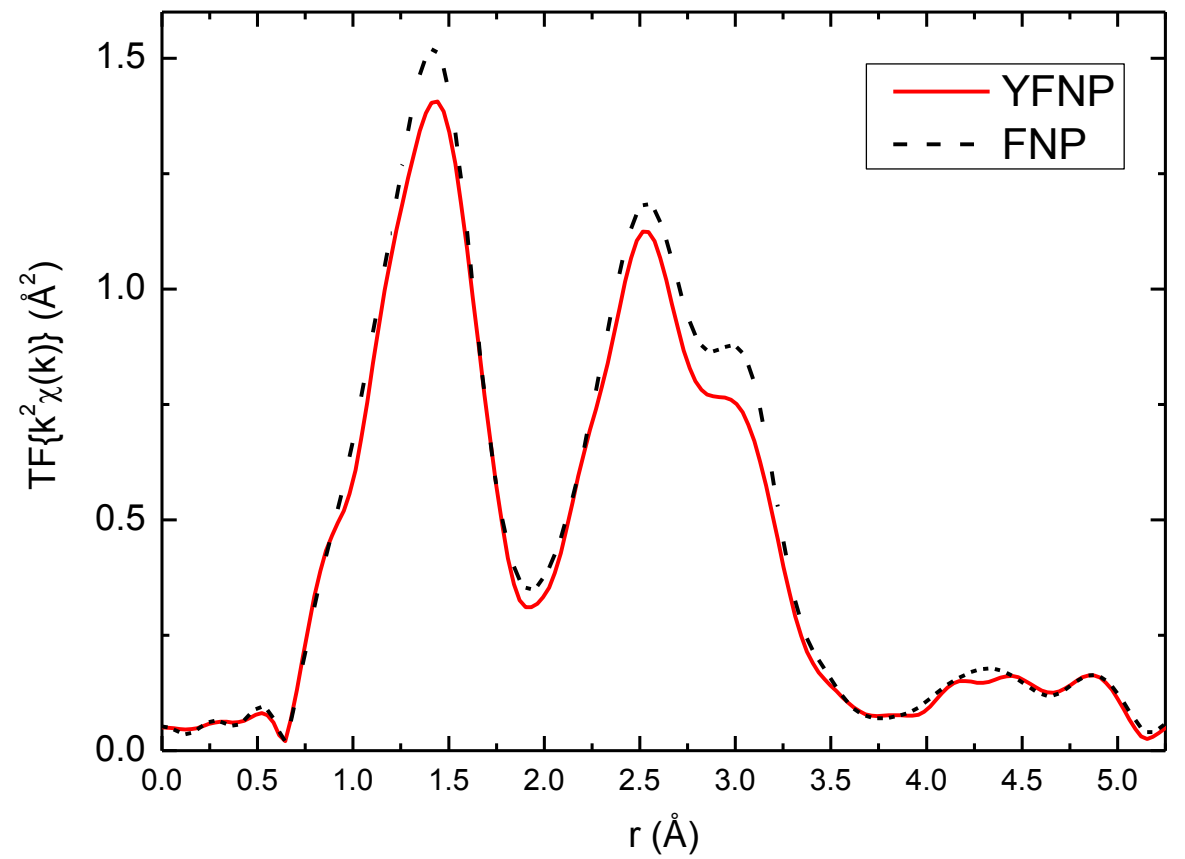

Figura 30. TF na borda K-Fe. A TF foi feita a partir do sinal multiplicado por $\boldsymbol{k}^{2}$.

$\mathrm{Na}$ estrutura espinélio, o número de sítios octaédricos é o dobro do número de tetraédricos $\left(\mathrm{N}_{[\mathrm{B}]} / \mathrm{N}_{[\mathrm{A}]}=2\right)$, além disso os átomos nos sítios $[\mathrm{B}]$ possuem seis átomos vizinhos contra quatro nos sítios [A], esses dois fatores fazem a primeira separação do segundo pico do espectro ser mais intensa que a segunda, pois a intensidade do sinal de EXAFS depende de ambos. Em medidas com pouca resolução nem mesmo é possível observar esta divisão no segundo pico, dessa maneira pode-se dizer que o pico em $2,5 \AA$ é consequência da ocupação do átomo absorvedor em sítios [B] e o segundo em sítios [A]. Acima de 4,0 ̊̊ nota-se um pico muito alargado, não sendo possível obter informações concretas deste pico, pois possui contribuições de muitos caminhos de espalhamento.

Simulações para as medidas na borda K-Fe foram feitas com o programa Artemis utilizando um modelo cristalográfico da magnetita como ponto de partida, com grupo espacial $\mathrm{Fd} \overline{3} \mathrm{~m}$, utilizando os valores para os parâmetros de rede determinados por DRX (disponíveis na Tabela 8) e a energia da borda de absorção obtida nas medidas de XAFS, $7131 \mathrm{eV}$. Estes parâmetros foram inseridos no programa Atoms que gera as listas com as coordenadas atômicas a serem então usadas nas simulações com o programa Artemis. A simulação foi feita com 90 átomos para as distâncias entre $1 \AA$ e $4 \AA$, e os parâmetros estruturais ajustados foram as distâncias radiais médias $r$ e os fatores de Debye-Waller $\sigma^{2}$. Para a amostra YFNP os átomos de Y presentes na rede foram desconsiderados no modelo de ponto de partida, devido sua baixa concentração alterações na rede são negligenciáveis, 
como foi visto com os resultados de DRX.Os ajustes estão nas Figura 31 eFigura 32, e os valores de $r$ e $\sigma^{2}$ obtidos estão, respectivamente, nas Tabela 9Tabela 10.

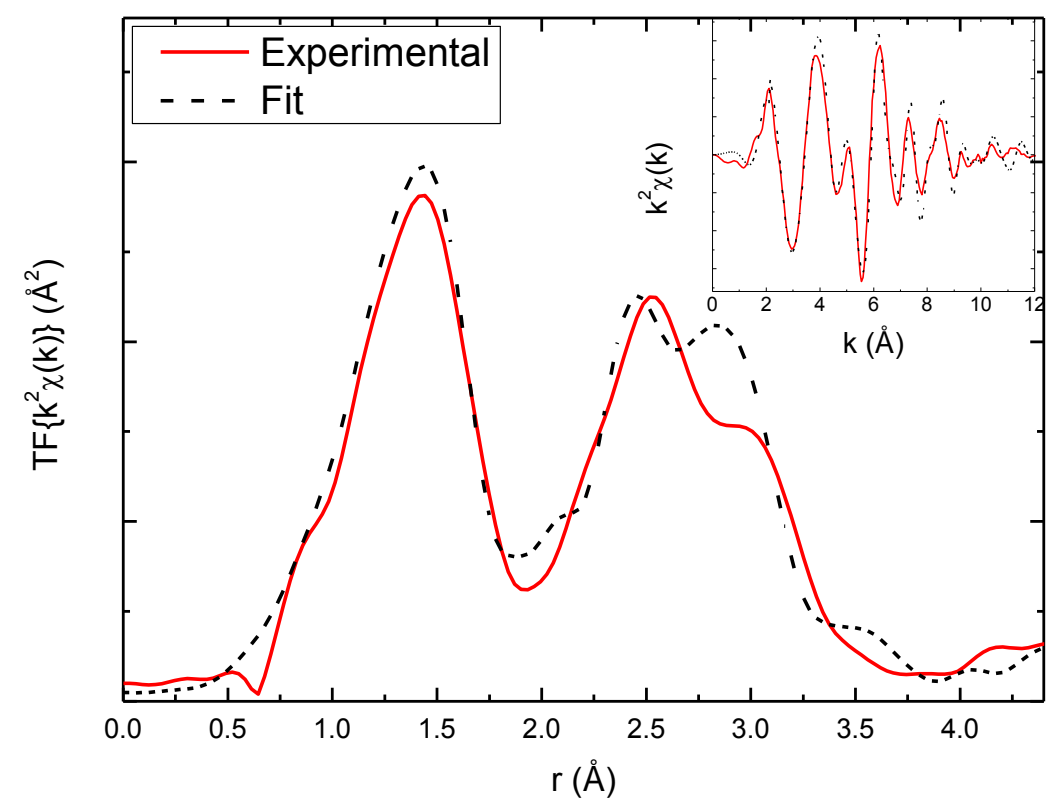

Figura 31. Sinal de $\chi(\mathbf{r})$ para os átomos de ferro presentes na amostra FNP e seu ajuste feito pelo programa Artemis, no insert é mostrado o ajuste para $\mathrm{k}^{2} \chi(\mathrm{k})$.

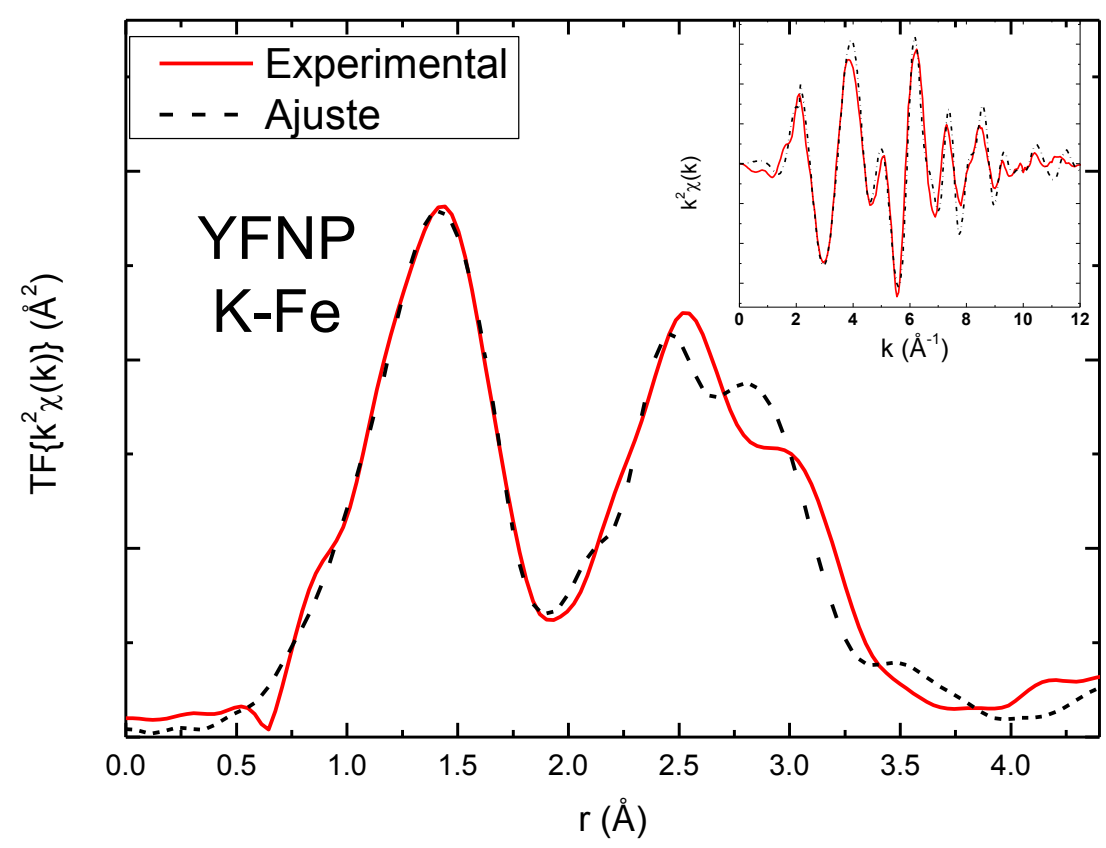

Figura 32. Sinal de $\chi(\mathbf{r})$ para os átomos de ferro presentes na amostra YFNP e seu ajuste feito pelo programa Artemis, no insert é mostrado o ajuste para $\mathbf{k}^{2} \chi(\mathbf{k})$. 
Tabela 9. Valores de $r$ obtidos pelo ajuste na borda K-Fe para as amostras FNP $\left(r_{F N P}\right)$ e YFNP $\left(r_{Y F N P}\right)$ e valores retirados das referências [102] $\left(r_{r e f 1}\right)$ e [106] $\left(r_{r e f 2}\right)$.

\begin{tabular}{|c|c|c|c|c|c|}
\hline Caminho & Átomos Envolvidos & $r_{F N P}(\AA)$ & $r_{Y F N P}(\AA)$ & $r_{\text {refl }}(\AA)$ & $\boldsymbol{r}_{r e f 2}(\AA)$ \\
\hline A1 & $\mathrm{Fe}_{[\mathrm{A}]}-\mathrm{O}$ & $1,84(4)$ & $1,85(4)$ & 1,8746 & 1,90 \\
\hline $\mathbf{A 2}$ & $\mathrm{Fe}_{[\mathrm{A}]}-\mathrm{Fe}_{[\mathrm{B}]}$ & $3,43(5)$ & $3,44(5)$ & 3,4783 & 3,49 \\
\hline A3 & $\mathrm{Fe}_{[\mathrm{A}]}-\mathrm{O}$ & $3,45(8)$ & $3,45(8)$ & 3,4889 & 3,44 \\
\hline A4 & $\mathrm{Fe}_{[\mathrm{A}]}-\mathrm{Fe}_{[\mathrm{A}]}$ & $3,59(6)$ & $3,59(6)$ & 3,6330 & 3,69 \\
\hline B1 & $\mathrm{Fe}_{[\mathrm{B}]}-\mathrm{O}$ & $2,04(3)$ & $2,04(3)$ & 2,0645 & 2,05 \\
\hline B2 & $\mathrm{Fe}_{[\mathrm{B}]}-\mathrm{Fe}_{[\mathrm{B}]}$ & $2,94(4)$ & $2,95(4)$ & 2,9663 & 2,99 \\
\hline B3 & $\mathrm{Fe}_{[\mathrm{B}]}-\mathrm{Fe}_{[\mathrm{A}]}$ & $3,43(5)$ & $3,44(5)$ & 3,4783 & 3,49 \\
\hline B4 & $\mathrm{Fe}_{[\mathrm{B}]}-\mathrm{O}$ & $3,53(6)$ & $3,53(6)$ & 3,5748 & 3,59 \\
\hline B5 & $\mathrm{Fe}_{[\mathrm{B}]}-\mathrm{O}$ & $3,58(8)$ & $3,58(8)$ & 3,6528 & 3,78 \\
\hline
\end{tabular}

Tabela 10. Valores de $r$ obtidos pelo ajuste na borda K-Fe para as amostras FNP $\left(\sigma_{\text {FNP }}^{2}\right.$ e YFNP $\left(\sigma^{2}\right.$ YFNP $)$ e valores retirados da referência [106] $\left(\sigma^{2}\right.$ ref $)$.

\begin{tabular}{|c|c|c|c|c|}
\hline Caminho & Átomos Envolvidos & $\sigma_{F N P}^{2}\left(\AA^{2}\right)$ & $\sigma_{Y F N P}^{2}\left(\AA^{2}\right)$ & $\sigma_{r e f}^{2}\left(\AA^{2}\right)$ \\
\hline A1 & $\mathrm{Fe}_{[\mathrm{A}]}-\mathrm{O}$ & $0,0029(3)$ & $0,0028(4)$ & 0,0040 \\
\hline A2 & $\mathrm{Fe}_{[\mathrm{A}]}-\mathrm{Fe}_{[\mathrm{B}]}$ & $0,010(2)$ & $0,010(2)$ & 0,011 \\
\hline A3 & $\mathrm{Fe}_{[\mathrm{A}]}-\mathrm{O}$ & $0,012(4)$ & $0,011(4)$ & 0,012 \\
\hline A4 & $\mathrm{Fe}_{[\mathrm{A}]}-\mathrm{Fe}_{[\mathrm{A}]}$ & $0,012(5)$ & $0,010(5)$ & 0,008 \\
\hline B1 & $\mathrm{Fe}_{[\mathrm{B}]}-\mathrm{O}$ & $0,0020(5)$ & $0,0020(5)$ & 0,0020 \\
\hline B2 & $\mathrm{Fe}_{[\mathrm{B}]}-\mathrm{Fe}_{[\mathrm{B}]}$ & $0,0096(6)$ & $0,0097(6)$ & 0,013 \\
\hline $\mathbf{B 3}$ & $\mathrm{Fe}_{[\mathrm{B}]}-\mathrm{Fe}_{[\mathrm{A}]}$ & $0,010(2)$ & $0,010(2)$ & 0,011 \\
\hline B4 & $\mathrm{Fe}_{[\mathrm{B}]}-\mathrm{O}$ & $0,0098(5)$ & $0,099(4)$ & 0,010 \\
\hline B5 & $\mathrm{Fe}_{[\mathrm{B}]}-\mathrm{O}$ & $0,018(8)$ & $0,017(7)$ & 0,016 \\
\hline
\end{tabular}

Os dois ajustes na borda K-Fe mostram boa concordância com os dados experimentais. Os parâmetros de rede das referências [102] e [106] são, respectivamente, $a_{\text {refl }}=8,3941 \pm 0,0007 \AA$ e $a_{\text {ref2 }}=8,3979 \pm 0,0009 \AA$, valores próximos aos encontrados por DRX, $a_{F N P}=8,33 \pm 0,07 \AA$ e $a_{Y F N P}=8,36 \pm 0,07 \AA$. Os valores de $r_{F N P}$ e $r_{Y F N P}$ mostram concordância com os valores da primeira referência [102], porém alguns valores estão ligeiramente abaixo dos valores da referência [106], uma possível explicação para isso pode ser o fato de as amostras FNP e YFNP possuírem uma constante de rede com 
tamanho menor que da amostra da segunda referência. Os fatores de Debye-Waller, $\sigma_{F N P}^{2}$ e $\sigma_{F Y N P}^{2}$, por sua vez, estão em boa concordância com os valores desta referência, $\sigma^{2}$ ref.

A Figura 32 mostra o espectro de absorção na borda K-Y, destacando a região de XANES. A borda de absorção se encontra em 17060 eV, e não foi observado nenhum pico pré-borda.

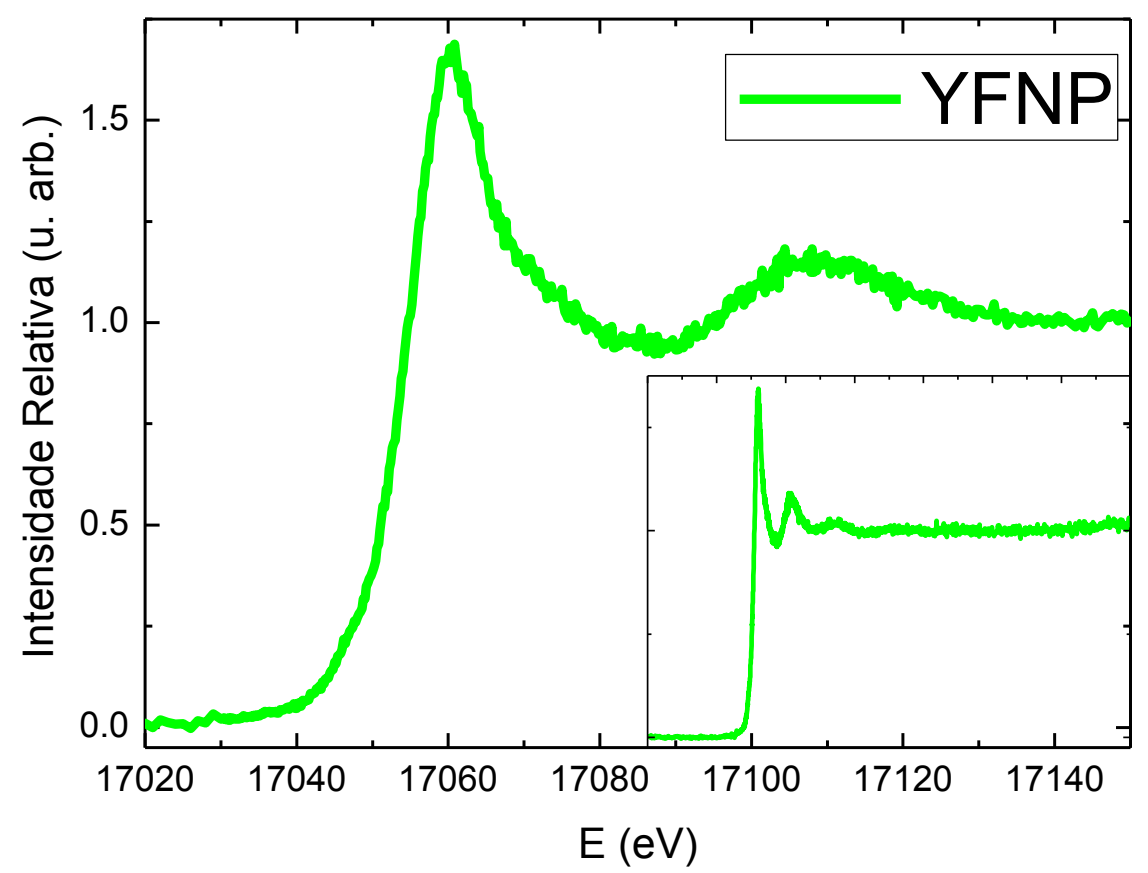

Figura 33. Espectro de absorção da NPs na borda K-Y na região de XANES e medida total no inset.

A Figura 34 apresenta as oscilações de EXAFS na borda K-Y, que mostra muita similaridade com o sinal na borda do ferro (Figura 29) o que é uma grande evidência da localização do ítrio em um dos dois sítios. Na Figura 345 temos a transformada de Fourier para o espectro de absorção da borda K-Y, que foi calculada considerando os valores de $k$ entre $3 \AA^{-1}$ e $12 \AA^{-1}$ (mesmos valores utilizados para a borda K-Fe). O fato desta TF apresentar um primeiro e um segundo picos bem definidos, que estão relacionados com as distâncias dos primeiros e segundos átomos vizinhos, respectivamente, mostra que a distribuição radial dos átomos de ítrio apresenta um ordenamento médio de pelo menos segunda ordem, sendo uma grande evidência de que tais átomos estão na rede cristalina e não na superfície ou em posições intersticiais. 


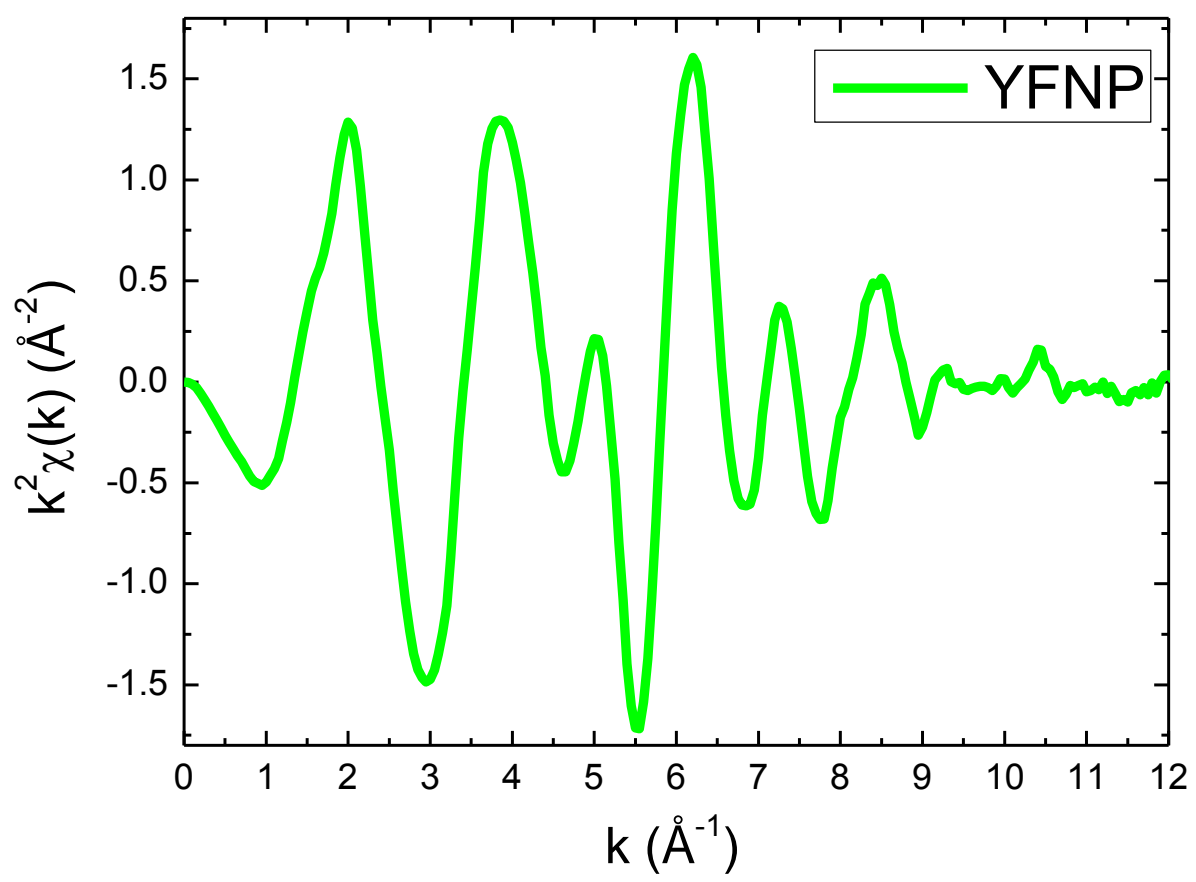

Figura 34. Sinal de EXAFS da borda K do ítrio. As oscilações são muito similares às da borda K - Fe, mostradas na Figura 29.

Para a situação de os dopantes estarem na superfície, a TF teria somente um pico definido, pois o ordenamento de primeira ordem continuaria a existir, porém não existiria ordenamento de segunda ordem, se o Y ocupasse posições intersticiais a TF também não apresentaria um segundo pico, e provavelmente nem mesmo um pico bem definido seria observado, sendo que dificilmente apresentaria uma forma de ordenamento.

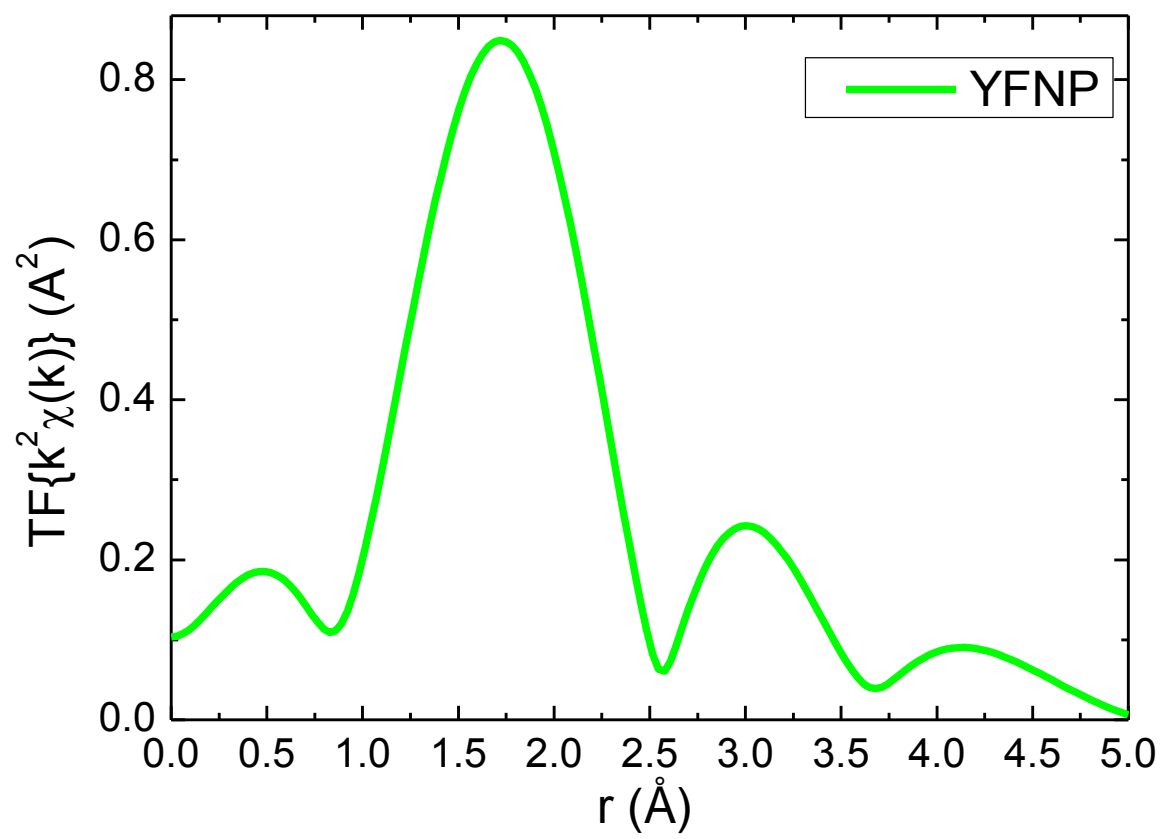

Figura 35. TF do sinal de EXAFS da borda K-Y. Os dois primeiros picos bem definidos são uma evidência da substituição de íons de Fe por íons de Y nos sítios da rede. 
Na Figura 356 temos as Transformadas de Fourier dos três espectros. Uma análise semi-quantitativa pode ser feita de acordo com as posições dos picos nas TFs, assim como a feita em [64 e 75]. A distância dos primeiros vizinhos é, aproximadamente, a mesma para os sítios tetraédricos [A] e octaédricos [B], quando se tem íons de ferro em ambos sítios, tratando-se da distância entre os dois núcleos atômicos. Se houver uma substituição um destes íons por um íon com raio consideravelmente maior esta distância sofrerá um aumento, o segundo pico, porém, não sofrerá uma alteração perceptível, pois os átomos da segunda camada de coordenação não sofreram estes efeitos de forma perceptível em medidas de EXAFS.

O primeiro pico está em $r \sim 1,5 \AA$ A tanto para os átomos de Fe da amostra FNP para os átomos de ferro da amostra YFNP, para a TF do Y o primeiro pico está em $\sim 1,7 \AA$, com isso podemos inferir que ambos os metais possuem átomos de oxigênio como primeiros vizinhos, porém não é uma prova de que o ítrio é substitucional ao ferro, já que pode apenas estar na superfície das NPs ligado a átomos de oxigênio. Esta prova é obtida a partir do segundo pico.

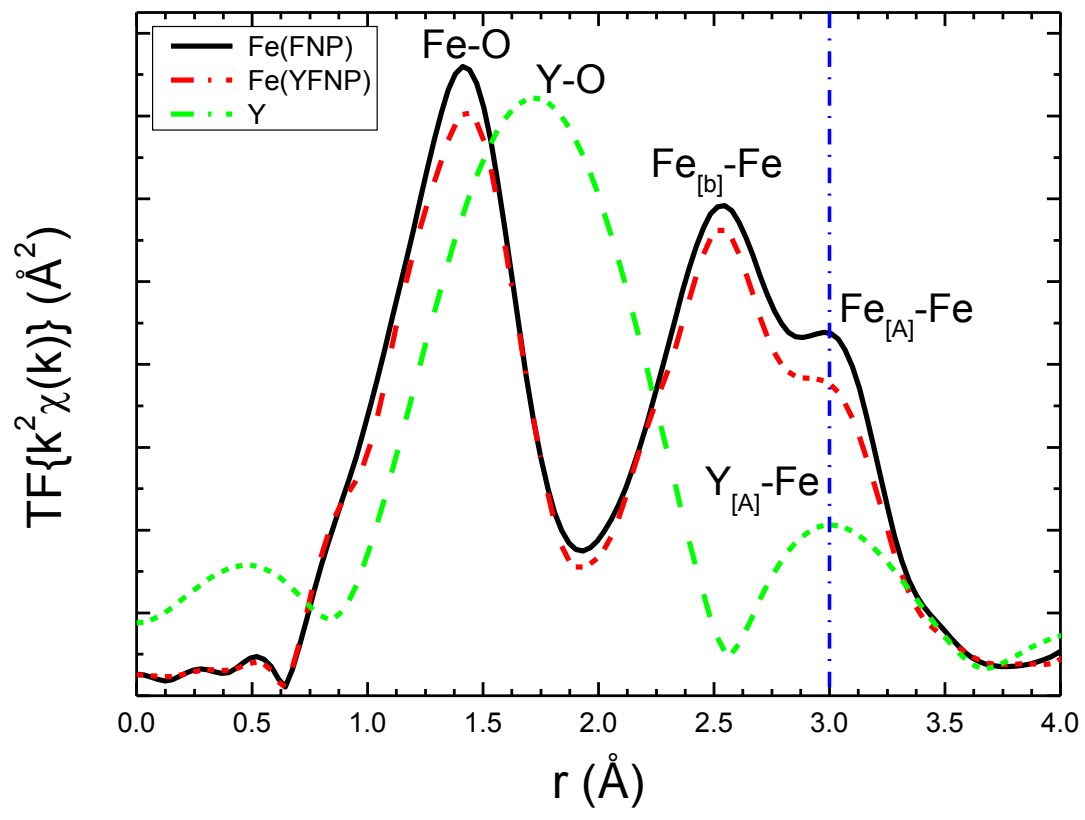

Figura 36. L3 do Y; vermelho: K do Fe para NPs sem Y; verde: K do Fe para NPs com Y. Os três espectros de absorção foram simulados pelo programa Artemis, e são mostrados na Figura 31.

Os segundos vizinhos, representados pelo segundo pico da TF, para os dois metais são metais, essencialmente Fe devido à baixa concentração de Y. No caso do Fe, o segundo pico possui uma divisão, sendo a primeira parte contribuições vindas dos 
sítios [B], que está em $r \sim 2,5 \AA$, a segunda parte resultado de contribuições, principalmente, dos sítios [A], localizada em 3,0 A. O segundo pico na TF do Y está em 3,0 A, justamente na mesma posição do pico relacionado com os segundos vizinhos dos sítios [A]. A distância para os segundos vizinhos nos sítios tetraédricos é maior que nos octaédricos, indicando que os átomos de Y ocupam os sítios [A].

Para as simulações na borda K-Y foram utilizadas as mesmas coordenadas geradas para a simulação na borda K-Fe da amostra YFNP, com a substituição de um átomo de ferro em um sítio tetraédrico por um de ítrio, sendo este o átomo absorvedor, e o valor para a borda de absorção encontrada por XAFS, $17060 \mathrm{eV}$. Os parâmetros ajustados foram novamente a distância radial média $r$ e o fator de Debye-Waller $\sigma^{2}$. Mais uma vez os efeitos dos átomos de ítrio na rede, que não o átomo absorvedor, foram desconsiderados. Devido a baixa concentração de dopantes, a possibilidade de um átomo de ítrio possuir um segundo vizinho de mesma espécie química é muito baixa. Os dados obtidos estão na

Tabela 11, e o ajuste é mostrado na Figura 37.

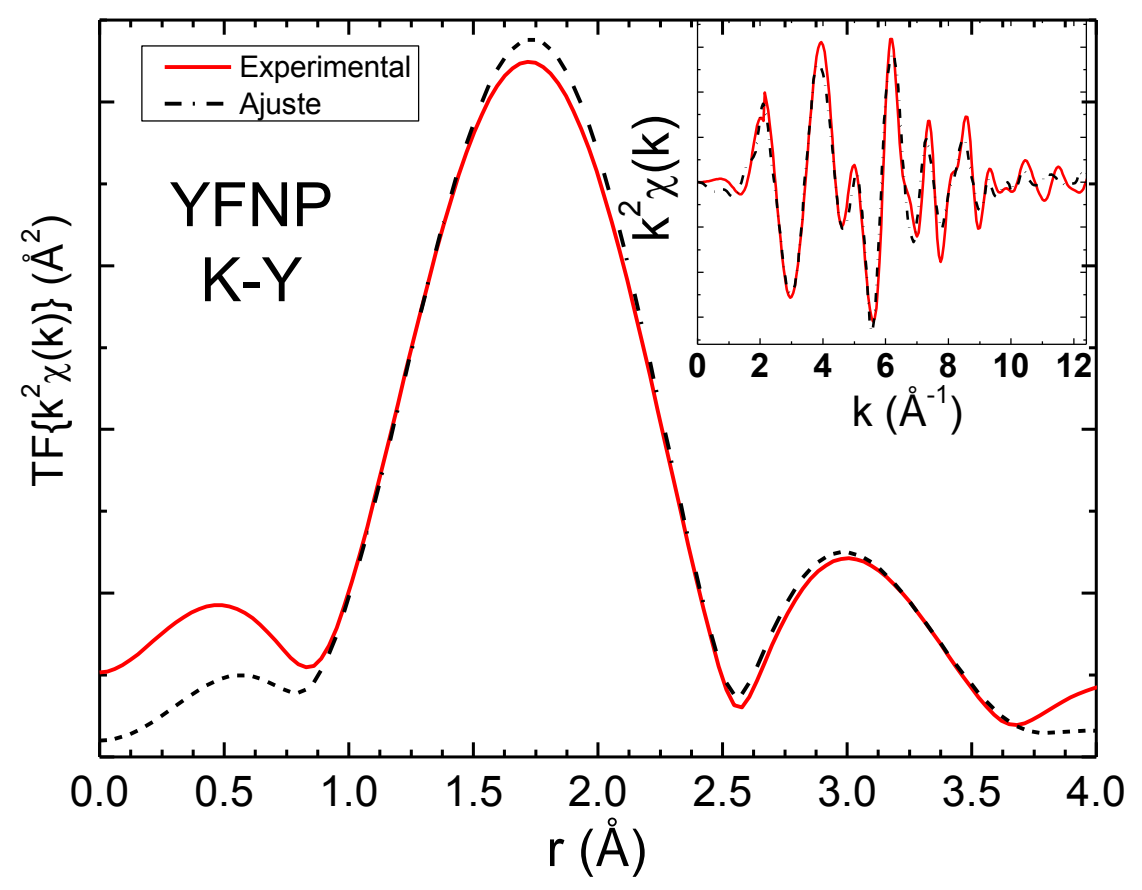

Figura 37. Sinal de $\chi(r)$ para os átomos de ítrio e seu fit feito pelo programa Artemis, no insert é mostrado o ajuste para $k^{2} \chi(k)$. 
Tabela 11. Valores de $\boldsymbol{r}$ e $\sigma^{2}$ obtidos pelo ajuste na borda K-Y para a amostra YFNP.

\begin{tabular}{cccc}
\hline Caminho & Átomos Envolvidos & $\boldsymbol{r}(\AA)$ & $\boldsymbol{\sigma}^{2}\left(\AA^{\mathbf{2}}\right)$ \\
\hline $\mathbf{Y} 1$ & $\mathrm{Y}_{[\mathrm{A}]}-\mathrm{O}$ & $2,36(4)$ & $0,011(1)$ \\
$\mathbf{Y} 2$ & $\mathrm{Y}_{[\mathrm{A}]}-\mathrm{Fe}_{[\mathrm{B}]}$ & $3,57(6)$ & $0,039(2)$ \\
$\mathbf{Y 3}$ & $\mathrm{Y}_{[\mathrm{A}]}-\mathrm{O}$ & $3,52(6)$ & $0,037(4)$ \\
$\mathbf{Y 4}$ & $\mathrm{Y}_{[\mathrm{A}]}-\mathrm{Fe}_{[\mathrm{A}]}$ & $3,72(7)$ & $0,040(5)$ \\
\hline
\end{tabular}

As distâncias obtidas para os caminhos Y2, Y3 e Y4 estão dentro dos valores obtidos para os caminhos A2, A3 e A4, respectivamente. Para a distância Y-O e valor encontrado, $r=2,36 \pm 0,04 \AA$, que está dentro do valor encontrado na referência [Erro! Fonte de referência não encontrada.], $r_{\text {ref }}=2,27 \pm 0,05$, onde foi determinada a distância entre átomos de ítrio e oxigênio para o óxido de ítrio. 


\section{CONCLUSÃO}

Neste trabalho foi realizado um estudo dos efeitos da dopagem de ítrio em nanopartículas de óxido de ferro, além da determinação da ocupação dos dopantes na estrutura cristalina. Para isso, nanopartículas de magnetita dopadas com ítrio foram sintetizadas pelo método de coprecipitação. Foi feita uma caracterização química e estrutural, tanto para nanopartículas dopadas com ítrio quanto para NPs sem dopagem sintetizadas em processo semelhante, para comparação, e uma espectroscopia de estrutura fina de absorção de raios $\mathrm{X}$ para determinação do posicionamento do ítrio. A concentração nominal em massa de ítrio foi de $1,4 \%$ em relação ao ferro, sendo sumarizada como amostra FNP, a amostra sem dopagem foi sumarizada como YFNP. Foram obtidos os resultados abaixo.

A concentração química das nanopartículas foi determinada por duas técnicas distintas, Fluorescência de Raios X e Espectroscopia de Emissão Ótica com Plasma Acoplado, e os resultados encontrados apresentam boa concordância. A porcentagem de ítrio determinada pelos experimentos de XRF e ICP foram 0,810\% e 0,877\%, respectivamente. Mostrando assim que mais de $60 \%$ do ítrio disponível na síntese está presente nas nanopartículas.

A Difração de Raio X revelou a estrutura espinélio inversa das nanopartículas, as quais possuem um diâmetro médio estimado pela fórmula de Scherrer de 13,02 nm e $12,92 \mathrm{~nm}$, para as NPs sem e com ítrio, respectivamente. A dopagem de ítrio gerou um aumento de $3 \times 10^{-3} \mathrm{~nm}$ no parâmetro de rede, o que seria uma indicação de que o ítrio permeia a estrutura cristalina das NPs, porém a incerteza na medida é maior que o dobro desta diferença, $7 \times 10^{-3} \mathrm{~nm}$.

Com um experimento de microeletroforese foi estimado o valor do potencial zeta, o qual teve um aumento de $27 \%$ com a dopagem $(-26,7 \mathrm{mV}$, sem dopagem de $\mathrm{Y}$, contra $-36,7 \mathrm{mV}$, com Y), sendo um aumento bastante notável devido à baixa concentração de ítrio nas nanopartículas (um átomo de ítrio para cada duzentos átomos de ferro). Este resultado mostra que fluidos magnéticos se tornam mais estáveis com a dopagem de ítrio devido, pelo menos em parte, a um aumento na carga superficial das nanopartículas do fluido magnético. 
A ocupação dos íons de ítrio nas nanopartículas foi determinada pela técnica de EXAFS, onde foi encontrado que este elemento é substitucional ao ferro e se encontra nos sítios tetraédricos $[\mathrm{A}]$, substituindo íons $\mathrm{Fe}^{3+}$. As medidas de EXAFS foram simuladas pelo programa Artemis e assim foi foram obtidas as distâncias interatômicas médias e os fatores de Debye-Waller para os átomos de ferro e ítrio e seus respectivos primeiros e segundos vizinhos. A distância dos primeiros vizinhos dos átomos de ferro não sofreu alteração significativa com a dopagem, foram encontrados os valores para as amostras FNP e YFNP $r_{F e-O}=1,84 \AA$ e $r_{F e-O}=1,85 \AA$, respectivamente. Para os segundos vizinhos a diferença continua irrisória, estando em conformidade com dados disponíveis na literatura, conforme pode ser conferido na Tabela 109. Os fatores de Debye-Waller obtidos para as duas amostras não mostram também uma diferença significativa, estando os valores na Tabela 10. Para os átomos de ítrio os valores encontrados para a distância aos primeiros vizinhos fo $r_{Y-O}=2,36 \AA$, para os segundos vizinhos os valores estão dentro dos encontrados para os átomos de ferro. Com a mesma medida de absorção de raios $\mathrm{X}$, foi feita uma análise de XANES determinando que o óxido se trata de um composto de magnetita e maghemita para ambas as amostras.

Com a caracterização das nanopartículas constatou-se que a dopagem de ítrio aparentemente não modifica as suas propriedades estruturais e morfológicas (diâmetro médio, distâncias interatômicas médias e fatores de Debye-Waller), porém suas propriedades coloidais (relacionadas com a carga de superfície) são notavelmente alteradas.

Em trabalhos futuros, dopagens com diferentes espécies químicas serão feitas a fim de estudar a ocupação catiônica nas nanopartículas e os efeitos nas propriedades físicas das mesmas. A utilização de um dopante divalente em uma síntese similar à deste trabalho e a localização deste dopante na nanopartícula contribuirá para o entendimento da relação entre a valência e a ocupação iônica. Uma síntese utilizando dois dopantes, um bivalente e outro trivalente também é uma possibilidade para este estudo.

$\mathrm{O}$ fato de o íon $\mathrm{Y}^{+3}$ não possuir momento magnético pode ser um fator decisivo para as alterações causadas nas NPs, é possível estudar o efeito deste parâmetro na estabilidade coloidal utilizando um elemento químico com um momento magnético alto como dopante na síntese e fazer uma caracterização similar a feita neste trabalho. $O$ elemento neodímio mostra-se uma interessante opção por possuir alto momento 
magnético e apresentar íons com valência +2 e +3 com raios iônicos 143 pm e 124 pm, respectivamente. Estas características tornam possível, em teoria, a ocupação deste elemento em ambos os sítios. Para distinguir a preferência de cada um dos íons por determinado sítio as espectroscopias Mossbauer e Dicroísmo Circular Magnético de Raios X podem ser utilizadas em conjunto com a técnica de EXAFS. 


\section{REFERÊNCIAS}

1. X. Batlle and A. Labarta. "Finite-size effects in fine particles: magnetic and transport properties." Journal of Physics D: Applied Physics 35.6 (2002): R15.

2. P. Guimarães. Principles of Nanomagnetism. Springer-Verlag, Berlin, (2009).

3. A. K. Giri et al. "Effect of light on the magnetic properties of cobalt ferrite nanoparticles." IEEE Transactions on Magnetics 36.5 (2000): 3029-3031.

4. $\quad$ A. K. Giri et al. "Photomagnetism and structure in cobalt ferrite nanoparticles." Applied Physics Letters 80.13 (2002): 2341-2343.

5. S. Mazzucchelli et al. "Single-domain protein A-engineered magnetic nanoparticles: toward a universal strategy to site-specific labeling of antibodies for targeted detection of tumor cells." ACS nano 4.10 (2010): 5693-5702.

6. C. Minelli, S. B. Lowe and M. M. Stevens. "Engineering nanocomposite materials for cancer therapy." Small 6.21 (2010): 2336-2357.

7. M. F. Casula et al. "Magnetic resonance imaging contrast agents based on iron oxide superparamagnetic ferrofluids." Chemistry of Materials 22.5 (2010): 1739-1748.

8. L. C. Branquinho et al. "Effect of magnetic dipolar interactions on nanoparticle heating efficiency: Implications for cancer hyperthermia." Scientific Reports 3 (2013).

9. M. Mahmoudi et al. "Superparamagnetic iron oxide nanoparticles: promises for diagnosis and treatment of multiple sclerosis." ACS chemical neuroscience 2.3 (2011): 118-140.

10. R. W. Viali et al. "Investigation of the molecular surface coating on the stability of insulating magnetic oils." The Journal of Physical Chemistry C114.1 (2009): 179-188.

11. Q. A. Pankhurst et al. "Applications of magnetic nanoparticles in biomedicine." Journal of physics D: Applied physics 36.13 (2003): R167.

12. E. Blums, A. Cebers and M. M. Maiorov. Magnetic Fluids. Walter de Gruyter, Berlin (1985).

13. $\quad$ K. Raj and R. Moskowitz. "Commercial applications of ferrofluids." Journal of Magnetism and Magnetic Materials 85.1 (1990): 233-245.

14. J. Anghel et al. "Correlation between saturation magnetization, bandgap, and lattice volume of transition metal, $\mathrm{M}=\mathrm{Cr}, \mathrm{Mn}, \mathrm{Fe}, \mathrm{Co}$, or Ni doped $\mathrm{Zn} 1-\mathrm{xMxO}$ nanoparticles." J. Appl. Phys 107.9 (2010): 09E314-09E317.

15. K. Riwotzki et al. "Liquid-Phase Synthesis of Colloids and Redispersible Powders of Strongly Luminescing LaPO4: Ce, Tb Nanocrystals." Angewandte Chemie International Edition 40.3 (2001): 573-576.

16. B. D. Cullity and C. D. GRAHAM. Introduction to Magnetic Materials, 2nd, John Wiley \& Sons (2009).

17. R. M. Cornell and U. Schwertmann. The Iron Oxides: Structure, Properties, Reactions, Occurrences and Uses. Wiley-VCH (2003).

18. $\quad$ R. Blakemore. "Magnetotactic bacteria." Science 190.4212 (1975): 377-379. 
19. W. Wiltschko and R. Wiltschko. "Magnetic orientation and magnetoreception in birds and other animals." Journal of Comparative Physiology A 191.8 (2005): 675-693.

20. W. H. Bragg. "The structure of magnetite and the spinels." Nature 95 (1915): 561.

21. S. Nishikawa. "Structure of some crystals of spinel group." Tokyo SugakuButurigakkwai Kizi Dai 2 Ki 8.7 (1915): 199-209.

22. J. Smit and H. P. J. Wijn, Ferrites. Wiley, New York (1959).

23. S. Calvin et al. "Multiedge refinement of extended $\mathrm{x}$-ray-absorption fine structure of manganese zinc ferrite nanoparticles." Physical Review B 66.22 (2002): 224405.

24. T. Albrecht et al. "First observation of ferromagnetism and ferromagnetic domains in a liquid metal." Applied Physics A 65.2 (1997): 215-220.

25. US Patent \# 3215572, 09 de outubro de 1963, disponível em: https://www.google.com/patents/US3215572

26. M. Zahn. "Magnetic fluid and nanoparticle applications to nanotechnology." Journal of Nanoparticle Research 3.1 (2001): 73-78.

27. W. Voit and D. K. Zapka. Magnetic behavior of coated superparamagnetic iron oxide nanoparticles in ferrofluids. NCBI. Pubmed. (2014).

28. V. Berkovski andB. M. Bashtovoy. Magnetic Fluids and Applications Handbook, Begell House, Wallingford (1996).

29. C. Scherer and A. M. Figueiredo Neto. "Ferrofluids: properties and applications." Brazilian Journal of Physics 35.3A (2005): 718-727.

30. Disponível em: http://www.ferrotec.com

31. Disponível em: http://www.sigma-hc.co.jp/english/index.html

32. S. Nigam, K. C. Barick, and D. Bahadur. "Development of citrate-stabilized $\mathrm{Fe}_{3} \mathrm{O}_{4}$ nanoparticles: conjugation and release of doxorubicin for therapeutic applications." Journal of magnetism and magnetic materials323.2 (2011): 237-243.

33. E. Cheraghipour, S. Javadpour and A. R. Mehdizadeh. "Citrate capped superparamagnetic iron oxide nanoparticles used for hyperthermia therapy." Journal of Biomedical Science and Engineering 5 (2012) 715-719.

34. C. Liu and P. M. Huang. "Atomic force microscopy and surface characteristics of iron oxides formed in citrate solutions." Soil Science Society of America Journal 63.1 (1999): 65-72.

35. S. Laurent et al. "Magnetic iron oxide nanoparticles: synthesis, stabilization, vectorization, physicochemical characterizations, and biological applications." Chemical Reviews 108.6 (2008): 2064-2110.

36. A. Bee, R. Massart and S. Neveu. "Synthesis of very fine maghemite particles." Journal of Magnetism and Magnetic Materials 149.1 (1995): 6-9.

37. F. Gazeau, M. Lévy and C. Wilhelm. "Optimizing magnetic nanoparticle design for nanothermotherapy." Future Medicine 1 (2008): 831-844. 
38. R. M. Pashley and M. E. Karaman. Applied Colloid and Surface Chemistry, John Wiley \& Sons (2004).

39. H. Butt, K. Graf and M. Kappl. Physics and Chemistry of Interfaces, $2^{\text {nd }}$ ed. Wiley-VCH: Weinheim, Germany (2006).

40. F. Fogolari, A. Brigo and H. Molinari. "The Poisson-Boltzmann equation for biomolecular electrostatics: a tool for structural biology." Journal of Molecular Recognition 15.6 (2002): 377-392.

41. M. V. Smoluchowski. "Contribution to the theory of electro-osmosis and related phenomena." Bull Int Acad Sci Cracovie 3 (1903): 184-199.

42. R. Greenwood and K. Kendall. "Selection of suitable dispersants for aqueous suspensions of zirconia and titania powders using acoustophoresis." Journal of the European Ceramic Society 19.4 (1999): 479-488.

43. C. Schwer and E. Kenndler. "Electrophoresis in fused-silica capillaries: the influence of organic solvents on the electroosmotic velocity and the zeta potential." Analytical Chemistry 63.17 (1991): 1801-1807.

44. K. Makino et al. "Temperature-and ionic strength-induced conformational changes in the lipid head group region of liposomes as suggested by zeta potential data." Biophysical chemistry 41.2 (1991): 175-183.

45. R. J. Hunter and H. J. L. Wright. "The dependence of electrokinetic potential on concentration of electrolyte." Journal of Colloid and Interface Science 37.3 (1971): 564580 .

46. M. de Broglie "Sur une nouveau procédé permettant d'obtenir la photographie des spectres de raies des rayons Röntgen." Comptes Rendus157 (1913): 924-926.

47. H. Fricke. "The K-characteristic absorption frequencies for the chemical elements magnesium to chromium." Physical Review 16.3 (1920): 202.

48. G. Hertz. "Über die Absorptionsgrenzen in derL-Serie." Zeitschrift für Physik A Hadrons and Nuclei 3.1 (1920): 19-25.

49. G. Wentzel. "Excitation potential of $\mathrm{K}_{\alpha 3,4}$ satellite lines: A case for astronomy." Ann. d. Phys 66 (1921): 437.

50. R. Kronig. "Zur Theorie der Feinstruktur in den Röntgenabsorptionsspektren." Zeitschrift für Physik 70.5-6 (1931): 317-323.

51. R. Kronig "Zur Theorie der Feinstruktur in den Röntgenabsorptionsspektren. II." Zeitschrift für Physik 75.3 (1932): 191-210.

52. D. E. Sayers et al. "Advances in X-ray Analysis." Plenum, New-York 13 (1970): 1970.

53. D. E. Sayers, E. A. Stern and F. W. Lytle. "New technique for investigating noncrystalline structures: Fourier analysis of the extended X-ray-absorption fine structure." Physical Review Letters 27.18 (1971): 1204.

54. D. E. Sayers, F. W. Lytle and E. A. Stern. "Adv. X-ray Analysis" Journal of noncrystalline Solids (1972): 8-10. 
55. M. G. Newville. "Fundamentals of XAFS. Consortium for Advanced Radiation Sources." University of Chicago, Chicago, IL (2004).

56. B. D. Cullity. The Elements of X-Ray Diffraction, 3rd. Adisson-Wesley, USA (2001).

57. S. D. Kelly. Introduction to XAFS Data Analisis. Argonne National Laboratory, USA (2005).

58. C. Y. Ralston et al. "Characterization of heterogeneous nickel sites in CO dehydrogenases from Clostridium thermoaceticum and Rhodospirillum rubrum by nickel L-edge X-ray spectroscopy." Journal of the American Chemical Society 122.43 (2000): 10553-10560.

59. O. Seifarth et al. "On the band gaps and electronic structure of thin single crystalline praseodymium oxide layers on Si (111)." Journal of vacuum science \& technology. B, Microelectronics and nanometer structures 27.1 (2009): 271.

60. S. Friedrich et al. "A 36-pixel tunnel junction soft x-ray spectrometer for scintillator material science." Applied Superconductivity, IEEE Transactions on 17.2 (2007): 351-354.

61. A. Bianconi. "Surface x-ray absorption spectroscopy: surface EXAFS and surface XANES." Applications of Surface Science 6.3 (1980): 392-418.

62. G. N. Greaves. "EXAFS and the structure of glass." Journal of Non-Crystalline Solids 71.1 (1985): 203-217.

63. M. Leetmaa. Structure Modeling with X-ray Absorption and Reverse Monte Carlo: Applications to Water, Stockholm University, Sweden (2009).

64. J. Rockenberger et al. "Near edge X-ray absorption fine structure measurements (XANES) and extended X-ray absorption fine structure measurements (EXAFS) of the valence state and coordination of antimony in doped nanocrystalline $\mathrm{SnO}_{2}$." The Journal of Chemical Physics 112.9 (2000): 4296-4304.

65. Y. Garcia et al. "Synthesis, Crystal Structure, EXAFS, and Magnetic Properties of catena-Poly [ $\mu$-tris (4-(2-hydroxyethyl)-1, 2, 4-triazole-N 1, N 2) copper (II)] Diperchlorate Trihydrate: Relevance with the Structure of the Iron (II) 1, 2, 4-Triazole Spin Transition Molecular Materials." Inorganic Chemistry 36.27 (1997): 6357-6365.

66. S. Surble et al. "An EXAFS study of the formation of a nanoporous metalorganic framework: evidence for the retention of secondary building units during synthesis." Chemical communications 14 (2006): 1518-1520.

67. R. W. Strange et al. "X-ray absorption spectroscopy of metal-histidine coordination in metalloproteins. Exact simulation of the EXAFS of tetrabis (imidazole) copper (II) nitrate and other copper-imidazole complexes by the use of a multiple-scattering treatment." Journal of the American Chemical Society 109.23 (1987): 7157-7162.

68. R. B. Greegor and F. W. Lytle. "Morphology of supported metal clusters: Determination by EXAFS and chemisorption." Journal of Catalysis 63.2 (1980): 476-486.

69. S. J. L. Ribeiro et al. "Structural studies in lead germanate glasses: EXAFS and vibrational spectroscopy." Journal of non-crystalline solids 159.3 (1993): 213-221. 
70. A. J. Dent, J. D. F. Ramsay and S. W. Swanton. "An EXAFS study of uranyl ion in solution and sorbed onto silica and montmorillonite clay colloids." Journal of colloid and interface science 150.1 (1992): 45-60.

71. G. F. L. Fabbris. Estudo de estrutura local da família $\mathrm{RMn}_{2} \mathrm{O}_{5}(\mathrm{R}=\mathrm{Bi}, \mathrm{Tb}$, $G d, P r)$. Dissertação de mestrado, Campinas, SP (2009).

72. A. Frenkel et al. "Origin of polarity in amorphous $\mathrm{SrTiO}_{3}$." Physical Review Letters 99.21 (2007): 215502.

73. V. G. Harris et al. "Direct measurement of octahedral and tetrahedral site environments in NiZn-ferrites." Magnetics, IEEE Transactions on 31.6 (1995): 3473-3475.

74. S. Calvin et al. "Multiedge refinement of extended x-ray-absorption fine structure of manganese zinc ferrite nanoparticles." Physical Review B 66.22 (2002): 224405.

75. A. Kodre et al. "An expanded EXAFS model of Mn, Zn, and Fe spinel nanoparticles." Acta chimica Slovenica 55.1 (2008): 125-131.

76. J. Stöhr. NEXAFS Spectroscopy. Vol. 25. Springer Science \& Business Media (2013).

77. P. H. Citrin, P. Eisenberger and R. C. Hewitt. "Sexafs studies of iodine adsorbed on single crystal substrates." Surface Science 89.1 (1979): 28-40.

78. S. P. Cramer and K. O. Hodgson. "X-ray absorption spectroscopy: a new structural method and its applications to bioinorganic chemistry." Progress in inorganic chemistry 25 (1979): 1-39.

79. H. Katô. "Magnetic circular dichroism of spin-forbidden transitions in the $\mathrm{Fe} 3+$ high-spin system." The Journal of Chemical Physics 59.4 (1973): 1732-1737.

80. G. Schütz et al. "Absorption of circularly polarized x rays in iron." Physical Review Letters 58.7 (1987): 737.

81. L. Ankoudinov. Relativistic Spin-dependent X-ray Absorption Theory. University of Washington, USA (1996).

82. G. Schütz et al. "Spin-dependent extended x-ray-absorption fine structure: Probing magnetic short-range order." Physical Review Letters 62.22 (1989): 2620.

83. R. Eisberg and R. Resnick. Quantum Physics of Atoms, Molecules, Solids, Nuclei, and Particles, Chapter2, Hardcover (1985).

84. G. Bunker. Introduction to XAFS: a practical guide to X-ray absorption fine structure spectroscopy. Cambridge University Press, 2010.

85. L. D. Landau and E. M. Lifshitz. Quantum Mechanics (Non-relativistic Theory). Butterworth Heinemann, 3rd (1977).

86. R. A. D. Pattrick et al. "Cation site occupancy in spinel ferrites studied by X-ray magnetic circular dichroism developing a method for mineralogists." European Journal of Mineralogy 14.6 (2002): 1095-1102.

87. B. Ravel and M. Newville. "ATHENA, ARTEMIS, HEPHAESTUS: data analysis for X-ray absorption spectroscopy using IFEFFIT." Journal of Synchrotron Radiation 12.4 (2005): 537-541. 
88. M. Newville, B. Ravel. Disponível em http://cars9.uchicago.edu/ifeffit/Ifeffit (2007).

89. J. J Rehr et al. "Theoretical X-ray absorption fine structure standards."Journal of the American Chemical Society 113.14 (1991): 5135-5140.

90. M. I. Oshtrakh et al. "Comparative study of iron oxide nanoparticles as-prepared and dispersed in Copaiba oil using Mössbauer spectroscopy with low and high velocity resolution." Spectrochimica Acta Part A: Molecular and Biomolecular Spectroscopy 100 (2013): 94-100.

91. B. Beckhoff et al. Handbook of Practical X-Ray Fluorescence Analysis, Springer (2006).

92. A. Prange, A. Knöchel and W. Michaelis. "Multi-element determination of dissolved heavy metal traces in sea water by total-reflection X-ray fluorescence spectrometry." Analytica Chimica Acta 172 (1985): 79-100.

93. K. Norrish and J. T. Hutton. "An accurate X-ray spectrographic method for the analysis of a wide range of geological samples." Geochimica et Cosmochimica Acta 33.4 (1969): 431-453.

94. Kumar, M. Mahesh, et al. "Ferroelectricity in a pure $\mathrm{BiFeO}_{3}$ ceramic." Applied Physics Letters 76.19 (2000): 2764-2766.

95. I. Stefánsson, A. I. Gunnarsson and N. Giroud. "New methods for the direct determination of dissolved inorganic, organic and total carbon in natural waters by Reagent-Free ${ }^{\mathrm{TM}}$ Ion Chromatography and inductively coupled plasma atomic emission spectrometry." Analytica chimica acta 582.1 (2007): 69-74.

96. J. M. Mermet, J. M. "Is it still possible, necessary and beneficial to perform research in ICP-atomic emission spectrometry?" Journal of Analytical Atomic Spectrometry 20.1 (2005): 11-16.

97. P. Smichowski, S. Farías and S. P. Arisnabarreta. "Chemical vapour generation of transition metal volatile species for analytical purposes: Determination of $\mathrm{Zn}$ by inductively coupled plasma-optical emission spectrometry." Analyst 128.6 (2003): 779785 .

98. M. I. Oshtrakh and V. A. Semionkin. "Mössbauer spectroscopy with a high velocity resolution: advances in biomedical, pharmaceutical, cosmochemical and nanotechnological research." Spectrochimica Acta Part A: Molecular and Biomolecular Spectroscopy 100 (2013): 78-87.

99. N. C. Sena. Síntese e Caracterização de Nanopartículas Magnéticas a Base de Ferritas de Gadolínio. Dissertação de mestrado, IF - UnB, Brasília (2012).

100. H. M. Rietveld. "A profile refinement method for nuclear and magnetic structures." Journal of applied Crystallography 2.2 (1969): 65-71.

101. Disponível em: http://www.webelements.com/. Acessado em junho de 2015.

102. M. E. Fleet. "The structure of magnetite." Acta Crystallographica Section B: Structural Crystallography and Crystal Chemistry 37.4 (1981): 917-920. 
103. L. Galoisy, G. Calas and M. A. Arrio. "High-resolution XANES spectra of iron in minerals and glasses: structural information from the pre-edge region." Chemical Geology 174.1 (2001): 307-319.

104. P-E. Petit et al. "Determination of the iron oxidation state in Earth materials using XANES pre-edge information." Journal of Synchrotron Radiation 8.2 (2001): 952-954.

105. M. Wilke et al. "Determination of the iron oxidation state in basaltic glasses using XANES at the K-edge." Chemical Geology 220.1 (2005): 143-161.

106. C. M. B. Henderson, J. M. Charnock and D. A. Plant. "Cation occupancies in Mg, Co, Ni, Zn, Al ferrite spinels: a multi-element EXAFS study." Journal of Physics: Condensed Matter 19.7 (2007): 076214.

107. J. Zhang et al. "Electron energy-loss spectroscopy investigation of $\mathrm{Y}_{2} \mathrm{O}_{3}$ films on Si (001) substrate." Thin Solid Films 496.2 (2006): 266-272. 